\title{
THE DIATOM FLORA AND VEGETATION OF LAKE BALATON FROM SEDIMENT CORES ACCORDING TO MÁRTA HAJÓS'S LEGACY
}

\author{
K. BUCZKÓ ${ }^{1}$, L. VÖRÖS ${ }^{2}$ and T. CSERNY ${ }^{3}$ \\ ${ }^{1}$ Department of Botany, Hungarian Natural History Museum \\ H-1476, Budapest, Pf. 222, Hungary; E-mail: buczko@bot.nhmus.hu \\ ${ }^{2}$ Balaton Limnological Research Institute \\ H-8237 Tihany, Klebelsberg K. út 3, Hungary; E-mail: vorosl@tres.blki.hu \\ ${ }^{3}$ Geological Institute of Hungary, H-1143 Budapest, Stefánia út 14, Hungary \\ E-mail: cserny@mafi.hu
}

(Received 19 April, 2004)

\begin{abstract}
The diatoms of bottom sediment core samples were studied from Lake Balaton. During the 1980s altogether 33 boreholes were drilled into the Quaternary layers down to 10-12 m. This paper presents the diatom flora and vegetation of 17 boreholes based on the legacy of Márta Hajós who spent 16 years working on this subject. The enumeration contains occurrences of 385 diatom taxa. It is hoped that this scientific account will serve as a "diatom databank" and helps better understanding of recent environmental changes in the larger area.
\end{abstract}

Key words: diatoms, Hungary, Lake Balaton, palaeolimnology, shallow lakes

\section{INTRODUCTION}

Diatoms are unicellular algae belonging to the class Bacillariophyceae and are sensitive indicators of environmental changes. They have been successfully used to monitor disturbances like eutrophication, changes to the physical and chemical properties of water as well as fluctuation of water level (Stoermer and Smol 1999). Diatoms are particularly useful, because they are often well preserved in lake sediments and have frequently been used for long-term environmental monitoring.

Many diatom-based studies have focused on arctic treeline lakes in Europe and Canada (reviewed in Lotter et al. 1999, Ponader et al. 2002), though there are only a few available data from continental shallow lakes (e.g. Brenner et al. 1999).

Lake Balaton is one of the well-known and thoroughly studied shallow lakes of the world, as well as from algological point of view. In the past 150 years a number of excellent algologists conducted high-level investigation in their respective times. 
The algological literature dealing with Lake Balaton is very extensive, but it is not the aim of the present article to summarise it. We only refer to Padisák's paper, who made a complete overview of the algological results from 1981 until 1996 (Padisák 1997).

The accumulative knowledge about the diatoms of Lake Balaton has got two milestones. The first one is Josef Pantocsek's monograph published in 1901. With 378 figures on 17 tables the book is a masterpiece which combined high-level visual documentation and detailed description of 363 taxa. Onehundred twenty of these were new for science. It should be noted though that some of the taxa were collected from ponds, springs close to Lake Balaton, and from other lakes e.g. Lake Fertő and Sóstó at Fehérvár.

The second one is an attempt to summarise our knowledge about the diatoms of Lake Balaton, published by Gábor Szemes (Szemes 1957). In this paper, spatial and time patterns of 516 diatom taxa, as well as their life forms are discussed. Szemes made some taxonomic treatments and has promised making additional revisions of Pantocsek's taxa; unfortunately, this revision not achieved.

A later contribution to the knowledge of the diatoms of the lake was accomplished by Tamás (i.e. Tamás 1963, 1964, Tamás and Gellért 1958).

The systematic study of microphytobentos was also begun by Tamás (Tamás 1966) who continued her work for a decade (Tamás 1967, 1968, 1971, 1974). Her approach was followed by Uherkovich, who presented the algal vegetation of the sediment surface of Lake Balaton and contributed several excellent illustrations to the knowledge of the algal flora of the lake (Uherkovich and Lantos 1987, Uherkovich 1988, 1992, 1996).

\section{Background}

In 1981, the Geological Institute of Hungary (MÁFI) initiated a comprehensive survey of the geology of Lake Balaton. Altogether 33 boreholes (Fig. 1) were drilled into the Quaternary layers down to 10-12 $\mathrm{m}$. The Holocene mud thickness was $5 \mathrm{~m}$ in average. Up to 1986, 17 boreholes were drilled, and later (in 1989) another 16 boreholes (Tó-18-33) ones for studying the geological history and lacustrine sedimentary process (Cserny and Nagy-Bodor 2000, Cserny 2002).

In some cases thick peat layers were identified in the uniform calcareous mud (e.g. borehole Tó-17 and -20). These peat layers encountered at the bottom of the Holocene complex were ${ }^{14} \mathrm{C}$ dated as $10,000-12,500$ years B.P. (Cserny et al. 1991a, b, Cserny and Nagy-Bodor 2000, Cserny 2002). 
The floristical survey and listing of the diatoms was conducted by Márta Hajós for many years. However, only one of the drillings (borehole Tó-24) had been published in her lifetime (Cserny et al. 1991a,b). Five boreholes (Tó-9, -11, -13, 15-16) were analysed by E. Kőváry-Gulyás as Márta Hajós's Ph.D. student. Kôváry-Gulyás's results are available only in manuscript. Boreholes Tó-1 and - 25 were studied by K. Buczkó, the results will be published later.

This paper wishes to present the results of Márta Hajós's documentation, by certifying the lists according to boreholes and permanent diatom slides. This account will hopefully provide basis for later taxonomic and floristical studies, and assist planning of future work, e.g. identifying the most promising places for drilling. It is also hoped that the data presented here will be a useful reference for subsequent complex analyses.

The changes in diatom taxonomy and the uncertainties of this field have also made an impetus to make this account available. The hundreds of new taxa published in the past 10 or so years have brought substantial refinement in the diatom taxonomy (see e.g. series Bibliotheca Diatomologica and the series of Diatoms of Europe). Moreover, the genetic approach will bring a new wave of treatments in this field, so maybe this paper can be regarded as closing of the 20th century's diatom taxonomy in the case of Lake Balaton.

The first author of this paper had been in work connection with Márta Hajós from 1989 until her death. In this enumeration we accepted M. Hajós's taxonomic views, who followed Pantocsek's concept (instead of that of Krammer and Lange-Bertalot, but the basis of the identification were the 4 volumes of the Süsswasserflora series (Krammer and Lange-Bertalot 1986, 1988, $1991 a, b))$.

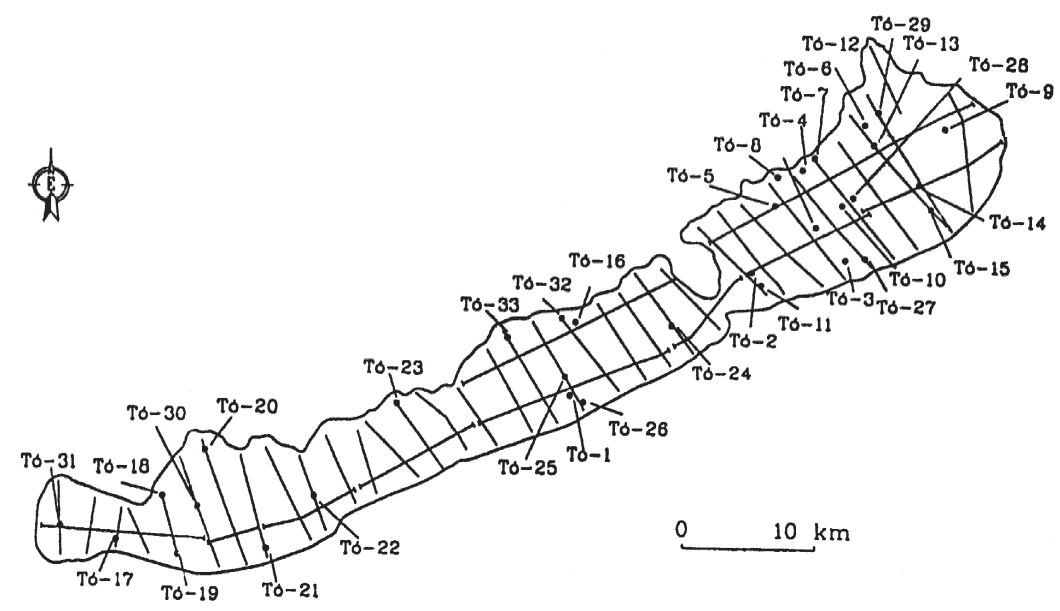

Fig. 1. Locations of the boreholes in Lake Balaton 
Table 1

A summary table of the diatom studies of the boreholes from lake Balaton drilled between 1981 and 1989

\begin{tabular}{|c|c|c|c|c|c|c|}
\hline $\begin{array}{l}\text { Bore- } \\
\text { hole }\end{array}$ & Studied by & $\begin{array}{l}\text { Depth of } \\
\text { borehole } \\
\text { (m) }\end{array}$ & $\begin{array}{c}\text { Serial } \\
\text { number of } \\
\text { slides }\end{array}$ & $\begin{array}{l}\text { Photo docu- } \\
\text { mentation } \\
\text { (serial No. of } \\
\text { negative) }\end{array}$ & $\begin{array}{l}\text { Sum of the } \\
\text { taxa in the } \\
\text { borehole }\end{array}$ & $\begin{array}{l}\text { The year } \\
\text { of study }\end{array}$ \\
\hline Tó-1 & K. Buczkó & & & & & \\
\hline \multicolumn{7}{|l|}{ Tó-2 } \\
\hline \multicolumn{7}{|l|}{ Tó-3 } \\
\hline Tó-4 & M. Hajós & $2.40-0.20$ & $5523-5533$ & 897 & 112 & 1995 \\
\hline Tó-5 & M. Hajós & $2.45-0.05$ & 8379-8385 & & 131 & 1994 \\
\hline \multicolumn{7}{|l|}{ Tó-6 } \\
\hline Tó-7 & M. Hajós & $2.10-0.00$ & $8386-8403$ & & 110 & 1994 \\
\hline Tó-8 & M. Hajós & $2.2-0.10$ & $8404-8410$ & & 109 & 1994 \\
\hline Tó-9 & Kőváry-Gulyás & & & & & \\
\hline \multicolumn{7}{|l|}{ Tó-10 } \\
\hline Tó-11 & $\begin{array}{l}\text { M. Hajós and } \\
\text { Kőváry-Gulyás }\end{array}$ & $4.25-0.20$ & $5559-5539$ & 898 & 148 & 1995 \\
\hline \multicolumn{7}{|l|}{ Tó-12 } \\
\hline Tó-13 & Kőváry-Gulyás & & & & & \\
\hline \multicolumn{7}{|l|}{ Tó-14 } \\
\hline Tó-15 & Kőváry-Gulyás & & & & & \\
\hline Tó-16 & Kőváry-Gulyás & & & & & \\
\hline Tó-17 & M. Hajós & $3.40-0.00$ & $7551-7630$ & $876-879$ & 139 & 1992 \\
\hline \multicolumn{7}{|l|}{ Tó-18 } \\
\hline \multicolumn{7}{|l|}{ Tó-19 } \\
\hline Tó-20 & M. Hajós & $3.00-0.00$ & $6609-6719$ & $862-864$ & 144 & 1991 \\
\hline Tó-21 & M. Hajós & $2.00-0.00$ & $\begin{array}{l}6998-7090 \\
7335-7351\end{array}$ & $865-869$ & 163 & 1991 \\
\hline Tó-22 & M. Hajós & $3.50-0.50$ & $7260-7333$ & $873-875$ & 159 & 1991 \\
\hline Tó-23 & M. Hajós & $6.92-0.00$ & 7093-7228 & 888 & 218 & 1993 \\
\hline Tó-24 & \multicolumn{5}{|c|}{$\begin{array}{l}\text { published earlier by M. } \\
\text { Hajós }\end{array}$} & 1990 \\
\hline Tó-25 & K. Buczkó & & & & & $1989 ?$ \\
\hline Tó-26 & M. Hajós & $1.90-0.00$ & 7364-7401 & $878-880$ & 138 & 1992 \\
\hline Tó-27 & M. Hajós & $1.65-0.00$ & 7457-7489 & & 140 & 1992 \\
\hline Tó-28 & M. Hajós & $2.63-0.00$ & 6465-6412 & & 84 & 1991 \\
\hline Tó-29 & M. Hajós & $8.42-0.00$ & 7790-7976 & & 131 & 1992 \\
\hline Tó-30 & M. Hajós & $4.03-0.08$ & $\begin{array}{l}\text { 7643-7717; } \\
\text { 7498-7504; } \\
\text { 7925-7928 }\end{array}$ & $881-886$ & 193 & 1992 \\
\hline Tó-31 & M. Hajós & $5.80-0.30$ & $6782-6875$ & $859-860$ & 104 & 1991 \\
\hline Tó-32 & & & & & & \\
\hline Tó-33 & M. Hajós & $4.60-0.02$ & $7922-8045$ & 894 & 152 & 1994 \\
\hline
\end{tabular}




\section{MATERIAL AND METHODS}

According to the workbooks the diatom slides were prepared by the following cleaning methods: the samples were first treated with $\mathrm{HCl}$ solution, and then digested by hydrogen peroxide. The name of the mounting medium used has not turned out until now.

In the workbooks the following groups are also mentioned: Chrysophyta stomatocysts, Chlorophyta spp., Siderocelis sp., Phytolitharia (Lithodontium, Lithostylidium, Lithodesmites, Porifera, Oxea, Isochela). Some more details (quantitative data) are also available about the groups mentioned above, but they are not presented here.

All diatom identification, taxonomy and enumeration followed Krammer and Lange-Bertalot (1986, 1988, 1991a, b) and Pantocsek (1901).

The main features of samples, including the depth, the serial number of permanent diatom slides, the sum of identified valves in a certain slide, and the number of taxa Tables 2 to 18 present. Usually we give the serial number of permanent diatom slide, but sometimes from the workbooks it is not certain, what data correspond to what slides, since they appear as summed-up values (e.g. borehole Tó-17 7558-7560). In some cases the merger affected long sections e.g. borehole Tó-23, where a $70 \mathrm{~cm}$ long section was handled as a single item.

A sample key has been introduced in order to find the relative abundance of each taxon both in the tables and enumeration.

As an example the data structure of Table 2 about the borehole Tó- 4 is given, where data about the permanent slide no 5527 is found. Altogether 1008

Table 2

Data of the "Borehole Tó-4"

\begin{tabular}{lrrrrrrrrrrr}
\hline Depth (m) & \multicolumn{1}{c}{ 2.4 } & \multicolumn{1}{c}{2} & \multicolumn{1}{c}{1.8} & \multicolumn{1}{c}{1.6} & \multicolumn{1}{c}{1.4} & 1.2 & 1 & 0.8 & 0.6 & 0.4 & 0.2 \\
No. of slide(s) & 5533 & 5531 & 5530 & 5529 & 5528 & 5527 & 5526 & 5525 & 5524 & 5523 & 5523 \\
Total valves & 111 & 18 & 530 & 564 & 467 & 1008 & 364 & 596 & 809 & 573 & 1134 \\
No. of taxa & 19 & 6 & 33 & 41 & 32 & 40 & 22 & 35 & 45 & 32 & 20 \\
\hline
\end{tabular}

Table 3

Data of the "Borehole Tó-5"

\begin{tabular}{lrrrrrrr}
\hline Depth bottom & 2.45 & 2.15 & 1.75 & 1.35 & 0.95 & 0.55 & 0.15 \\
Depth top & 2.40 & 2.05 & 1.65 & 1.25 & 0.85 & 0.45 & 0.05 \\
No. of slide(s) & 8379 & 8380 & 8384 & 8382 & 8383 & 8384 & 8385 \\
Total valves & 875 & 861 & 448 & 451 & 529 & 420 & 570 \\
No. of taxa & 43 & 38 & 45 & 40 & 37 & 43 & 39 \\
\hline
\end{tabular}


Table 4

Data of the "Borehole Tó-7"

\begin{tabular}{lrrrrrrrr}
\hline Depth top & 2.10 & 1.95 & 1.80 & 1.65 & 1.25 & 0.85 & 0.45 & 0.00 \\
Depth bottom & 2.05 & 1.90 & 1.85 & 1.75 & 1.35 & 0.95 & 0.55 & 0.15 \\
No. of slide(s) & 8386 & 8387 & 8388 & 8389 & 8400 & 8401 & 8402 & 8403 \\
Total valves & 711 & 569 & 628 & 661 & 745 & 464 & 657 & 531 \\
No. of taxa & 13 & 21 & 35 & 41 & 41 & 37 & 35 & 44 \\
\hline
\end{tabular}

Table 5

\begin{tabular}{lrrrrrrr}
\multicolumn{7}{c}{ Data of the “Borehole Tó-8" } \\
\hline Depth bottom & 2.2 & 2.15 & 1.75 & 1.35 & 0.95 & 0.55 & 0.15 \\
Depth top & & 2.05 & 1.65 & 1.25 & 0.85 & 0.45 & 0.10 \\
No. of slide(s) & 8404 & 8405 & 8406 & 8407 & 8408 & 8049 & 8410 \\
Total valves & 623 & 663 & 165 & 445 & 551 & 425 & 462 \\
No. of taxa & 30 & 25 & 25 & 26 & 39 & 36 & 33 \\
\hline
\end{tabular}

specimens were counted on that slide, so $10 / 1008=0.010$ is the relative abundance of $A$. clevei at $1.2 \mathrm{~m}$ depth. In the upper section, at $0.8 \mathrm{~m}$ the relative abundance of $A$. clevei is $15 / 596=0.025$, on slide no 5525 . The third occurrence of $A$. clevei in borehole Tó- 4 is at $0.6 \mathrm{~m}$, where the relative abundance of this taxon is $0.033(=27 / 809)$, on slide no 5524 .

Following this the conceptual framework of data sets in enumaration is illustrated: e.g. Achnanthes clevei Grun. - Tó-4 5527:10, 5525:15, 5524:27; Tó-7 8388:8, 8402:2, 8403:8 ...

This data sequence means that Achnanthes clevei was found in borehole Tó-4. In slide 5527, and altogether 10 specimens were counted.

In borehole Tó-7 the relative abundances of Achnanthes clevei are 0.0127 (= $8 / 628)$ between 1.85 and $1.80 \mathrm{~m} ; 0.0030(=2 / 657)$ between 0.55 and $0.45 \mathrm{~m}$; and $0.0151(=8 / 531)$ at the sediment surface, between 0.15 and $0.00 \mathrm{~m}$.

The data sheet was made in Excel file, which has a size exceeding the limits of this publication. This file is available upon request to interested researchers.

\section{RESULTS}

Altogether 385 taxa were identified on species, variety or form level. Specimens identified only at genus level (e.g. Achnanthes sp., Amphora sp.) are not listed in the enumeration at all, since they have no floristic importance. However, these are included in the "No. of taxa" of the samples, as their occurrences contribute to the diversity of the algal assemblages. 


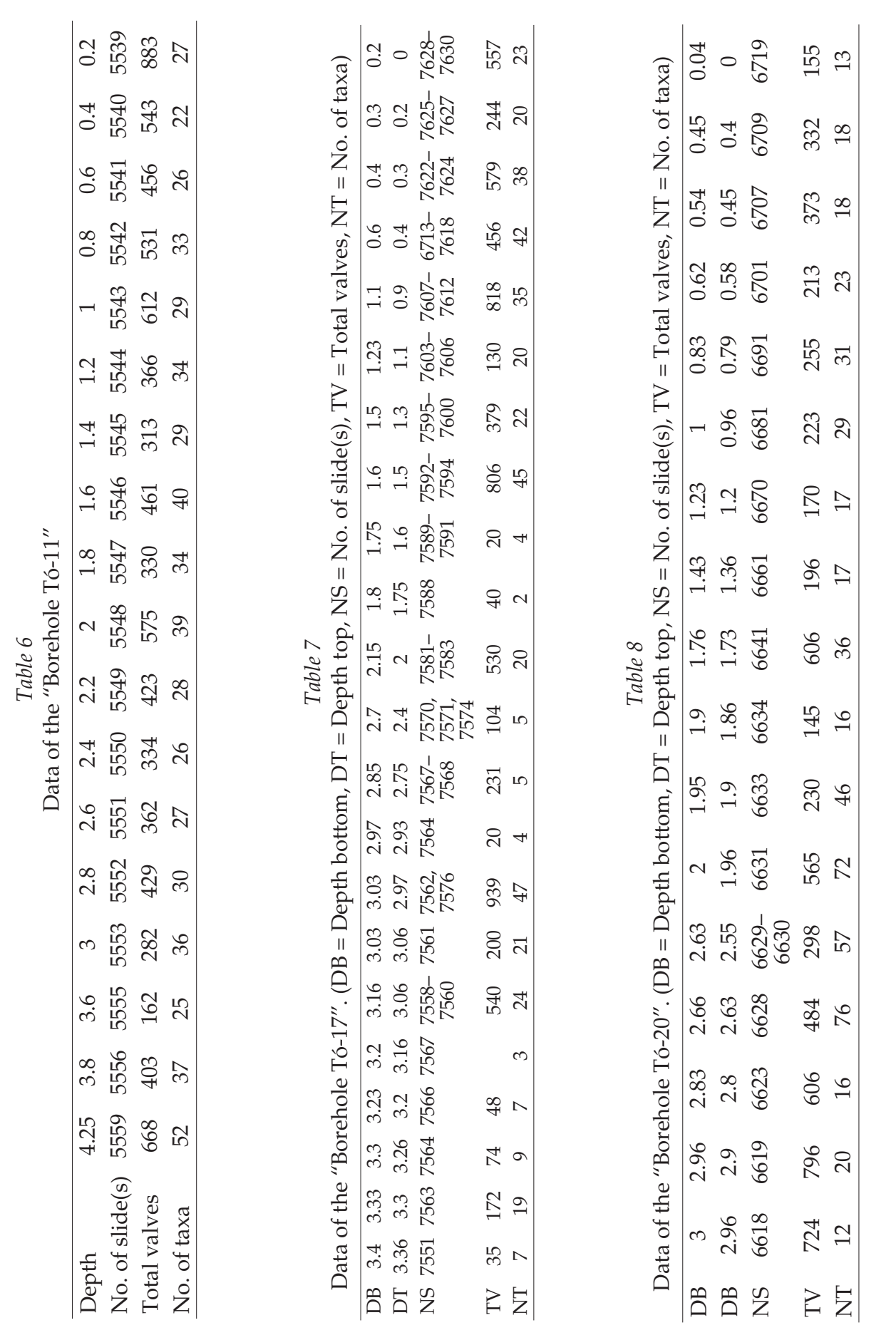




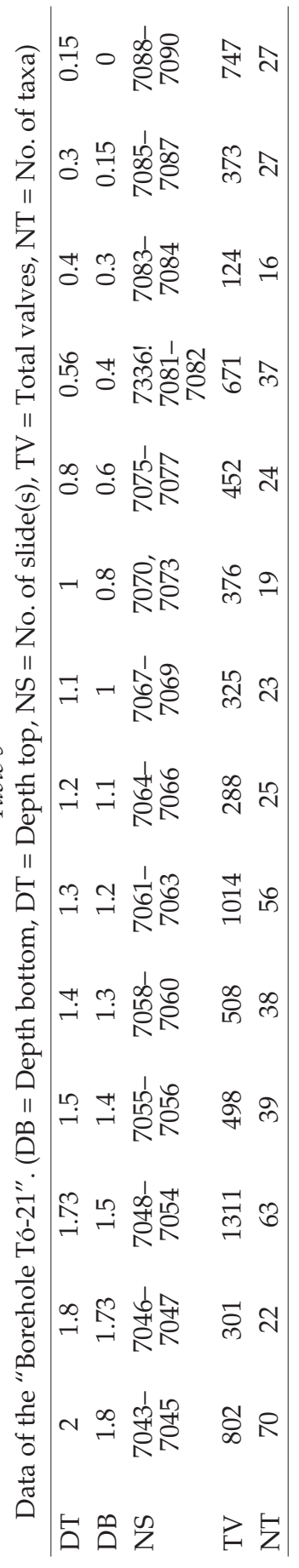

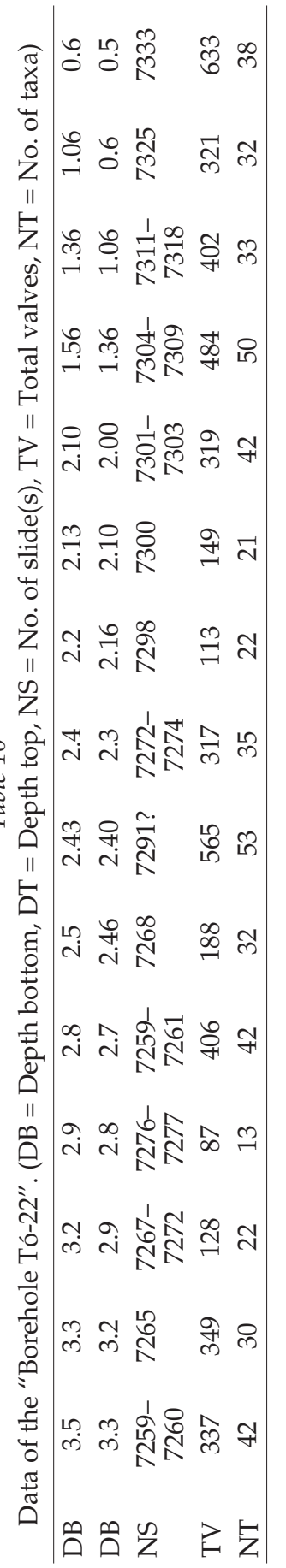

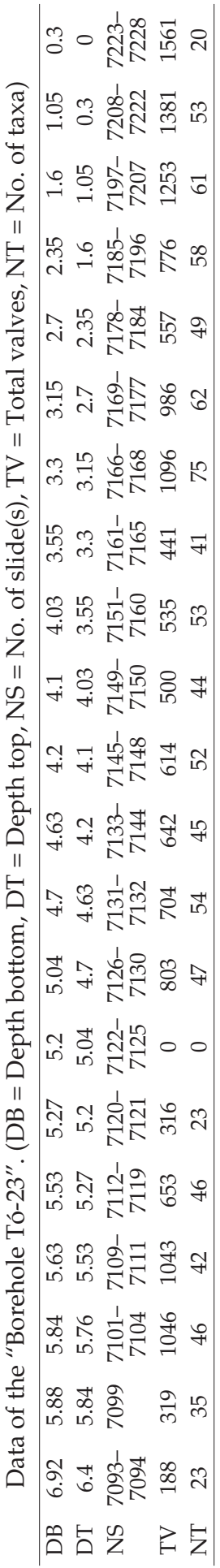




\section{Enumeration}

Achnanthes clevei Grun. - Tó-4 5527:10, 5525:15, 5524:27; Tó-7 8402:2, 8388:8, 8403:8; Tó-8 8405:10, 8407:10, 8049:11; Tó-11 5550:2, 5546:2; Tó-21 7043-7045:18, 7048-7054:10, 7055-7056:16, 7070, 7073:5; Tó-22 7304-7309:6; Tó-23 7120-7121:4; Tó-26 7364:3, 7365:1, 7366-7367:10, 7373:12, 7383, 7384:7; Tó-27 7463-7466:4，7467-7469:14， 7473-7474:10, 7475-7476:4, 7485-7486:7.

Achnanthes clevei Grun. var. rostrata Hust. - Tó-4 5527:16; Tó-27 7467-7469:2.

Achnanthes conspicua (Bréb.) Grun. - Tó-33 8054:2.

Achnanthes delicatula (Kütz.) Grun. - Tó-21 7336!, 7081-7082:10, 7085-7087:3; Tó-23

7166-7168:2; Tó-28 6427:2; Tó-29 7817-7819:20.

Achnanthes dispar Cl. - Tó-4 5529:4; Tó-21 7055-7056:5; Tó-26 7365:10.

Achnanthes exigua Grun. - Tó-21 7043-7045:6; Tó-22 7291?:2; Tó-23 7145-7148:4; Tó-27

7473-7474:2; Tó-30 7643:2, 7644-7645:42, 7650-7654:55, 7717:1.

Achnanthes flexella (Kütz.) Brun - Tó-20 6628:1, 6629-6630:2, 6631:1, 6633:2, 6641:4;

Tó-21 7058-7060:4; Tó-22 7259-7260:1, 7276-7277:1, 7291?:2; Tó-23 7131-7132:2, 7133-7144:2,

7145-7148:1; Tó-33 8059:2, 8054:2.

Achnanthes hauckiana Grun. - Tó-26 7399-7401:3; Tó-33 8042:1.

Achnanthes hungarica (Grun.) Grun. - Tó-21 7061-7063:4; Tó-22 7304-7309:1.

Achnanthes joursacense Héribaud - Tó-23 7101-7104:1.

Achnanthes kolbei Hust. - Tó-7 8388:3; Tó-23 7112-7119:2.

Achnanthes lanceolata (Bréb.) Grun. - Tó-7 8387:8, 8389:12, 8400:4; Tó-11 5559:4, 5556:2;

Tó-17 6713-7618:2, 7625-7627:1; Tó-20 6618:4; Tó-22 7291?:6; Tó-23 7099:2, 7101-7104:12, 7112-7119:3, 7126-7130:9, 7131-7132:22, 7145-7148:8, 7149-7150:2, 7151-7160:1, 7161-7165:14, 7166-7168:15, 7169-7177:4; Tó-26 7366-7367:5; Tó-29 7860-7863:5, 7864-7866:5, 7896-7897:15, 7898-7993:5; Tó-30 7644-7645:7, 7680:7, 7683, 7686:2; Tó-33 7434:6, 8150:10, 8068:8.

Achnanthes lanceolata Bréb. f. capitata O. Müll. - Tó-23 7101-7104:2.

Achnanthes lanceolata Bréb. var. elliptica Cleve sensu Straub - Tó-23 7101-7104:6, 7131-7132:4; Tó-29 7893-7895:5.

Achnanthes lanceolata Bréb. var. rostrata (Oestrup) Hustedt - Tó-23 7131-7132:5, 7166-7168:6.

Achnanthes minutissima Kütz. - Tó-20 6628:2, 6629-6630:2, 6631:2.

Achnanthes rupestroides Hohn - Tó-26 7395, 7396:2; Tó-30 7644-7645:5, 7650-7654:2.

Achnanthes trinodis (W. Sm.) Grun. - Tó-27 7488:2.

Amphora balatonis Pant. - Tó-4 5533:2, 5524:12; Tó-8 8404:2; Tó-17 7592, 7593, 7594:6, 6713-7618:5; Tó-20 6628:1, 6629-6630:3, 6631:2; Tó-21 7048-7054:19, 7055-7056:9, 7058-7060:5, 7061-7063:5, 7075-7077:5, 7085-7087:2, 7088-7090:10; Tó-22 7268:2; Tó-23 7126-7130:5, 7131-7132:1,7178-7184:2,7208-7222:11; Tó-26 7365:4, 7366-7367:5, 7373:2; Tó-27 7463-7466:2, 7475-7476:4; Tó-28 6454:3; Tó-29 7864-7866:46, 78, 677, 868:10; Tó-30 7689-7691:10, 7708-7710:4; Tó-33 7922:5, 8144:5, 8126:4, 8084:21, 8083:13, 8054:3.

Amphora coffeaeformis (Ag.) Kütz. - Tó-33 8050:4.

Amphora commutata Grun. - Tó-22 7298:5.

Amphora delicatissima Krasske - Tó-20 6619:2.

Amphora holsatica Hust. - Tó-26 7365:5; Tó-29 7800:5, 7805-7809:5.

Amphora inariensis Krammer - Tó-20 6628:1, 6629-6630:2, 6631:1.

Amphora lybica E. - Tó-4 5533:2, 5530:36, 5529:16, 5528:30, 5527:9, 5526:5, 5525:4, 5524:23, 5523:24; Tó-5 6801:11, 6802:2; Tó-7 8402:3, 8389:5, 8400:14; Tó-8 8404:10, 8405:4, 8408:2, 8049:4; Tó-11 5559:12, 5556:38, 5549:5, 5548:2, 5547:9, 5544:29, 5543:45; Tó-17 7566:3, 


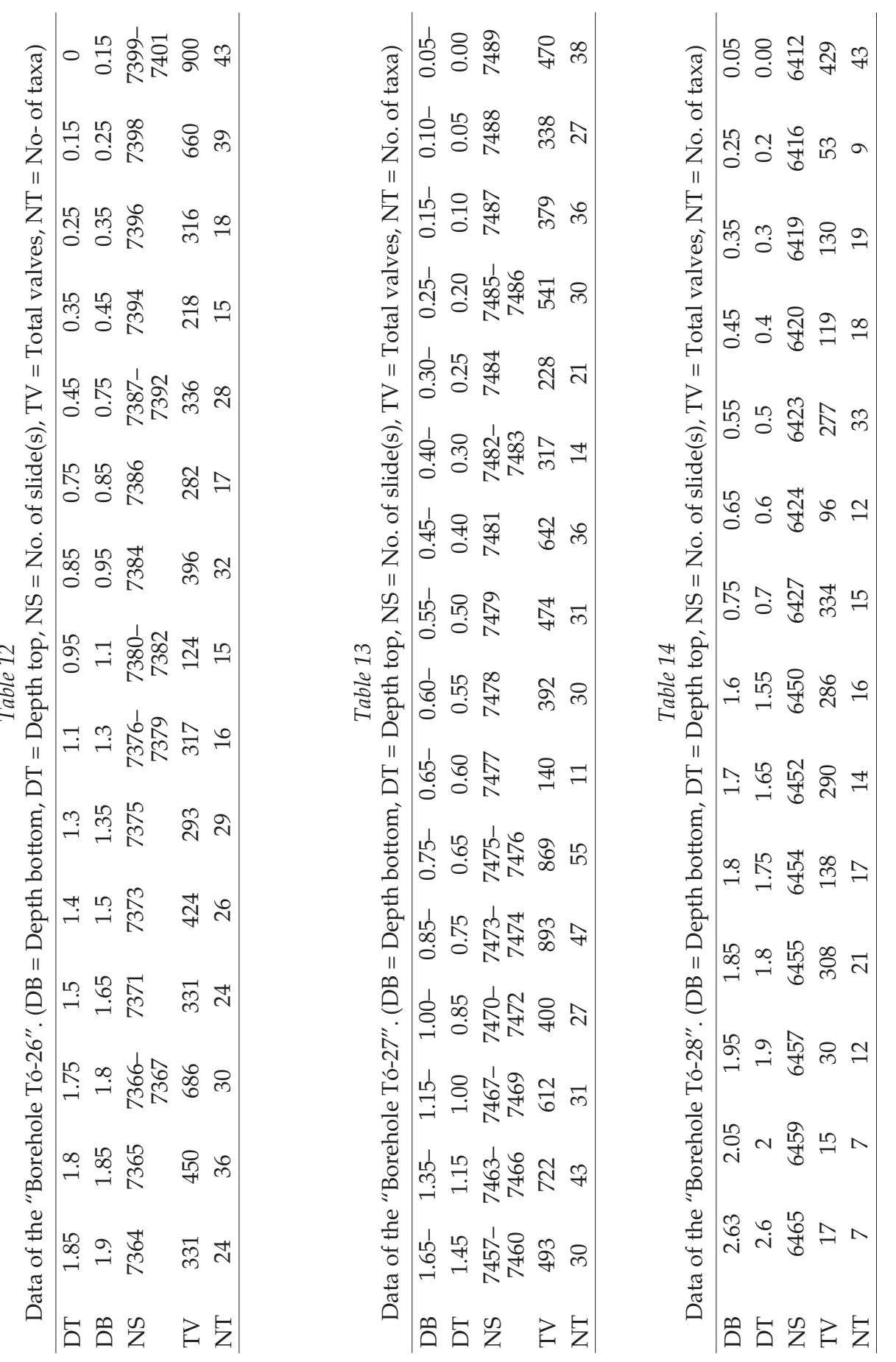




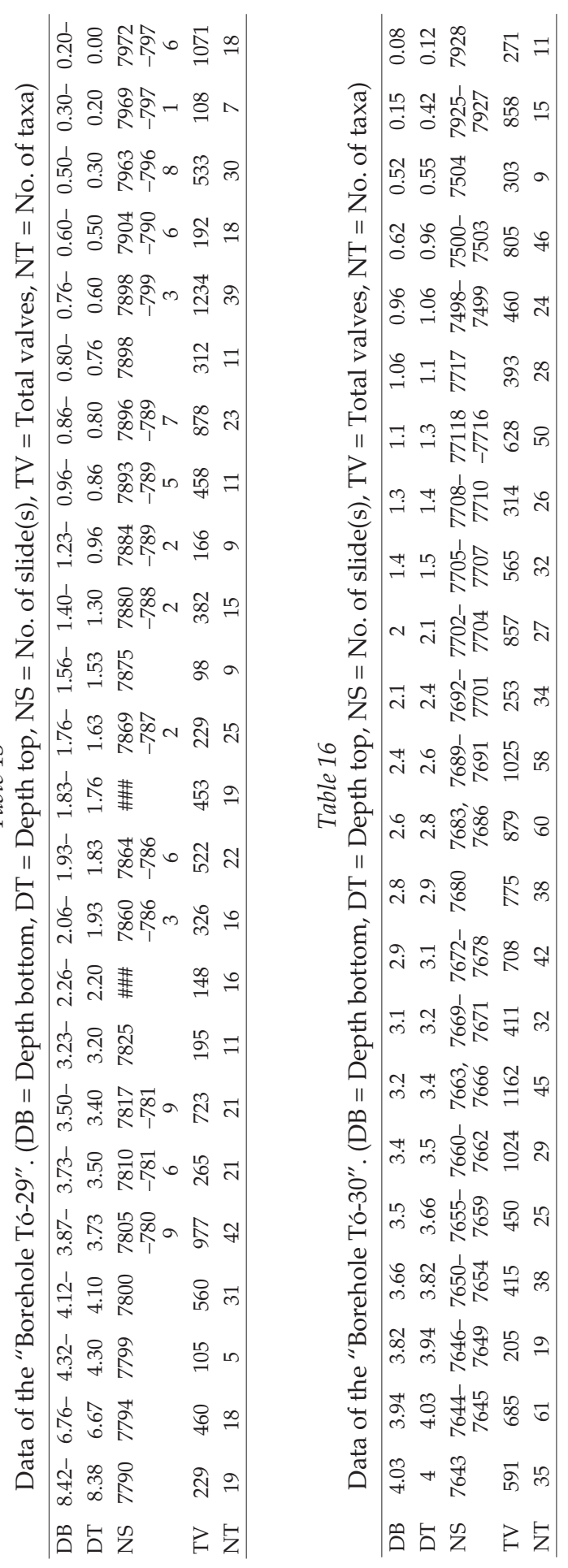

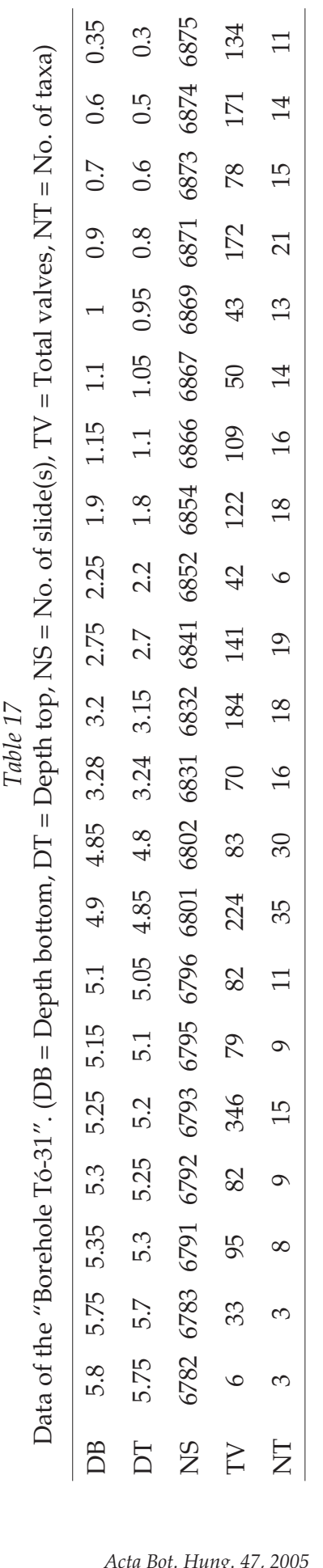


7561:6, 7562, 7563:6, 7581-7583:4, 7592, 7593, 7594:17, 76077612:5, 6713-7618:9; Tó-20 6628:12, 6629-6630:21, 6631:10, 6633:2, 6681:2, 6691:2; Tó-21 7043-7045:18, 7048-7054:5, 7055-7056:18， 7058-7060:15， 7336! 7081-7082:2; Tó-22 7259-7260:2, 7265:7, 7267-7272:1, 7276-7277:1, 7259-7261: 20, 7291?:2, 7272-7274:41, 7300:1, 7301-7303:5, 7304-7309:3, 7311-7318:1, 7325:2; Tó-23 7093-7094:5, 7099:2, 7101-7104:6, 7109-7111:13, 7112-7119:5, 7126-7130:14, 7131-7132:61, 7133-7144:3, 7145-7148:10, 7149-7150:2, 7161-7165:5, 71667168:2, 7169-7177:8, 7178-7184:7, 7185-7196:5, 7197-7207:13, 7208-7222:20; Tó-26 7364:5, 7366-7367:5, 7370, 7371:5, 7397, 7398:3; Tó-27 7463-7466:2, 7470-7472:3, 7473-7474:6, 7475-7476:9, 7487:4; Tó-28 6455:15, 6452:1; Tó-29 7790:5, 7864-7866:25, 78, 677, 868:54, 7869-7872:10, 7904-7906:5; Tó-30 7644-7645:2, 7650-7654:5, 7655-7659:2, 7663, 7666:2, 7669-7671:2, 7672-7678:14, 7692-7701:5, 7702-7704:2, 77087710:4, 7717:4, 7500-7503:2, 7925-7927:20; Tó-31 6801:11, 6802:2; Tó-33 7922:4, 7434:5, 7492:5, 8150:5, 8138:5, 8132:24, 8126:14, 8114:9, 8084:8.

Amphora ovalis (Kütz.) Kütz. - Tó-4 5529:12, 5527:5, 5526:7, 5525:5, 5524:12; Tó-5 6792:1, 6793:20, 6802:1, 6831:1, 6832:1，6852:1，6854:2; Tó-7 8402:13; Tó-8 8405:8, 8408:8, 8049:2; Tó-11 5559:2, 5556:2, 5553:2, 5551:10, 5548:8, 5546:9, 5544:30, 5543:35, 5542:15, 5541:9; Tó-17 7561:4, 7562, 7563:8, 7567-7568:20, 7592, 7593, 7594:11, 7603-7606:5, 6713-7618:3, 7622-7624:9; Tó-20 6618:8, 6628:11, 6629-6630:21, 6631:10, 6633:1, 6660, 6661:1, 6681:4, 6701:2, 6709:2; Tó-21 7046-7047: 12, 7048-7054:40, 7058-7060:10, 7061-7063:4, 7067-7069:4, 7336! 7081-7082:5, 7085-7087:1, 7088-7090:20; Tó-22 72597260:2, 7259-7261:42, 7268:10, 7291?:4, 7272-7274:3, 7298:20, 7301-7303:11; Tó-23 7099:4, 7101-7104:8, 7109-7111:2, 7112-7119:4, 7126-7130:9, 7131-7132:6, 7133-7144:5, 71497150:10, 7151-7160:36, 7166-7168:15, 7185-7196:6, 7197-7207: 25, 7208-7222:26; Tó-26 7364:5, 7373:3, 7375:15, 7385, 7386:6, 7395, 7396:15, 7399-7401:3; Tó-27 7463-7466:10, 7467-7469:4, 7470-7472:4, 7473-7474:8, 7475-7476:5, 7479:8, 7485-7486:4, 7487:4; Tó-28 6423:5; Tó-29 7800:5, 7805-7809:14, 7860-7863:5, 78, 677, 868:10, 7869-7872:2, 7898-7993:10, 7904-7906:5; Tó-30 7643:9, 7644-7645:12, 7650-7654:2, 7655-7659:3, 76607662:4, 7669-7671:5, 7672-7678:6, 7683, 7686:7, 7689-7691:10, 7702-7704:3, 7705-7707:2, 77118-7716:2, 7498-7499:2; Tó-31 6792:1, 6793:20, 6802:1, 6831:1, 6832:1, 6852:1, 6854:2; Tó-33 $8144: 14,8100: 3,8090: 4,8083: 19$, 8068:5, 8059:6, 8054:2, 8045:3.

Amphora pediculus (Kütz.) Grun. - Tó-4 5530:22, 5529:36, 5528:50, 5527:44, 5526:33, 5525:100, 5524:86, 5523:43; Tó-5 6866:7, 6867:1, 6869:5, 6871:17, 6873:10, 6874:5; Tó-7 8386:9, 8402:36, 8388:8, 8403:20, 8389:12, 8400:8; Tó-8 8405:16,

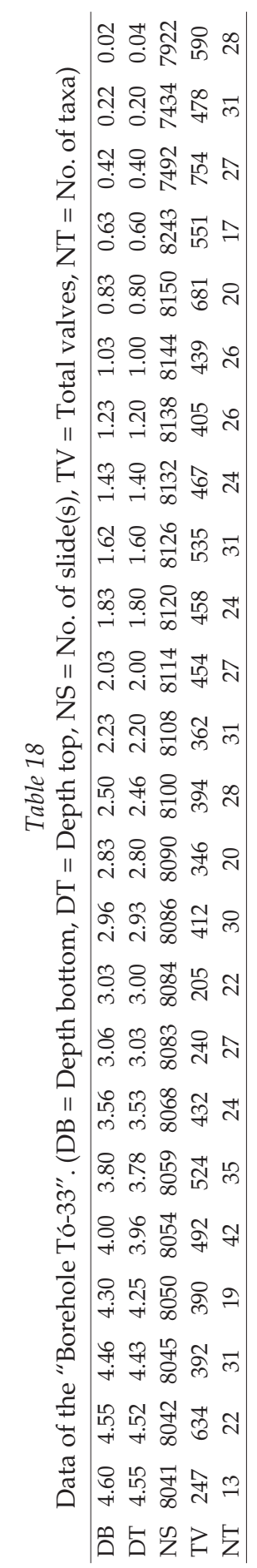


8407:45, 8408:28, 8049:19; Tó-11 5559:13, 5556:13, 5555:4, 5553:4, 5552:6, 5551:11, 5550:13, 5549:2, 5547:6, 5546:33, 5545:8, 5544:4, 5543:93, 5542:26, 5541:6, 5540:30; Tó-17 7581-7583:10, 7592, 7593, 7594:104, 7607-7612:14, 6713-7618:58, 7622-7624:34, 7625-7627:40; Tó-20 6623:26, 6628:4, 6629-6630:13, 6631:9, 6633:4, 6641:36, 6670:7, 6681:9, 6691:8, 6701:20, 6707:23, 6709:26, 6719:35; Tó-21 7043-7045:25, 7055-7056:15, 7061-7063:53, 7064-7066:15, 7067-7069:3, 7070, 7073:27, 7075-7077:16, 7336! 7081-7082:38, 7085-7087:19, 7088-7090:11; Tó-22 7259-7260:2, 7265:25, 7259-7261:10, 7304-7309:27, 7311-7318:29, 7325:19; Tó-23 7109-7111:6, 7112-7119:2, 7120-7121:8, 7133-7144:11, 7149-7150:10, 7166-7168:2, 7169-7177:15, 7185-7196:58, 71977207:51, 7208-7222:83; Tó-26 7365:19, 7366-7367:74, 7370, 7371:47, 7373:58, 7376-7379:30, 7383, 7384:37, 7387-7392:10, 7393, 7394:4, 7395, 7396:10, 7397, 7398:8, 7399-7401:25; Tó-27 7457-7460:8, 7463-7466:41, 7467-7469:15, 7470-7472:15, 7473-7474:31, 7475-7476:42, 7484:4, 7485-7486:10, 7487:37, 7488:9; Tó-28 6457:7, 6455:63, 6452:6, 6450:17, 6427:6, 6423:5, 6420:4, 6419:14; Tó-29 7800:5, 7805-7809:20, 7817-7819:10, 78, 547, 855:5, 7860-7863:35, 78, 677, 868:16, 7869-7872:5, 7893-7895:69, 7896-7897:125, 7898:24, 7898-7993:26, 7963-7968:65, 7969-7971:10; Tó-30 7643:5, 7644-7645:2, 7655-7659:19, 7660-7662:21, 7663, 7666:80, 7669-7671:20, 7672-7678:80, 7680:100, 7683, 7686:48, 7689-7691:126, 7692-7701:4, 7702-7704:49, 7705-7707:51, 7708-7710:5, 77118-7716:47, 7717:26, 7498-7499:28, 7500-7503:15, 7504:92, 7925-7927:19; Tó-31 6866:7, 6867:1, 6869:5, 6871:17, 6873:10, 6874:5; Tó-33 7922:81, 7434:22, 7492:66, 8243:7, 8150:32, 8138:30, 8132:12, 8126:8, 8120:55, 8114:30, 8108:2, 8090:22, 8086:14, 8068:2, 8059:12, 8050:11, 8045:2.

Amphora thumensis (A. Mayer) Cl. - Tó-11 5559:10, 5550:10, 5547:2, 5544:4; Tó-17 7558-7560:2, 7561:2, 7562, 7563:7; Tó-20 6619:2, 6628:4, 6629-6630:6, 6631:4; Tó-22 7265:1, 7301-7303:2; Tó-30 7692-7701:1; Tó-33 7492:3, 8068:8, 8059:2, 8054:20, 8041:1, 8042:18.

Amphora veneta Kütz. - Tó-7 8388:14; Tó-11 5547:4; Tó-22 7259-7260:1, 7300:4; Tó-23 7131-7132:3; Tó-29 7817-7819:10.

Anomoeoneis sphaerophora (Ehr.) Pfitz. - Tó-4 5533:25, 5530:24, 5529:14; Tó-7 8400:28; Tó-11 5556:2, 5555:20, 5553:7, 5549:2; Tó-17 7562, 7563:2, 7595, 7596, 7597, 7599, 7600:4; Tó-20 6628:6, 6629-6630:6, 6631:5, 6633:1; Tó-22 7259-7260:4, 7259-7261:8, 7268:1, 7291?:2, 7272-7274:3, 7298:8, 7301-7303:16; Tó-23 7133-7144:4, 7151-7160:6, 7166-7168:3, 7169-7177:8, 7178-7184:16; Tó-26 7364:16, 7366-7367:2, 7370, 7371:15, 7376-7379:5; Tó-27 7463-7466:91, 7467-7469:3; Tó-29 78, 547, 855:5, 7860-7863:14, 7869-7872:10, 7884-7892:5; Tó-30 7650-7654:1, 7655-7659:1, 7663, 7666:6, 7683, 7686:2; Tó-33 8108:8, 8100:5, 8090:2, 8086:4, 8084:9.

Anomoeoneis sphaerophora (Ehr.) Pfitz. f. costata (Kütz.) Schmid - Tó-11 5553:2, 5550:2; Tó-21 7061-7063:5; Tó-22 7272-7274:5; Tó-27 7463-7466:20.

Aucaloseira italica (Ehr.) Sim. - Tó-5 6831:4; Tó-7 8387:8, 8388:25, 8403:8, 8389:11, 8400:8; Tó-8 8404:45, 8405:62; Tó-11 5559:84, 5556:200, 5555:11, 5553:2; Tó-17 7566:9, 7558-7560:6, 7561:30, 7562, 7563:251, 7592, 7593, 7594:4, 7603-7606:10, 7607-7612:4, 6713-7618:1, 7622-7624:2; Tó-20 6619:20, 6628:12, 6629-6630:7, 6631:18, 6641:146; Tó-21 7043-7045:74, 7048-7054:169, 7055-7056:18, 7058-7060:25, 7061-7063:12, 7088-7090:20; Tó-22 7259-7260:159, 7265:69, 7267-7272:30, 7276-7277:10, 7259-7261:10, 7268:11, 7291?:10, 7272-7274:7, 7301-7303:4, 7304-7309:113, 7311-7318:3, 7325:2; Tó-23 7093-7094:3, 7099:12, 7101-7104:137, 7120-7121:13, 7126-7130:214, 7131-7132:15, 7133-7144:205, 7145-7148:120, 7149-7150:91, 7151-7160:20, 7161-7165:27, 7166-7168:8, 7169-7177:5, 7185-7196:31, 7197-7207:10, 7208-7222:2; Tó-26 7366-7367:3, 7397, 7398:5; Tó-29 7794:40, 7817-7819:160, 7825:20; Tó-30 7644-7645:35, 7646-7649:3, 7650-7654:4, 7655-7659:20, 7660-7662:7, 7663, 7666:60, 7669-7671:12, 7672-7678:3, 7680:2, 7683, 7686:4, 7689-7691:11, 7500-7503:4; Tó-31 6831:4; Tó-33 8114:13, 8108:6, 8100:3, 8084:2, 8083:6, 8068:11, 8059:91. 
Aucaloseira italica (Ehr.) Sim. var. tenuissima (Grun.) Sim. - Tó-8 8405:2; Tó-23 7099:7, 7101-7104:4, 7120-7121:4, 7126-7130:8, 7145-7148:15, 7185-7196:5.

Aucaloseira subarctica (O. Müll.) Sim. - Tó-21 7043-7045:4, 7061-7063:5; Tó-22 7265:5, 7267-7272:5.

Aulacoseira distans (Ehr.) Simonsen - Tó-11 5550:10, 5548:23; Tó-21 7043-7045:2; Tó-26 7370, 7371:10, 7373:2; Tó-27 7485-7486:22; Tó-30 7705-7707:4, 7717:2.

Aulacoseira granulata (Ehr.) Sim. - Tó-4 5531:4, 5528:20, 5527:310, 5526:101, 5525:102, 5524:33, 5523:140; Tó-5 6801:2, 6841:57, 6852:1, 6854:12, 6867:1, 6869:1, 6871:2; Tó-7 8402:53, 8403:4; Tó-8 8407:6, 8408:149, 8049:23; Tó-11 5553:18, 5552:184, 5551:128, 5550:105, 5549:172, 5548:300, 5547:156, 5546:200, 5545:70, 5544:45, 5543:35, 5542:21, 5541:33; Tó-17 7581-7583:12, 7603-7606:14, 7607-7612:12, 6713-7618:24, 7622-7624:20, 7625-7627:13; Tó-20 6628:3, 6631:2, 6633:4, 6634:10, 6641:208, 6670:1, 6691:103, 6701:19, 6709:27, 6719:3; Tó-21 7043-7045:3, 7055-7056:12, 7058-7060:30, 7061-7063:131, 7064-7066:93, 7067-7069:67, 7070, 7073:45, 7075-7077:5, 7336! 7081-7082:130, 7083-7084:7, 7088-7090:33; Tó-22 7298:5, 7304-7309:91, 7311-7318:157, 7325:85; Tó-23 7112-7119:3，7161-7165:14，7166-7168:12, 7178-7184:20, 7185-7196:154, 7197-7207:215, 7208-7222:35; Tó-26 7370, 7371:80, 7373:35, 7375:9, 7376-7379:130, 7380-7382:9, 7383, 7384:82; Tó-27 7457-7460:82, 7463-7466:58, 7467-7469:90, 7470-7472:165, 7473-7474:202, 7475-7476:75, 7479:22, 7481:17, 7485-7486:110, 7487:87, 7488:79; Tó-28 6465:11, 6455:10, 6454:60, 6452:245, 6450:165, 6427:230, 6424:40, 6423:8, 6420:7, 6419:2, 6416:2; Tó-29 7790:20, 7794:30, 7860-7863:45, 7869-7872:5, 7875:35, 7880-7882:181, 7884-7892:65, 7893-7895:202, 7896-7897:130, 7898:165, 7898-7993:840, 7904-7906:57; Tó-30 7660-7662:107, 7663, 7666:210, 7669-7671:140, 7672-7678:149, 7680:204, 7683, 7686:312, 7689-7691:270, 7692-7701:25, 7702-7704:519, 7705-7707:294, 7708-7710:74, 77118-7716:124, 7717:66, 7498-7499:112, 7500-7503:27, 7504:34, 7925-7927:33; Tó-31 6801:2, 6841:57, 6852:1, 6854:12, 6867:1, 6869:1, 6871:2; Tó-33 7922:28, 7434:35, 7492:37, 8150:10, 8144:23, 8138:5, 8132:70, 8126:140, 8120:152, 8114:87, 8068:5.

Aulacoseira granulata (Ehr.) Sim. var. angustissima (O. Müller) Sim. - Tó-4 5527:40; Tó-5 6867:3; Tó-7 8402:3; Tó-8 8408:42; Tó-11 5559:21, 5545:29; Tó-20 6628:13, 6641:10, 6670:1, 6681:2, 6691:50, 6701:8, 6709:20，6719:5; Tó-21 7055-7056:4，7336! 7081-7082:7; Tó-23 7161-7165:4, 7185-7196:13, 7197-7207:15, 7208-7222:3; Tó-26 7383, 7384:5, 7385, 7386:7; Tó-27 7463-7466:4, 7473-7474:24, 7475-7476:7, 7479:6, 7484:2, 7487:5, 7488:4; Tó-28 6465:1, 6423:3; Tó-29 78, 547, 855:4, 7893-7895:50, 7896-7897:16, 7963-7968:4; Tó-30 7644-7645:2, 7660-7662:140, 7663, 7666:23, 7702-7704:59, 7705-7707:45, 7708-7710:8, 77118-7716:3, 7498-7499:6; Tó-31 6867:3; Tó-33 7434:5, 7492:7, 8120:4.

Aulacoseira islandica (O. Müller) Sim. - Tó-11 5546:5, 5544:4; Tó-20 6619:54.

Aulacoseira islandica (O. Müller) Sim. morphotyp helvetica - Tó-30 7644-7645:2.

Bacillaria paradoxa Gmelin - Tó-17 7563:8, 7592, 7593, 7594:12; Tó-30 7692-7701:18.

Caloneis bacillum (Grun.) Cl. - Tó-4 5533:4; Tó-7 8387:2, 8388:9, 8389:2; Tó-8 8408:4, 8049:4; Tó-11 5549:10, 5548:4, 5546:9, 5545:8, 5543:15; Tó-17 7561:6, 7562, 7563:8, 7570, 7571, 7574:8, 7592, 7593, 7594:8, 7603-7606:4; Tó-20 6628:15, 6629-6630:26, 6631:16; Tó-21 7336! 7081-7082:6; Tó-22 7291?:8, 7304-7309:4, 7311-7318:4; Tó-23 7109-7111:4, 7133-7144:9, 7166-7168:7, 7169-7177:22, 7185-7196:15; Tó-26 7370, 7371:2, 7387-7392:3, 7397, 7398:2, 7399-7401:2; Tó-27 7457-7460:8, 7463-7466:2, 7475-7476:8, 7478:6; Tó-29 7817-7819:5, 78, 677, 868:25, 7880-7882:15, 7893-7895:5, 7898-7993:5; Tó-30 7643:1, 7672-7678:13, 7683, 7686:4, 7708-7710:14; Tó-33 7922:15, 7434:5, 8120:9.

Caloneis bacillum (Grun.) Cl. var. lancettula (Schulz) Hust. - Tó-11 5556:2, 5555:9, 5553:12, 5549:8, 5548:5; Tó-26 7373:3; Tó-33 8114:2.

Caloneis clevei (Lagst.) Cl. - Tó-17 7562, 7563:8. 
Caloneis latiuscula (Kütz.) Cl. - Tó-23 7185-7196:4.

Caloneis macedonica Hust. - Tó-20 6628:2, 6629-6630:2, 6631:2, 6633:1.

Caloneis schumanniana (Grun.) Cl. - Tó-4 5533:2, 5530:22, 5527:37, 5525:12, 5524:23, 5523:5; Tó-5 6801:1, 6832:1; Tó-7 8402:7, 8403:3; Tó-8 8405:2, 8406:2, 8049:8; Tó-11 5556:8, 5552:11, 5548:10, 5547:9, 5545:4; Tó-17 7563:4, 7562, 7563:5, 7625-7627:4; Tó-20 6623:4, 6628:5, 6629-6630:15, 6641:4, 6691:7, 6701:1; Tó-21 7058-7060:5, 7061-7063:7, 7064-7066:6, 7075-7077:5; Tó-22 7259-7260:8, 7267-7272:1, 7259-7261:2, 7268:20, 7272-7274:10, 7298:2, 7304-7309:5, 7311-7318:13; Tó-23 7109-7111:7, 7112-7119:16, 7149-7150:2, 7166-7168:9, 7169-7177:20, 7208-7222:16; Tó-26 7365:10, 7366-7367:8, 7375:10, 7376-7379:24, 7387-7392:10, 7395, 7396:7, 7399-7401:2; Tó-27 7457-7460:7, 7463-7466:6, 7467-7469:20, 7475-7476:8, 7477:5, 7478:25, 7485-7486:20, 7487:4, 7488:2; Tó-28 6423:2, 6420:2; Tó-29 78, 677, 868:30, 7869-7872:5, 7898-7993:1, 7904-7906:5; Tó-30 7663, 7666:13, 7669-7671:2, 7683, 7686:17, 7702-7704:2, 7705-7707:2, 77118-7716:1, 7500-7503:3; Tó-31 6801:1, 6832:1; Tó-33 7434:5, 7492:5.

Caloneis schumanniana (Grun.) Cl. var. biconstricta (Grun.) Reichelt - Tó-4 5529:16, 5528:5, 5527:4, 5526:5, 5524:26; Tó-7 8388:16, 8400:5; Tó-8 8404:2, 8405:6, 8408:3; Tó-11 5555:2, 5553:4, 5546:2, 5542:12; Tó-20 6631:13, 6691:1; Tó-21 7043-7045:5, 7046-7047:3, 7048-7054:4, 7058-7060:8, 7085-7087:5; Tó-22 7259-7260:1, 7291?:1, 7272-7274:2, 7300:3, 7301-7303:3; Tó-23 7101-7104:5, 7109-7111:4, 7126-7130:4，7131-7132:2, 7149-7150:3, 7178-7184:3, 7185-7196:21, 7197-7207:19; Tó-26 7365:22, 7375:4, 7383, 7384:7, 7385, 7386:5, 7387-7392:4; Tó-27 7467-7469:2, 7473-7474:6, 7475-7476:1, 7484:2, 7485-7486:2; Tó-28 6455:1, 6424:2, 6423:12, 6420:1; Tó-29 7794:10, 7864-7866:13, 78, 677, 868:25, 7904-7906:10; Tó-30 7643:3, 7655-7659:2, 7663, 7666:2, 7672-7678:2, 7683, 7686:6, 7689-7691:8, 7702-7704:2, 7705-7707:2, 77118-7716:4; Tó-33 8132:14, 8114:2, 8059:2, 8054:8.

Caloneis schumanniana (Grun.) Cl. var. lancettula Hust. - Tó-4 5533:2; Tó-30 7692-7701:3; Tó-33 8108:33.

Caloneis silicula (Ehr.) Cl. - Tó-5 6801:2, 6802:1, 6831:1; Tó-11 5559:4, 5552:2, 5551:2; Tó-17 7622-7624:3; Tó-20 6623:2, 6628:13, 6631:14, 6633:2, 6670:1; Tó-22 7259-7260:3, 7265:3, 7291?:4; Tó-23 7101-7104:4, 7149-7150:3; Tó-26 7365:20, 7380-7382:12; Tó-27 7463-7466:10, 7488:10; Tó-30 7683, 7686:5; Tó-31 6801:2, 6802:1, 6831:1.

Caloneis silicula (Ehr.) Cl. var. truncatula Grun. - Tó-21 7048-7054:5; Tó-23 7109-7111:12, 7112-7119:5, 7126-7130:3; Tó-26 7364:6, 7365:5; Tó-30 7669-7671:2.

Caloneis sublinearis (Grun.) Krammer - Tó-20 6628:1.

Campylodiscus balatonis Pant. - Tó-4 5524:7, 5523:22; Tó-7 8402:2, 8403:2; Tó-8 8049:2; Tó-11 5552:10, 5549:2, 5548:6, 5547:9, 5546:22, 5545:2, 5544:11, 5543:1, 5540:5; Tó-17 7595, 7596, 7597, 7599, 7600:9; Tó-20 6628:5, 6641:8; Tó-21 7043-7045:2, 7058-7060:4, 7061-7063:12, 7064-7066:10, 7067-7069:12, 7070, 7073:13, 7336! 7081-7082:5; Tó-22 7276-7277:1,7272-7274:3, 7304-7309:4, 7311-7318:5; Tó-23 7185-7196:38, 7197-7207:10; Tó-26 7373:5, 7380-7382:11, 7383, 7384:5, 7385, 7386:7; Tó-27 7457-7460:6, 7470-7472:6, 7475-7476:8, 7481:1, 7488:2; Tó-28 6455:3, 6427:2; Tó-29 7869-7872:5, 7880-7882:5, 7884-7892:5, 7898-7993:14; Tó-30 7660-7662:15, 7663, 7666:17, 7669-7671:2, 7672-7678:15, 7683, 7686:10, 7689-7691:5, 7692-7701:2, 7708-7710:10, 77118-7716:30, 7717:4, 7498-7499:2; Tó-33 7922:7, 7434:4, 8114:4, 8084:2.

Campylodiscus bicostatus W. Smith - Tó-27 7457-7460:4.

Campylodiscus clypeus E. - Tó-5 6841:1, 6866:1; Tó-11 5553:5, 5552:20, 5551:5; Tó-22 7300:29, 7301-7303:5; Tó-23 7178-7184:3; Tó-26 7399-7401:4; Tó-27 7457-7460:144; Tó-30 7643:2, 7683, 7686:2, 7689-7691:4, 7500-7503:1; Tó-31 6841:1, 6866:1. 
Campylodiscus hibernicus E. - Tó-5 6791:1, 6832:4; Tó-11 5552:14, 5551:5; Tó-17 7622-7624:2; Tó-22 7291?:5, 7300:1, 7301-7303:11; Tó-26 7364:5; Tó-27 7470-7472:1; Tó-30 7650-7654:25, 7655-7659:1, 7663, 7666:11, 7683, 7686:7, 7689-7691:13; Tó-31 6791:1, 6832:4; Tó-33 8150:3.

Campylodiscus noricus E. - Tó-11 5553:4, 5551:5, 5546:5; Tó-17 7562, 7563:2; Tó-21 7070, 7073:1; Tó-22 7298:3; Tó-26 7383, 7384:5; Tó-33 8108:4.

Campylodiscus noricus E. var. hungarica Pant. - Tó-11 5559:4, 5553:16, 5552:7, 5551:5, 5542:7; Tó-21 7043-7045:3; Tó-23 7126-7130:2, 7178-7184:10, 7185-7196:4, 7197-7207:4.

Campylodiscus peisonis Pant. - Tó-11 5553:5; Tó-23 7178-7184:12.

Cocconeis diminuta Pant. - Tó-4 5528:15, 5527:47, 5526:28, 5525:30, 5524:27, 5523:75; Tó-5 6801:1, 6866:1, 6869:1, 6871:3, 6873:11, 6874:2; Tó-7 8402:3, 8403:8; Tó-8 8408:5, 8049:2; Tó-11 5548:2, 5547:4, 5543:10, 5542:10, 5540:50; Tó-17 7592, 7593, 7594:9, 7595, 7596, 7597, 7599, 7600:72, 7607-7612:45, 6713-7618:31, 7622-7624:52, 7625-7627:34; Tó-20 6641:2, 6670:1, 6709:2, 6719:1; Tó-21 7061-7063:5, 7064-7066:5, 7070, 7073:5, 7075-7077:20, 7336! 7081-7082:8，7083-7084:4，7085-7087:10，7088-7090:7; Tó-22 7325:8; Tó-23 7161-7165:1, 7185-7196:3, 7197-7207:35; Tó-26 7370, 7371:20, 7373:27, 7375:10, 7376-7379:25, 7383, 7384:40, 7385, 7386:36, 7387-7392:9, 7393, 7394:10, 7397, 7398:9, 7399-7401:9; Tó-27 7467-7469:7, 7470-7472:65, 7473-7474:57, 7475-7476:4, 7478:45, 7479:23, 7481:40, 7482-7483:2, 7484:20, 7485-7486:6, 7487:4, 7488:5; Tó-28 6455:35, 6452:6, 6450:17, 6427:22, 6424:14, 6423:5, 6419:19, 6416:6; Tó-29 7896-7897:75, 7898:26, 7898-7993:52; Tó-30 7643:1, 7655-7659:2, 7692-7701:26, 7702-7704:2, 7705-7707:5, 7708-7710:2, 77118-7716:9, 7498-7499:2, 7500-7503:12, 7925-7927:35; Tó-31 6801:1, 6866:1, 6869:1, 6871:3, 6873:11, 6874:2; Tó-33 7922:5, 8243:55, 8150:140, 8138:10, 8132:18, 8126:17.

Cocconeis disculus (Schum.) Cl. - Tó-17 7622-7624:1; Tó-22 7259-7260:1; Tó-30 7650-7654:2.

Cocconeis pediculus Ehr. - Tó-20 6628:1, 6629-6630:2, 6631:2, 6633:2, 6701:6, 6707:1.

Cocconeis placentula Ehr. - Tó-4 5529:4; Tó-5 6801:3, 6802:3, 6867:1; Tó-7 8403:5; Tó-11 5559:2, 5551:2, 5546:2, 5544:4, 5541:5; Tó-17 7592, 7593, 7594:6, 6713-7618:5, 7622-7624:1; Tó-20 6628:1, 6629-6630:1, 6660, 6661:2, 6681:5, 6691:1; Tó-21 7048-7054:16, 7061-7063:3, 7067-7069:3, 7070, 7073:5, 7336! 7081-7082:6, 7085-7087:1; Tó-22 7267-7272:1, 7259-7261:32, 7291?:2, 7272-7274:3, 7301-7303:7, 7311-7318:2, 7325:5; Tó-23 7099:2, 7101-7104:6, 7112-7119:1, 7131-7132:3, 7133-7144:3, 7151-7160:4, 7169-7177:20, 7178-7184:2, 7185-7196:5; Tó-26 7375:4; Tó-27 7473-7474:4; Tó-29 7898-7993:3; Tó-30 7644-7645:17, 7650-7654:5, 7663, 7666:3; Tó-31 6801:3, 6802:3, 6867:1; Tó-33 8138:4, 8108:4, 8100:2, 8086:5, 8059:2, 8054:4, 8050:5, 8041:1.

Cocconeis placentula Ehr. var. euglypta E. - Tó-4 5530:1; Tó-5 6792:1, 6793:33, 6795:1, 6796:1, 6801:1, 6802:1; Tó-7 8403:2, 8389:4; Tó-8 8406:2, 8407:4, 8049:2; Tó-11 5556:6, 5555:7, 5540:5; Tó-17 7562, 7563:2, 7603-7606:4, 7607-7612:2; Tó-20 6628:2, 6629-6630:2, 6633:6, 6641:4, 6707:1; Tó-21 7043-7045:10, 7046-7047:5, 7048-7054:20, 7075-7077:5, 7336! 7081-7082:4, 7083-7084:4; Tó-22 7259-7261:7, 7268:1, 7272-7274:3, 7300:1, 7301-7303:3; Tó-23 7131-7132:3, 7145-7148:4, 7149-7150:2, 7166-7168:9, 7169-7177:38, 7178-7184:4, 7185-7196:2, 7197-7207:5, 7208-7222:5; Tó-26 7370, 7371:2, 7387-7392:4; Tó-27 7457-7460:2,7467-7469:5; Tó-29 78, 547, 855:15, 7963-7968:3; Tó-30 7644-7645:5, 7500-7503:10; Tó-31 6792:1, 6793:33, 6795:1, 6796:1, 6801:1, 6802:1; Tó-33 8138:30, 8132:4, 8090:21, 8086:2, 8084:4.

Cocconeis placentula E. var. lineata (Ehr.) van Heurck - Tó-5 6802:3, 6873:1; Tó-31 6802:3, 6873:1.

Cocconeis scutellum Ehr. - Tó-4 5526:5.

Cocconeis thumensis A Mayer - Tó-4 5530:3, 5529:28, 5528:10, 5527:73, 5525:45, 5524:28, 5523:15; Tó-7 8402:16, 8388:11, 8403:38, 8389:30; Tó-8 8404:15, 8405:37, 8407:61, 8408:19, 
8049:12; Tó-11 5543:5, 5540:5; Tó-17 7558-7560:3, 7562, 7563:4, 7581-7583:23, 7592, 7593, 7594:31, 6713-7618:8, 7622-7624:4, 7625-7627:7; Tó-20 6641:2; Tó-21 7048-7054:20, 7058-7060:3 7061-7063:22, 7085-7087:3; Tó-22 7301-7303:2, 7304-7309:5, 7311-7318:3; Tó-23 7109-7111:2, 7120-7121:5, 7133-7144:5, 7145-7148:10, 7151-7160:4, 7161-7165:10, 7166-7168:17, 7185-7196:10, 7197-7207:10; Tó-26 7364:4, 7365:13, 7366-7367:213, 7373:15, 7375:6, 7383, 7384:2, 7387-7392:1, 7393, 7394:4，7397, 7398:9, 7399-7401:2; Tó-27 7463-7466:6, 7467-7469:27, 7470-7472:15, 7473-7474:12, 7475-7476:7, 7478:13, 7479:33, 7481:2, 7485-7486:4; Tó-28 6455:2; Tó-29 7817-7819:15, 7864-7866:5, 7880-7882:5, 7896-7897:120, 7898:40, 7898-7993:10; Tó-30 7643:2, 7660-7662:4, 7663, 7666:5, 7669-7671:2, 7672-7678:1, 7680:2, 7683, 7686:6, 7689-7691:36, 7692-7701:10, 7702-7704:7, 7705-7707:5, 77118-7716:2, 7717:1; Tó-33 7922:5, 7434:15, 7492:17, 8243:6, 8144:2, 8120:17, 8114:6, 8086:2, 8068:12, 8059:2, 8054:2, 8041:1, 8042:1.

Cyclostephanos dubius (Fricke) Round - Tó-7 8402:2; Tó-11 5559:4, 5556:2, 5545:2; Tó-21 7048-7054:16, 7055-7056:4, 7058-7060:2, 7336! 7081-7082:5; Tó-23 7161-7165:45, 7166-7168:8; Tó-30 7500-7503:3, 7504:4; Tó-33 8243:19, 8068:4, 8054:2, 8042:1.

Cyclotella antiqua W. Sm. - Tó-21 7043-7045:2, 7048-7054:2; Tó-23 7101-7104:1, 7145-7148:1; Tó-30 7717:2.

Cyclotella balatonis Pant. - Tó-11 5559:2, 5549:4, 5547:7, 5545:11; Tó-17 7607-7612:4, 7622-7624:1; Tó-33 7922:1, 7492:14.

Cyclotella bodanica Grun. - Tó-11 5547:1; Tó-20 6709:15.

Cyclotella comensis Grun. - Tó-26 7387-7392:4.

Cyclotella comta (Ehr.) Kütz. - Tó-4 5529:8; Tó-7 8400:24; Tó-11 5547:6; Tó-20 6628:2, 6629-6630:2; Tó-21 7058-7060:5, 7064-7066:2; Tó-22 7304-7309:2; Tó-23 7099:2, 7109-7111:7, 7149-7150:2, 7151-7160:5, 7161-7165:15; Tó-26 7375:4, 7376-7379:3, 7383, 7384:5; Tó-27 7481:2; Tó-29 7817-7819:5; Tó-30 7663, 7666:4, 7669-7671:5; Tó-33 7922:5, 8144:6, 8138:9, 8120:9.

Cyclotella comta (Ehr.) Kütz. var. paucipunctata Grun. - Tó-11 5556:2; Tó-23 7161-7165:7, 7166-7168:2; Tó-30 7669-7671:3.

Cyclotella distinguenda Hust. - Tó-5 6832:6; Tó-7 8387:2, 8400:24; Tó-11 5553:4; Tó-21 7055-7056:5, 7061-7063:12; Tó-23 7145-7148:1; Tó-29 7864-7866:15, 7963-7968:5; Tó-30 7663, 7666:11, 7672-7678:3, 7680:8, 7683, 7686:4, 7689-7691:8, 7702-7704:2, 7705-7707:2; Tó-31 6832:6; Tó-33 8059:2, 8054:20.

Cyclotella glomerata Bachmann - Tó-23 7109-7111:9.

Cyclotella meneghiniana Kütz. - Tó-4 5524:15; Tó-5 6871:1; Tó-7 8389:2; Tó-8 8404:2, 8406:7, 8408:6; Tó-17 7562, 7563:12, 7567-7568:8, 7622-7624:2; Tó-20 6623:2, 6631:4, 6681:1, 6719:1; Tó-21 7085-7087:3; Tó-22 7259-7260:2, 7265:1, 7300:1, 7301-7303:3, 7304-7309:1; Tó-23 7131-7132:6, 7133-7144:15, 7161-7165:10, 7166-7168:3, 7197-7207:6; Tó-26 7397, 7398:3, 7399-7401:2; Tó-27 7475-7476:8; Tó-28 6423:1, 6420:1; Tó-29 7799:5, 7800:5, 7805-7809:10, 7810-7816:41, 7817-7819:5; Tó-30 7644-7645:4; Tó-31 6871:1.

Cyclotella ocellata Pant. - Tó-5 6871:1; Tó-11 5546:2, 5544:7; Tó-17 7592, 7593, 7594:8, 7622-7624:2, 7625-7627:20; Tó-20 6628:5, 6629-6630:5, 6631:6, 6633:5, 6709:28, 6719:5; Tó-21 7061-7063:15, 7075-7077:6; Tó-22 7276-7277:1; Tó-23 7133-7144:5, 7151-7160:2, 7208-7222:5; Tó-26 7365:11, 7375:4, 7383, 7384:1, 7385, 7386:32, 7387-7392:3, 7395, 7396:16, 7397, 7398:4; Tó-27 7457-7460:3, 7475-7476:14, 7478:4, 7487:2; Tó-29 7898-7993:5; Tó-30 7643:1, 7644-7645:9 7650-7654:3, 7660-7662:43, 7669-7671:2, 7672-7678:9, 7680:10, 7683, 7686:2, 7689-7691:5, 7692-7701:4, 77118-7716:2, 7498-7499:4, 7500-7503:8; Tó-31 6871:1; Tó-33 7922:10, 7434:10, 7492:10, 8132:33, 8054:2

Cyclotella radiosa (Grun.) Lemm. - Tó-4 5530:19, 5529:28, 5528:5, 5527:15, 5526:5, 5525:5; Tó-8 8404:2; Tó-11 5548:2; Tó-17 7592, 7593, 7594:2, 6713-7618:2; Tó-20 6628:5, 
6629-6630:5，6631:4，6691:1，6701:2，6709:29，6719:1; Tó-21 7043-7045:2，7048-7054:5, 7055-7056:7, 7061-7063:25, 7064-7066:7, 7336! 7081-7082:10, 7085-7087:4; Tó-22 7265:2 7267-7272:1, 7298:5, 7301-7303:6, 7304-7309:3, 7325:3; Tó-23 7101-7104:3, 7126-7130:3, 7131-7132:10, 7133-7144:7, 7161-7165:20, 7166-7168:4, 7185-7196:3, 7197-7207:16; Tó-26 7376-7379:9, 7383, 7384:16, 7387-7392:20, 7395, 7396:4, 7397, 7398:9; Tó-27 7463-7466:10, 7473-7474:16, 7479:4, 7488:4; Tó-28 6427:2, 6420:1; Tó-29 7794:35, 7800:10, 7805-7809:10, 7817-7819:5, 7860-7863:5, 7864-7866:47, 7896-7897:10; Tó-30 7644-7645:10, 7655-7659:21, 7660-7662:62, 7663, 7666:5, 7672-7678:5, 7680:9, 7683, 7686:2, 7689-7691:13, 77118-7716:4, 7717:6, 7498-7499:5, 7500-7503:6, 7504:30; Tó-33 7434:3, 7492:29, 8108:3, 8084:4.

Cyclotella stelligera Cl. et Grun. - Tó-30 7644-7645:3.

Cyclotella striata (Kütz.) Grun. - Tó-22 7304-7309:2.

Cymatopleura brunii Petit et Brun - Tó-26 7373:2.

Cymatopleura elliptica (Bréb.) W. Sm. - Tó-4 5527:2; Tó-5 6796:1, 6832:15; Tó-7 8387:2; Tó-11 5559:2, 5556:1, 5549:2, 5546:5, 5545:2, 5544:1, 5543:11; Tó-17 7561:2, 7562, 7563:21, 7592, 7593, 7594:3, 7607-7612:2; Tó-20 6628:3, 6631:5, 6633:4, 6634:2, 6641:2, 6691:3; Tó-21 7043-7045:1, 7046-7047:31, 7048-7054:8, 7058-7060:9, 7061-7063:2, 7085-7087:1; Tó-22 7259-7260:2, 7291?:1, 7272-7274:1, 7304-7309:1; Tó-23 7109-7111:13, 7112-7119:16, 7120-7121:3, 7149-7150:3, 7151-7160:5, 7197-7207:3, 7208-7222:13; Tó-26 7365:4, 7376-7379:10, 7385, 7386:53, 7397, 7398:2, 7399-7401:2; Tó-27 7467-7469:3, 7470-7472:2, 7473-7474:2, 7475-7476:2, 7479:2, 7482-7483:2; Tó-29 7810-7816:6; Tó-30 7660-7662:5, 7663, 7666:2, 7669-7671:3, 7683, 7686:9, 7689-7691:9, 7705-7707:4, 77118-7716:10, 7500-7503:4, 7504:15, 7925-7927:12; Tó-31 6796:1, 6832:15; Tó-33 7922:10, 8144:7.

Cymatopleura elliptica (Bréb.) W. Sm. var. hibernica (W. Sm.) van Heurck - Tó-20 6707:3; Tó-21 7088-7090:1; Tó-22 7291?:4; Tó-28 6427:2.

Cymatopleura solea (Bréb.) W. Sm. - Tó-4 5533:1, 5530:14, 5529:4, 5527:15, 5523:22; Tó-5 6871:1; Tó-7 8402:3, 8388:3, 8389:13, 8400:10; Tó-8 8404:6; Tó-11 5559:14, 5556:6, 5551:2, 5549:2, 5548:8, 5546:2, 5542:8, 5540:5; Tó-17 7562, 7563:4, 7592, 7593, 7594:3, 7595, 7596, 7597, 7599, 7600:2, 7607-7612:10; Tó-20 6628:2, 6631:1, 6633:5, 6660, 6661:1, 6681:3, 6707:2; Tó-21 7043-7045:3, 7046-7047:10, 7048-7054:22, 7055-7056:5, 7058-7060:5, 7061-7063:3, 7064-7066:5, 7067-7069:3, 7075-7077:10; Tó-22 7259-7260:2, 7265:1, 7259-7261:2, 7291?:2, 7301-7303:1, 7304-7309:1; Tó-23 7109-7111:18, 7112-7119:4, 7131-7132:11, 7145-7148:4, 7151-7160:11, 7166-7168:34, 7169-7177:5, 7178-7184:6, 7185-7196:2, 7197-7207:7, 7208-7222:10; Tó-26 7366-7367:4, 7380-7382:4, 7383, 7384:5, 7385, 7386:52, 7399-7401:1; Tó-27 7463-7466:2, 7473-7474:4, 7475-7476:7, 7477:10, 7479:4, 7481:6, 7485-7486:8, 7487:4; Tó-28 6454:2, 6427:2, 6420:1; Tó-29 7805-7809:5, 7810-7816:5, 7898-7993:5; Tó-30 7646-7649:2, 7650-7654:5, 7660-7662:4, 7672-7678:1, 7683, 7686:11, 77118-7716:8, 7500-7503:2; Tó-31 6871:1; Tó-33 8144:4, 8126:8, 8108:3.

Cymatopleura solea (Bréb.) W. Sm. var. apiculata (W. Sm.) Ralfs - Tó-23 7109-7111:4, 7112-7119:19, 7151-7160:2.

Cymbella aequalis W. Sm. - Tó-4 5530:15, 5528:10, 5525:5; Tó-21 7058-7060:3; Tó-22 7291?:2; Tó-23 7126-7130:1; Tó-26 7366-7367:5; Tó-30 7683, 7686:5; Tó-33 7434:4, 7492:3, 8243:5.

Cymbella affinis Kütz. - Tó-4 5529:12; Tó-5 6802:2; Tó-7 8402:3, 8388:6, 8403:12, 8389:2, 8400:20; Tó-8 8406:17; Tó-11 5556:4, 5555:2, 5553:4, 5550:8, 5546:12, 5545:4, 5542:8, 5541:10; Tó-17 7592, 7593, 7594:2, 6713-7618:2; Tó-20 6670:1; Tó-21 7043-7045:8; Tó-22 7259-7261:7, 7291?:2, 7301-7303:12, 7304-7309:4, 7311-7318:4; Tó-23 7093-7094:2, 7101-7104:16, 7145-7148:2, 7149-7150:5, 7166-7168:4, 7178-7184:4, 7185-7196:9, 7208-7222:15; Tó-26 7399-7401:22; Tó-29 7800:25, 7805-7809:25, 7817-7819:5, 7825:5, 78, 547, 855:25, 7869-7872:5, 7880-7882:5, 
7904-7906:5; Tó-30 7680:2, 7692-7701:1; Tó-31 6802:2; Tó-33 8243:15, 8144:7, 8138:16, 8132:8, 8120:4, 8108:4, 8100:24, 8090:5, 8086:15, 8083:7, 8059:7, 8054:8, 8050:22.

Cymbella amphicephala Naegeli - Tó-4 5531:2, 5530:40, 5529:41, 5528:35, 5525:5; Tó-8 8405:2; Tó-26 7365:8, 7366-7367:10, 7375:18; Tó-11 5544:2; Tó-27 7467-7469:2, 7470-7472:5, 7473-7474:14, 7475-7476:2; Tó-29 78, 547, 855:15; Tó-33 8100:2, 8090:220, 8086:92, 8084:13, 8083:2, 8059:5.

Cymbella amphicephala Naegeli var. citrus (Carter et Bailey-Watts) Krammer - Tó-7 8387:2; Tó-23 7126-7130:7, 7133-7144:4, 7145-7148:4, 7149-7150:1, 7169-7177:7, 7178-7184:18; Tó-30 7680:4, 7692-7701:2, 7500-7503:2.

Cymbella aspera (Ehr.) Cl. - Tó-4 5523:5; Tó-5 6793:20, 6832:25, 6841:5; Tó-7 8403:2; Tó-8 8408:2; Tó-11 5549:6, 5542:3, 5541:11; Tó-17 7595, 7596, 7597, 7599, 7600:5; Tó-20 6619:2, 6628:2, 6629-6630:1, 6631:2, 6633:2, 6634:20, 6641:2, 6709:2; Tó-23 7151-7160:15, 7178-7184:7, 7208-7222:7; Tó-27 7457-7460:2; Tó-29 7810-7816:20, 7898-7993:16; Tó-30 7650-7654:4, 7660-7662:1, 7683, 7686:6, 7689-7691:1, 7717:2; Tó-31 6793:20, 6832:25, 6841:5; Tó-33 8243:5, 8138:4.

Cymbella austriaca Grun. - Tó-30 7692-7701:1.

Cymbella balatonis Grun. - Tó-11 5553:4.

Cymbella cesatii (Rabh.) Grun. - Tó-7 8387:1; Tó-8 8406:19; Tó-27 7479:2.

Cymbella cistula (Ehr.) Kirchner - Tó-5 6801:3; Tó-11 5559:2; Tó-22 7291?:2; Tó-23 7109-7111:8, 7185-7196:6, 7197-7207:5; Tó-27 7478:7; Tó-30 7500-7503:3; Tó-31 6801:3.

Cymbella cuspidata Kütz. - Tó-4 5530:57, 5529:20; Tó-8 8406:2, 8407:2; Tó-11 5552:2, 5549:8, 5546:2, 5545:6; Tó-23 7161-7165:5, 7178-7184:12; Tó-26 7375:3; Tó-27 7477:8, 7485-7486:7, 7487:4, 7488:10; Tó-30 7672-7678:4; Tó-33 8068:2.

Cymbella cymbiformis Agardh - Tó-5 6802:2, 6841:1; Tó-7 8389:2; Tó-11 5559:2, 5551:4, 5548:4; Tó-17 7563:4; Tó-21 7070, 7073:5, 7088-7090:1; Tó-22 7259-7261:4, 7300:2, 7301-7303:2, 7311-7318:2; Tó-23 7126-7130:5, 7151-7160:3, 7169-7177:5, 7178-7184:20, 7185-7196:3; Tó-27 7467-7469:3, 7473-7474:2, 7478:4, 7484:2; Tó-29 7794:10, 7817-7819:5, 78, 547, 855:15, 7869-7872:5; Tó-30 7643:5, 7650-7654:5, 7660-7662:4, 7500-7503:1; Tó-31 6802:2, 6841:1; Tó-33 7434:5, 8144:19, 8108:7, 8100:5, 8054:3, 8042:2.

Cymbella ehrenbergii Kütz. - Tó-4 5529:4, 5528:5, 5525:5, 5524:66, 5523:21; Tó-5 6801:1, 6832:2; Tó-7 8400:4; Tó-8 8406:2, 8408:5, 8049:2; Tó-11 5553:7, 5551:8, 5548:5, 5547:1, 5544:6, 5542:8, 5541:5; Tó-17 7581-7583:2, 7595, 7596, 7597, 7599, 7600:5; Tó-20 6628:1, 6660, 6661:3; Tó-21 7336! 7081-7082:4; Tó-22 7259-7260:4, 7259-7261:6, 7291?:11, 7311-7318:1, 7325:1; Tó-23 7131-7132:8, 7151-7160:19, 7166-7168:10, 7169-7177:11, 7178-7184:6, 7185-7196:46, 7197-7207:48; Tó-26 7373:3, 7375:3, 7376-7379:6, 7383, 7384:1, 7387-7392:10, 7397, 7398:2; Tó-27 7457-7460:4, 7463-7466:6, 7467-7469:15, 7473-7474:5, 7475-7476:17, 7479:8, 7487:2, 7488:2; Tó-29 7794:15, 7805-7809:10, 7860-7863:10, 7904-7906:4; Tó-30 7643:2, 7646-7649:2, 7650-7654:20, 7655-7659:5, 7660-7662:5, 7669-7671:6, 7672-7678:7, 7680:2, 7683, 7686:2, 7689-7691:5, 7708-7710:4, 77118-7716:4, 7717:2; Tó-31 6801:1, 6832:2; Tó-33 8108:14, 8100:34, 8084:5.

Cymbella ehrenbergii Kütz. var. hungarica Pant. - Tó-20 6629-6630:1, 6631:3; Tó-21 7048-7054:2; Tó-22 7259-7260:4, 7265:1, 7268:1, 7272-7274:1, 7298:4, 7301-7303:2; Tó-26 7365:3, 7385, 7386:7; Tó-28 6455:15, 6450:3; Tó-30 7689-7691:1; Tó-33 8132:5.

Cymbella elginensis Krammer - Tó-22 7291?:2, 7300:4, 7301-7303:4; Tó-23 7109-7111:2, 7112-7119:6, 7145-7148:7, 7149-7150:5, 7151-7160:7, 7161-7165:5, 7178-7184:8; Tó-27 7484:4; Tó-29 7799:5, 7898-7993:2; Tó-30 7680:2, 7683, 7686:2, 77118-7716:2.

Cymbella hauckii Van Heurck - Tó-20 6628:5, 6629-6630:14, 6631:4.

Cymbella hebridica (Grun.) Cl. - Tó-23 7208-7222:6. 
Cymbella helvetica Kütz. - Tó-4 5529:4, 5528:5, 5525:5, 5523:4; Tó-7 8402:11, 8403:4, 8389:3, 8400:44; Tó-11 5540:5; Tó-17 7581-7583:4; Tó-23 7126-7130:1; Tó-26 7399-7401:5; Tó-29 7869-7872:5; Tó-30 7646-7649:1, 7663, 7666:1, 7683, 7686:2, 7702-7704:4; Tó-33 8138:8, 8120:5, 8108:2, 8086:5, 8059:6, 8054:7, 8050:12.

Cymbella helvetica Kütz. var. elongata Pant. - Tó-21 7043-7045:2.

Cymbella helvetica Kütz. var. balatonis (Grun.) Cl. - Tó-22 7301-7303:10.

Cymbella hungarica (Grun.) Pant. - Tó-11 5559:2; Tó-21 7048-7054:6; Tó-26 7383, 7384:7.

Cymbella hustedtii Krasske - Tó-7 8402:2; Tó-20 6631:3, 6633:2.

Cymbella hybrida Grun. - Tó-22 7325:2; Tó-23 7131-7132:2; Tó-29 7794:10, 7805-7809:6.

Cymbella lacustris (Ag.) Cl. - Tó-4 5530:10, 5528:5, 5523:5; Tó-7 8388:4, 8389:1, 8400:21; Tó-8 8404:4; Tó-11 5556:4, 5553:4, 5547:2, 5544:2; Tó-17 7561:2, 7562, 7563:2, 7581-7583:6; Tó-20 6631:11, 6633:16, 6634:6; Tó-22 7259-7261:2, 7298:2, 7301-7303:7, 7304-7309:2; Tó-23 7131-7132:20, 7145-7148:4, 7149-7150:5, 7161-7165:5, 7178-7184:17, 7185-7196:3, 7197-7207:5; Tó-28 6457:2, 6423:1; Tó-29 7790:45, 7794:90, 7799:55, 7800:23, 7805-7809:96, 7810-7816:40, 7825:15, 7860-7863:20, 7864-7866:15, 7869-7872:5, 7875:5, 7898-7993:2; Tó-30 7644-7645:9, 7663, 7666:6, 7689-7691:13, 7717:2; Tó-33 8144:5, 8126:8, 8114:2, 8108:11, 8086:9, 8083:4, 8059:2, 8054:20, 8050:2, 8041:1. 8059:4.

Cymbella laevis Naegeli - Tó-4 5533:4, 5530:2; Tó-23 7169-7177:10; Tó-29 7794:20; Tó-33

Cymbella lanceolata (Ehr.) Kirchner - Tó-4 5530:34; Tó-11 5541:5; Tó-17 7595, 7596, 7597, 7599, 7600:11; Tó-27 7463-7466:2; Tó-29 7810-7816:5; Tó-33 8108:2, 8083:4.

Cymbella lata Grun. - Tó-17 7603-7606:5, 6713-7618:2; Tó-23 7178-7184:5; Tó-30 7689-7691:4.

Cymbella leptoceros (Ehr.) Kütz. - Tó-4 5523:3; Tó-20 6618:4, 6628:3, 6629-6630:3, 6631:4, 6633:23, 6660, 6661:1, 6681:1, 6707:1; Tó-30 7498-7499:6; Tó-33 8083:13.

Cymbella lóczyi Pant. - Tó-17 7595, 7596, 7597, 7599, 7600:5, 7625-7627:3; Tó-20 6631:2; Tó-22 7265:1, 7259-7261:2, 7300:4, 7304-7309:1; Tó-23 7178-7184:13; Tó-26 7375:4; Tó-30 7689-7691:1.

Cymbella microcephala Grun. - Tó-20 6628:7, 6631:7, 6633:6.

Cymbella minuta Hilse - Tó-20 6641:2; Tó-23 7178-7184:5.

Cymbella naviculiformis Auerswald - Tó-17 7562, 7563:4; Tó-22 7272-7274:5; Tó-27 7463-7466:60

Cymbella prostrata (Berkeley) Cl. - Tó-5 6801:1, 6802:1; Tó-11 5559:2, 5545:4; Tó-20 6628:5, 6631:5; Tó-22 7268:1; Tó-23 7112-7119:5, 7126-7130:2, 7145-7148:1; Tó-27 7470-7472:5, 7487:2; Tó-29 7794:15, 7800:5, 7805-7809:10; Tó-30 7643:6, 7705-7707:2; Tó-31 6801:1, 6802:1; Tó-33 8243:10, 8100:5, 8050:8, 8042:5.

Cymbella signata Pant. - Tó-21 7061-7063:2.

Cymbella subaequalis Grun. - Tó-20 6633:2.

Cymbella thumensis (A. Mayer) Cl. - Tó-7 8388:30, 8389:20; Tó-8 8404:10, 8408:2; Tó-21 7043-7045:2, 7046-7047:12, 7048-7054:6, 7055-7056:10, 7058-7060:10, 7061-7063:38, 7088-7090:10; Tó-22 7265:4, 7291?:4, 7304-7309:6, 7311-7318:2, 7325:3; Tó-23 7120-7121:14, 7131-7132:4, 7145-7148:6, 7161-7165:20, 7185-7196:5, 7208-7222:5; Tó-26 7395, 7396:3; Tó-29 7805-7809:5, 7817-7819:5, 7896-7897:12, 7963-7968:5; Tó-30 7643:16, 7644-7645:2, 7669-7671:11,7672-7678:2, $7680: 9,7683,7686: 8,7692-7701: 10,77118-7716: 22,7717: 4$.

Diatomella balfouriana Grev. - Tó-30 77118-7716:1.

Diploneis elliptica (Kütz.) Cl. - Tó-4 5533:4, 5528:5, 5527:17, 5526:13, 5525:25, 5524:43, 5523:16; Tó-5 6832:1; Tó-7 8403:22, 8389:2; Tó-8 8407:33, 8408:23, 8049:7; Tó-11 5559:8, 5556:2, 5553:3, 5552:18, 5548:4, 5547:5, 5546:4, 5545:35, 5544:14, 5543:6, 5542:14, 5541:10, 
5540:10; Tó-17 7581-7583:5, 7592, 7593, 7594:2, 7595, 7596, 7597, 7599, 7600:4, 7603-7606:17, 7607-7612:2, 6713-7618:8, 7622-7624:14, 7625-7627:19; Tó-20 6618:8, 6701:1; Tó-21 7043-7045:17, 7055-7056:1, 7058-7060:29, 7061-7063:22, 7336! 7081-7082:5, 7083-7084:2, 7088-7090:21; Tó-22 7265:10, 7268:1, 7291?:2, 7301-7303:10, 7304-7309:19, 7311-7318:12, 7325:1; Tó-23 7101-7104:6, 7112-7119:3, 7131-7132:13, 7133-7144:4, 7145-7148:2, 7149-7150:1, 7151-7160:5， 7161-7165:5， 7166-7168:4， 7169-7177:64， 7185-7196:35， 7197-7207:22， 7208-7222:12; Tó-26 7364:3, 7365:94, 7366-7367:20, 7370, 7371:10, 7373:20, 7376-7379:20, 7383, 7384:13, 7395, 7396:2, 7397, 7398:12, 7399-7401:11; Tó-27 7457-7460:4, 7467-7469:63, 7470-7472:5, 7473-7474:121, 7475-7476:9, 7477:40, 7478:81, 7479:60, 7481:64, 7485-7486:6, 7487:15, 7488:14; Tó-28 6455:1, 6452:2, 6423:1; Tó-29 7790:5, 7805-7809:17, 7864-7866:5, 78, 677, 868:57, 7880-7882:15, 7896-7897:5, 7898:15, 7898-7993:20, 7904-7906:20; Tó-30 7644-7645:2, 7660-7662:138, 7663, 7666:21， 7669-7671:8， 7672-7678:23， 7680:67, 7683， 7686:98, 7689-7691:85, 7702-7704:2, 7705-7707:4, 7708-7710:2, 77118-7716:2, 7498-7499:10, 7500-7503:4; Tó-31 6832:1; Tó-33 7922:14, 7434:19, 7492:10, 8132:12, 8126:4, 8120:4, 8114:25, 8108:4, 8086:2, 8059:4, 8050:10, 8042:1.

Diploneis marginestriata Hust. - Tó-7 8402:8; Tó-8 8405:2; Tó-17 7622-7624:1; Tó-22 7304-7309:6; Tó-23 7131-7132:3, 7166-7168:2, 7169-7177:2; Tó-26 7397, 7398:3; Tó-27 7473-7474:17, 7481:2; Tó-29 78, 677, 868:10; Tó-30 7680:2.

Diploneis oblongella (Naegeli) Cleve-Euler - Tó-5 6801:4; Tó-11 5559:1; Tó-21 7043-7045:5; Tó-31 6801:4.

Diploneis oculata (Bréb.) Cl. - Tó-20 6641:2; Tó-21 7048-7054:2; Tó-22 7304-7309:2; Tó-23 7166-7168:2; Tó-27 7473-7474:4; Tó-30 7672-7678:1, 7680:4.

Diploneis ovalis (Hilse) Cl. - Tó-5 6796:2, 6802:1, 6867:3, 6871:3, 6874:1; Tó-17 7562, 7563:2, 7607-7612:17; Tó-20 6619:2, 6628:5, 6631:2, 6633:7, 6641:2, 6681:1, 6691:1, 6701:2, 6719:2; Tó-21 7064-7066:3, 7075-7077:10; Tó-22 7265:1, 7300:6, 7301-7303:1, 7304-7309:1; Tó-23 7099:3, 7101-7104:2, 7145-7148:2, 7161-7165:4, 7169-7177:3; Tó-26 7373:5, 7383, 7384:17, 7393, 7394:3, 7399-7401:3; Tó-27 7481:4, 7487:4, 7488:4; Tó-28 6419:2; Tó-30 7500-7503:4; Tó-31 6796:2, 6802:1, 6867:3, 6871:3, 6874:1; Tó-33 7492:10.

Diploneis pseudo-ovalis Hust. - Tó-7 8403:8; Tó-30 7663, 7666:8.

Diploneis puella (Schum.) Cl. - Tó-8 8408:2; Tó-11 5547:4; Tó-21 7055-7056:5; Tó-23 7169-7177:2.

Diploneis smithii (Bréb.) Cl. - Tó-22 7259-7260:1.

Ellerbeckia arenaria (Moore) Crawford - Tó-4 5533:2; Tó-5 6854:3, 6874:1; Tó-11 5549:1, 5540:5; Tó-17 7566:9, 7562, 7563:2, 7595, 7596, 7597, 7599, 7600:5, 7603-7606:8, 7607-7612:2, 7622-7624:3; Tó-20 6629-6630:1, 6641:2; Tó-21 7058-7060:4, 7067-7069:1, 7336! 7081-7082:3; Tó-22 7259-7260:36, 7267-7272:1, 7291?:229; Tó-23 7126-7130:3, 7208-7222:8; Tó-27 7457-7460:1; Tó-28 6452:1; Tó-29 7963-7968:10, 7969-7971:8; Tó-30 7644-7645:17, 7646-7649:51, 7669-7671:2, 7672-7678:3, 7500-7503:5; Tó-31 6854:3, 6874:1.

Epithemia adnata (Kütz.) Bréb. - Tó-4 5530:9, 5529:4, 5528:1, 5525:15, 5524:7, 5523:4; Tó-5 6791:1, 6796:2, 6801:5, 6802:1, 6831:17, 6869:4, 6871:4, 6873:1; Tó-7 8403:8; Tó-8 8408:7, 8049:9; Tó-11 5559:3, 5556:4, 5555:8, 5552:2, 5551:16, 5550:8, 5549:7, 5546:16, 5545:10, 5544:12, 5543:15， 5542:20， 5541:32， 5540:30; Tó-17 7551:5， 7563:66， 7564:35， 7566:18， 7567:5, 7558-7560:43, 7561:14, 7562, 7563:14, 7581-7583:24, 7589, 7590, 7591:4, 7592, 7593, 7594:10, 7595, 7596, 7597, 7599, 7600:4, 7607-7612:4, 7622-7624:4; Tó-20 6619:2, 6623:2, 6629-6630:3, 6634:4; Tó-21 7046-7047:57, 7048-7054:1, 7061-7063:15, 7075-7077:5, 7336! 7081-7082:11, 7085-7087:5, 7088-7090:11; Tó-22 7259-7260:2, 7265:2, 7259-7261:8, 7268:1, 7291?:6, 7298:1, 7301-7303:2, 7311-7318:1; Tó-23 7109-7111:8, 7126-7130:4， 7131-7132:5, 7133-7144:2, 7149-7150:5, 7151-7160:27, 7166-7168:17, 7169-7177:5, 7178-7184:3, 7185-7196:9, 7208-7222:26; 
Tó-26 7395, 7396:8, 7397, 7398:4; Tó-27 7457-7460:10, 7463-7466:2, 7473-7474:6, 7475-7476:2, 7479:4, 7482-7483:15, 7484:6, 7485-7486:4; Tó-28 6424:2, 6419:2; Tó-29 7790:15, 7794:10, 7800:17, 7805-7809:44, 78, 547, 855:10, 7898:5, 7898-7993:9, 7963-7968:10, 7969-7971:10; Tó-30 7643:2, 7650-7654:2, 7655-7659:3, 7669-7671:12, 7689-7691:10, 7702-7704:2, 7705-7707:4, 77118-7716:2, 7500-7503:11; Tó-31 6791:1, 6796:2, 6801:5, 6802:1, 6831:17, 6869:4, 6871:4, 6873:1; Tó-33 7492:17, 8144:14, 8132:4, 8114:3, 8108:12, 8086:10, 8084:20, 8083:16, 8050:14.

Epithemia argus (Ehr.) Kütz. - Tó-4 5524:5; Tó-5 6831:2, 6832:40, 6841:1, 6854:2; Tó-7 8402:8, 8403:2, 8400:5; Tó-11 5555:11, 5553:2, 5550:2, 5548:2, 5547:2, 5546:2, 5541:20; Tó-17 7551:14, 7563:18, 7566:2, 7622-7624:4; Tó-20 6619:6, 6691:1; Tó-21 7048-7054:5, 7336! 7081-7082:5, 7088-7090:3; Tó-22 7259-7260:6, 7291?:4, 7301-7303:10; Tó-23 7178-7184:5, 7197-7207:17, 7208-7222:6; Tó-26 7364:10, 7373:5, 7375:4, 7387-7392:14, 7399-7401:7; Tó-27 7475-7476:3; Tó-28 6424:2; Tó-29 7790:5, 7799:5, 7800:17, 7805-7809:66, 7817-7819:5, 78, 547, 855:5, 7898:7; Tó-30 7646-7649:3, 7683, 7686:2, 7689-7691:9, 7692-7701:2, 7708-7710:2, 77118-7716:2, 7500-7503:3; Tó-31 6831:2, 6832:40, 6841:1, 6854:2; Tó-33 7492:20, 8144:10, 8132:4, 8126:8, 8120:8, 8114:2, 8108:15, 8084:9, 8083:10, 8059:10, 8054:14.

Epithemia frickei Krammer - Tó-4 5530:4; Tó-5 6873:1; Tó-8 8406:6, 8049:4; Tó-11 5543:10, 5541:13; Tó-17 7563:2, 7558-7560:2, 7561:4, 7562, 7563:4, 7592, 7593, 7594:2, 7595, 7596, 7597, 7599, 7600:16, 7603-7606:5, 6713-7618:5, 7622-7624:6; Tó-21 7075-7077:5, 7336! 7081-7082:5, 7085-7087:5, 7088-7090:1; Tó-22 7265:3, 7291?:2, 7301-7303:2; Tó-23 7178-7184:2, 7197-7207:23, 7208-7222:13; Tó-26 7364:5, 7387-7392:3, 7399-7401:9; Tó-27 7470-7472:2, 7475-7476:2, 7481:2, 7488:4; Tó-29 7805-7809:5, 7810-7816:10, 7869-7872:20; Tó-30 7705-7707:4; Tó-31 6873:1; Tó-33 7434:5, 8243:15, 8132:2, 8100:2, 8084:4, 8083:2.

Epithemia goeppertiana Hilse - Tó-4 5533:20, 5531:4, 5530:6, 5528:5; Tó-5 6791:1, 6831:8, 6832:10, 6841:6, 6854:3, 6866:5, 6867:1, 6869:1; Tó-7 8386:5, 8403:6, 8389:2, 8400:4; Tó-8 8407:2, 8408:2; Tó-11 5559:4, 5555:32, 5553:34, 5552:45, 5551:20, 5550:9, 5549:60, 5548:9, 5547:2, 5544:2, 5541:6, 5540:5; Tó-17 7563:15, 7558-7560:4, 7581-7583:7, 7588:30, 6713-7618:1; Tó-20 6619:8, 6631:2, 6633:1, 6641:2; Tó-21 7055-7056:5, 7061-7063:27, 7067-7069:23, 7075-7077:15, 7336! 7081-7082:7; Tó-22 7259-7260:5, 7267-7272:5, 7259-7261:10, 7268:36, 7291?:8, 7298:7, 7300:14, 7301-7303:32, 7304-7309:1, 7311-7318:4; Tó-23 7126-7130:5, 7169-7177:24, 7178-7184:12, 7185-7196:3，7197-7207:31，7208-7222:15; Tó-26 7364:20, 7366-7367:10, 7370, 7371:7, 7397, 7398:3, 7399-7401:8; Tó-27 7457-7460:19, 7463-7466:10, 7470-7472:7, 7473-7474:2, 7475-7476:2, 7485-7486:10, 7487:7; Tó-28 6459:1, 6427:6, 6423:1; Tó-29 7790:8, 7800:5, 7805-7809:5, 7810-7816:10, 78, 547, 855:5, 78, 677, 868:5, 7869-7872:17, 7875:17, 7884-7892:3, 7893-7895:5, 7896-7897:10; Tó-30 7644-7645:1, 7655-7659:2, 7660-7662:8, 7663, 7666:6, 7672-7678:8, 7683, 7686:10, 7689-7691:24, 7705-7707:6, 7498-7499:2, 7500-7503:17; Tó-31 6791:1, 6831:8, 6832:10, 6841:6, 6854:3, 6866:5, 6867:1, 6869:1; Tó-33 7492:5, 8243:6, 8144:16, 8138:5, 8126:8, 8108:83, 8100:100, 8090:5, 8086:4, 8084:32, 8083:14, 8054:10.

Epithemia hyndmannii W. Sm. - Tó-4 5530:4, 5529:8, 5527:4; Tó-7 8402:6, 8400:4; Tó-11 5559:2, 5556:2, 5555:5, 5553:12, 5552:5, 5551:13, 5549:14, 5548:5, 5544:2, 5543:10, 5542:17, 5541:16, 5540:15; Tó-17 7592, 7593, 7594:17, 7603-7606:5, 7607-7612:5, 6713-7618:3, 7622-7624:7; Tó-20 6619:2, 6628:1, 6634:12, 6691:5; Tó-21 7046-7047:15, 7061-7063:4, 7067-7069:3, 7070, 7073:5, 7336! 7081-7082:17, 7083-7084:2; Tó-22 7259-7260:1, 7259-7261:1, 7268:1, 7291?:3, 7272-7274:10, 7298:3, 7300:1, 7301-7303:3, 7311-7318:1, 7325:3; Tó-23 7169-7177:13, 7185-7196:12, 7197-7207:25, 7208-7222:5; Tó-26 7364:4, 7366-7367:4, 7387-7392:3, 7397, 7398:2, 7399-7401:14; Tó-27 7457-7460:2, 7482-7483:4; Tó-29 78, 677, 868:9, 7869-7872:5, 7884-7892:4, 7898-7993:9, 7963-7968:7; Tó-30 7644-7645:1, 7683, 7686:5, 7692-7701:2, 7705-7707:4, 7708-7710:2, 77118-7716:4; Tó-33 7922:3, 7434:5, 7492:5, 8144:24, 8126:29, 8120:5, 8108:7, 8100:51, 8084:29, 8083:18. 
Epithemia sorex Kütz. - Tó-4 5527:7; Tó-5 6793:26, 6831:18, 6869:5, 6871:4; Tó-8 8406:11; Tó-11 5559:6, 5556:4, 5550:2, 5549:2, 5541:3, 5540:10; Tó-17 7622-7624:2; Tó-20 6628:1, 6629-6630:1，6631:1，6634:40，6641:4，6681:2, 6691:1; Tó-21 7058-7060:10, 7061-7063:2, 7064-7066:10; Tó-22 7265:10, 7259-7261:11, 7300:15, 7311-7318:1; Tó-23 7093-7094:7, 7126-7130:2, 7161-7165:7, 7169-7177:5, 7178-7184:2, 7185-7196:4, 7197-7207:10; Tó-26 7365:5, 7370, 7371:5; Tó-27 7475-7476:4, 7484:2; Tó-28 6459:1, 6424:2, 6420:1, 6419:2; Tó-30 7643:3, 7683, 7686:2; Tó-31 6793:26, 6831:18, 6869:5, 6871:4; Tó-33 8144:16, 8054:4, 8050:56.

Epithemia turgida (Ehr.) Kütz. - Tó-4 5533:2, 5523:5; Tó-5 6801:1, 6832:25, 6841:8, 6871:2, 6874:1; Tó-11 5551:4; Tó-17 7603-7606:2, 7607-7612:2; Tó-20 6619:2, 6628:2, 6631:2, 6660, 6661:4; Tó-21 7048-7054:1, 7067-7069:4, 7075-7077:16, 7085-7087:3; Tó-23 7169-7177:4, 7197-7207:10; Tó-26 7399-7401:4; Tó-28 6450:5; Tó-30 7644-7645:1, 7650-7654:2, 7500-7503:2; Tó-31 6801:1, 6832:25, 6841:8, 6871:2, 6874:1; Tó-33 8144:22, 8126:4, 8108:2, 8100:20.

Epithemia turgida (Ehr.) Kütz. var. granulata (Ehr.) Brun - Tó-17 7566:2, 7607-7612:5;

Tó-21 7058-7060:5, 7064-7066:5, 7336! 7081-7082:10; Tó-23 7151-7160:3; Tó-27 7482-7483:2. Eucocconeis flexella (Kütz.) Hust. - Tó-5 6801:3; Tó-31 6801:3.

Eunotia arcus E. - Tó-20 6628:2; Tó-21 7043-7045:5, 7058-7060:3; Tó-22 7259-7260:2, 7267-7272:1, 7276-7277:1; Tó-23 7133-7144:3; Tó-33 8054:4.

Eunotia bilunaris (Ehr.) Mills - Tó-17 7563:6; Tó-21 7043-7045:10; Tó-23 7169-7177:3.

Eunotia bilunaris (Ehr.) Mills var. mucophila Lange-Bert. et Nörpel - Tó-26 7366-7367:1.

Eunotia exigua (Ehr.) Rabh. - Tó-11 5546:2; Tó-17 7558-7560:4.

Eunotia flexuosa (Bréb.) Kütz. - Tó-23 7145-7148:6.

Eunotia glacialis Meister - Tó-8 8408:2, 8049:2; Tó-17 7625-7627:1; Tó-22 7267-7272:2;

Tó-23 7149-7150:5, 7161-7165:1,7185-7196:4, 7197-7207:5; Tó-29 7810-7816:5; Tó-33 8150:5. Eunotia monodon E. - Tó-17 7551:8, 7563:5, 7564:4; Tó-21 7043-7045:1; Tó-30 7644-7645:1.

Eunotia pectinalis (Kütz.) Rabh. - Tó-5 6869:1; Tó-17 7563:4, 7564:4, 7567:5; Tó-21

7043-7045:4; Tó-23 7120-7121:2, 7149-7150:20; Tó-31 6869:1; Tó-33 8054:2.

Eunotia praerupta E. - Tó-23 7126-7130:2; Tó-33 8068:2.

Fragilaria balatonis Pant. - Tó-11 5559:12; Tó-20 6628:5; Tó-21 7085-7087:2; Tó-22 7259-7260:2; Tó-26 7397, 7398:2, 7399-7401:3.

Fragilaria bicapitata Mayer - Tó-5 6796:1, 6871:30; Tó-31 6796:1, 6871:30.

Fragilaria biceps (Kütz.) Lange-Bert. - Tó-20 6629-6630:5, 6631:5; Tó-22 7268:3; Tó-23 7151-7160:5, 7185-7196:3; Tó-30 77118-7716:2.

Fragilaria brevistriata Grun. - Tó-4 5530:24, 5529:23, 5528:45, 5527:125, 5525:80, 5524:93; Tó-5 6791:3, 6795:1, 6801:18, 6802:2, 6831:3, 6832:1, 6873:33, 6874:35; Tó-7 8386:51, 8387:98, 8402:107, 8388:130, 8403:132, 8389:125, 8400:30; Tó-8 8405:102, 8406:2, 8407:66, 8408:42, 8049:125; Tó-11 5559:100, 5556:34, 5553:5, 5550:10, 5548:25, 5547:22, 5546:32, 5545:15, 5544:70, 5543:74, 5542:90, 5541:40, 5540:145; Tó-17 7558-7560:15, 7561:5, 7562, 7563:10, 7581-7583:20, 7589, 7590, 7591:5, 7592, 7593, 7594:27, 7607-7612:7, 6713-7618:51, 7622-7624:18; Tó-20 6618:28, 6619:24, 6623:30, 6628:23, 6629-6630:22, 6631:23, 6633:3, 6634:2, 6641:24, 6660, 6661:12, 6670:11, 6681:17, 6691:4, 6701:15, 6707:48, 6709:115, 6719:55; Tó-21 7043-7045:68, 7048-7054:120, 7055-7056:10, 7058-7060:75, 7061-7063:280, 7070, 7073:25, 7085-7087:10, 7088-7090:58; Tó-22 7259-7260:4, 7265:18, 7267-7272:15, 7276-7277:30, 7259-7261:23, 7268:4, 7291?:80, 7272-7274:38, 7298:6, 7300:29, 7301-7303:55, 7304-7309:71, 7311-7318:7, 7325:25; Tó-23 7093-7094:45, 7099:63, 7101-7104:153, 7112-7119:35, 7120-7121:32, 7126-7130:83, 7131-7132:85, 7133-7144:70, 7145-7148:50, 7149-7150:43, 7151-7160:20, 7161-7165:20, 7166-7168:82,7169-7177:162, 7178-7184:30, 7185-7196:5, 7197-7207:12, 7208-7222:85; Tó-26 7365:20, 7366-7367:130, 7370, 7371:40, 7373:55, 7375:10, 7376-7379:5, 7383, 7384:10, 7387-7392:37, 7393, 7394:10, 7395, 7396:20, 7397, 7398:85, 7399-7401:85; Tó-27 7457-7460:5, 
7463-7466:52, 7467-7469:110, 7470-7472:10, 7473-7474:95, 7475-7476:145, 7478:14, 7479:74, 7481:300, 7482-7483:450, 7484:53, 7485-7486:140, 7487:30, 7488:55; Tó-28 6455:24, 6452:5, 6450:25, 6427:4, 6423:50, 6420:25, 6419:22; Tó-29 7800:15, 7805-7809:15, 7810-7816:10, 7817-7819:135, 7825:40, 78, 547, 855:5, 7860-7863:5, 7864-7866:30, 78, 677, 868:10, 7869-7872:30, 7880-7882:15, 7884-7892:22, 7893-7895:42, 7896-7897:158, 7898:15, 7898-7993:50, 7904-7906:47, 7963-7968:30, 7969-7971:20; Tó-30 7643:153, 7644-7645:57, 7650-7654:69, 7655-7659:27, 7660-7662:380, 7663, 7666:395, 7669-7671:103, 7672-7678:210, 7680:122, 7683, 7686:99, 7689-7691:87, 7692-7701:10, 7702-7704:50, 7705-7707:20, 77118-7716:39, 7717:26, 7498-7499:20, 7500-7503:20; Tó-31 6791:3, 6795:1, 6801:18, 6802:2, 6831:3, 6832:1, 6873:33, 6874:35; Tó-33 7922:99, 7434:55, 7492:52, 8243:20, 8150:15, 8144:5, 8138:4, 8126:37, 8120:44, 8114:25, 8108:24, 8100:2, 8090:2, 8086:24, 8059:50, 8054:67, 8050:72, 8041:46, 8042:135.

Fragilaria brevistriata Grun. var. inflata (Pant.) Hust. - Tó-26 7397, 7398:1.

Fragilaria capucina Desm. - Tó-5 6802:4; Tó-22 7259-7261:3; Tó-23 7099:2, 7145-7148:9, 7161-7165:20; Tó-30 7646-7649:2, 7692-7701:2; Tó-31 6802:4.

Fragilaria capucina Desm. var. amphicephala (Grun.) Lange-Bert. - Tó-7 8403:4; Tó-17 7603-7606:1; Tó-20 6629-6630:1, 6633:1, 6641:2, 6709:2; Tó-21 7061-7063:12; Tó-22 7298:5, 7301-7303:11; Tó-23 7131-7132:2; Tó-29 7875:5, 7896-7897:5; Tó-30 7646-7649:22.

Fragilaria capucina Desm. var. mesolepta (Rabh.) Rabh. - Tó-23 7151-7160:5, 7161-7165:2, 7166-7168:6.

Fragilaria capucina Desm. var. vaucheriae (Kütz.) Lange-Bert. - Tó-4 5529:9, 5526:10, 5524:12; Tó-5 6841:1, 6871:4; Tó-7 8402:9, 8388:7, 8389:12, 8400:10; Tó-8 8404:18, 8405:9, 8407:6, 8408:2, 8049:5; Tó-11 5559:1; Tó-17 7562, 7563:8, 7592, 7593, 7594:3, 6713-7618:5, 7622-7624:2; Tó-20 6619:2, 6628:7, 6629-6630:3, 6631:5, 6633:20, 6634:8, 6641:18, 6670:1, 6681:4, 6691:1, 6701:10; Tó-21 7043-7045:23, 7048-7054:49, 7055-7056:2, 7058-7060:5, 7061-7063:9, 7067-7069:3; Tó-22 7276-7277:20, 7301-7303:1, 7304-7309:3, 7325:4; Tó-23 7093-7094:2, 7101-7104:17, 7112-7119:27, 7126-7130:10, 7131-7132:29, 7145-7148:10, 7151-7160:20,7166-7168:10, 7169-7177:11, 7178-7184:40, 7197-7207:10, 7208-7222:47; Tó-26 7387-7392:1; Tó-27 7477:2, 7484:5, 7487:8; Tó-28 6454:3, 6450:4, 6423:5, 6419:2; Tó-29 7800:25, 7805-7809:25, 7825:5, 7898-7993:5, 7963-7968:5; Tó-30 7643:10, 7660-7662:9, 7663, 7666:4, 7683, 7686:7, 7689-7691:4, 7708-7710:3, 7717:4; Tó-31 6841:1, 6871:4; Tó-33 7434:10, 8138:20, 8132:4, 8126:8, 8120:2, 8108:3, 8100:2, 8090:6, 8086:10, 8083:10, 8054:4, 8050:21, 8042:4.

Fragilaria constricta Ehr. - Tó-4 5525:5.

Fragilaria construens (Ehr.) Grun. - Tó-4 5530:23, 5529:38, 5527:75, 5524:56, 5523:5; Tó-5 6783:23, 6791:35, 6792:35, 6793:57, 6795:32, 6801:74, 6802:15, 6831:1, 6832:1, 6841:22, 6852:25, 6854:27, 6866:40, 6867:5, 6871:2, 6873:4, 6874:84; Tó-7 8386:392, 8387:290, 8402:105, 8388:160, 8403:95, 8389:85, 8400:24; Tó-8 8404:138, 8405:139, 8407:29, 8408:58, 8049:74; Tó-11 5559:140, 5556:17, 5553:3, 5552:11, 5550:15, 5549:4, 5547:7, 5546:2, 5545:4, 5544:20, 5543:54, 5542:31, 5541:25; Tó-17 7558-7560:282, 7561:70, 7562, 7563:325, 7567-7568:200, 7570, 7571, 7574:74, 7581-7583:260, 7589, 7590, 7591:10, 7592, 7593, 7594:159, 7607-7612:432, 6713-7618:54, 7622-7624:90; Tó-20 6618:520, 6619:600, 6623:450, 6628:121, 6629-6630:27, 6631:175, 6641:34, 6660, 6661:70, 6670:33, 6681:11, 6691:12, 6701:28, 6707:81, 6709:37; Tó-21 7043-7045:110, 7048-7054:188, 7055-7056:65, 7058-7060:85, 7061-7063:23, 7064-7066:25, 7067-7069:69, 7070, 7073:42, 7075-7077:64, 7336! 7081-7082:98, 7083-7084:20, 7085-7087:100, 7088-7090:301; Tó-22 7259-7260:7, 7265:70, 7267-7272:40, 7259-7261:36, 7268:32, 7272-7274:34, 7298:2, 7301-7303:30, 7304-7309:18, 7311-7318:15, 7325:69; Tó-23 7093-7094:20, 7099:48, 7101-7104:114, 7109-7111:149, 7112-7119:22, 7120-7121:70, 7126-7130:66, 7131-7132:52, 7133-7144:32, 7145-7148:30, 7149-7150:64, 7151-7160:20, 7161-7165:20, 7166-7168:280, 7169-7177:25, 7178-7184:35, 7185-7196:10, 7197-7207:153, 7208-7222:254; Tó-26 7365:23, 7366-7367:30, 
7376-7379:5, 7383, 7384:50, 7387-7392:44, 7393, 7394:63, 7395, 7396:165, 7397, 7398:397, 7399-7401:425; Tó-27 7463-7466:16, 7467-7469:30, 7470-7472:9, 7473-7474:25, 7475-7476:260, 7478:64, 7479:37, 7481:30, 7482-7483:30, 7484:70, 7485-7486:61, 7487:25, 7488:40; Tó-28 6455:93, 6452:3, 6450:23, 6423:97, 6420:35, 6419:29, 6416:20; Tó-29 7790:8, 7800:17, 7805-7809:27, 7810-7816:27, 7817-7819:103, 7825:25, 7860-7863:30, 7864-7866:162, 78, 677, 868:45, 7869-7872:15, 7875:5, 7880-7882:15, 7884-7892:53, 7896-7897:35, 7898-7993:14, 7963-7968:55; Tó-30 7643:109, 7644-7645:133, 7646-7649:10, 7650-7654:32, 7655-7659:113, 7660-7662:30, 7663, 7666:150, 7669-7671:31, 7672-7678:54, 7680:53, 7683, 7686:16, 7689-7691:45, 7692-7701:13, 7702-7704:35，7705-7707:23， 7708-7710:72, 77118-7716:133， 7717:160， 7498-7499:38, 7500-7503:208, 7504:103, 7925-7927:245; Tó-31 6783:23, 6791:35, 6792:35, 6793:57, 6795:32, 6801:74, 6802:15, 6831:1, 6832:1, 6841:22, 6852:25, 6854:27, 6866:40, 6867:5, 6871:2, 6873:4, 6874:84; Tó-33 7922:99, 7434:43, 7492:323, 8243:55, 8150:45, 8138:10, 8132:18, 8126:25, $8120: 20,8114: 20,8108: 28,8090: 5,8086: 100,8084: 4,8083: 16,8068: 281,8059: 57,8054: 31$, 8050:52, 8041:160, 8042:220.

Fragilaria construens (Ehr.) Grun. f. venter (Ehr.) Grun. - Tó-7 8403:12; Tó-11 5548:15; Tó-17 7607-7612:15, 6713-7618:1, 7622-7624:11,7625-7627:10; Tó-21 7043-7045:5, 7048-7054:15, 7061-7063:5, 7336! 7081-7082:5; Tó-22 7259-7260:6, 7291?:8; Tó-23 7120-7121:32, 7145-7148:30, 7161-7165:23, 7166-7168:45; Tó-26 7387-7392:5; Tó-27 7463-7466:14, 7467-7469:25, 7473-7474:22, 7481:8, 7485-7486:17, 7487:2, 7488:20; Tó-28 6420:15, 6419:2; Tó-29 7810-7816:5; Tó-30 7672-7678:5, 7689-7691:4, 7705-7707:3; Tó-33 8050:54.

Fragilaria construens (Ehr.) Grun. var. binodis (Ehr.) Grun. - Tó-7 8386:34, 8388:11, 8403:5, 8389:28; Tó-17 7588:10, 6713-7618:3, 7625-7627:10; Tó-21 7048-7054:15, 7061-7063:5, 7070, 7073:4; Tó-23 7093-7094:2, 7099:24, 7101-7104:15, 7145-7148:22, 7208-7222:3; Tó-33 8068:24, 8059:19, 8054:22, 8041:5, 8042:25.

Fragilaria construens (Ehr.) Grun. var. subsalina Hust. - Tó-26 7370, 7371:8; Tó-28 6427:14; Tó-30 7689-7691:2.

Fragilaria crotonensis Kitton - Tó-21 7048-7054:49.

Fragilaria dilatata (Bréb.) Lange-Bert. - Tó-4 5527:3, 5524:5, 5523:8; Tó-7 8402:8, 8400:4; Tó-8 8404:2, 8406:4; Tó-11 5555:2, 5553:4, 5551:6, 5550:4, 5549:6, 5542:4, 5541:11, 5540:5; Tó-17 7562, 7563:2, 7581-7583:2, 7592, 7593, 7594:15, 6713-7618:2; Tó-20 6629-6630:1, 6631:1, 6633:6, 6641:6, 6707:20; Tó-21 7043-7045:2, 7058-7060:5, 7061-7063:2, 7075-7077:20, 7083-7084:5, 7085-7087:4， 7088-7090:8; Tó-22 7291?:2, 7301-7303:2; Tó-23 7099:3, 7145-7148:2, 7151-7160:7, 7169-7177:11, 7178-7184:2, 7185-7196:8, 7197-7207:5; Tó-26 7366-7367:5, 7397, 7398:4, 7399-7401:2; Tó-27 7457-7460:2; Tó-28 6454:1; Tó-29 7898-7993:8, 7963-7968:5; Tó-30 7644-7645:5, 7672-7678:3, 7683, 7686:1, 7689-7691:2, 7692-7701:2, 7702-7704:2, 7708-7710:10, 77118-7716:4, 7498-7499:6, 7500-7503:28; Tó-33 8138:12, 8132:14, 8114:6, 8108:4, 8100:27, 8086:2, 8083:8.

Fragilaria fasciculata (Agardh) Lange-Bert. - Tó-5 6832:1; Tó-20 6629-6630:1; Tó-21 7336! 7081-7082:7; Tó-30 7644-7645:2, 7708-7710:3; Tó-31 6832:1.

Fragilaria heidenii Oestrup - Tó-7 8386:148, 8387:60, 8402:29, 8388:114, 8403:2, 8389:160; Tó-8 8404:213, 8405:204; Tó-11 5559:59; Tó-17 7562, 7563:19; Tó-20 6628:7, 6631:8; Tó-21 7043-7045:33, 7048-7054:53, 7055-7056:10, 7058-7060:15; Tó-22 7259-7261:2, 7291?:6; Tó-23 7093-7094:12, 7099:14, 7101-7104:15, 7109-7111:291, 7112-7119:133, 7120-7121:5, 7126-7130:7, 7131-7132:50, 7133-7144:50, 7145-7148:55, 7149-7150:45, 7151-7160:20, 7166-7168:11; Tó-30

7643:20; Tó-33 8068:13, 8059:36, 8041:15, 8042:70.

Fragilaria hungarica Pant. - Tó-21 7083-7084:2.

Fragilaria lapponica Grun. - Tó-5 6801:5, 6831:1, 6873:1; Tó-7 8386:2, 8403:2, 8389:10; Tó-11 5559:4, 5555:2, 5541:20; Tó-17 7558-7560:2, 7561:2, 7562, 7563:4, 7581-7583:4, 7592, 
7593, 7594:8, 7607-7612:2, 6713-7618:2; Tó-20 6623:2, 6628:11，6631:3，6707:1; Tó-21 7043-7045:15, 7046-7047:12, 7055-7056:1, 7061-7063:9, 7088-7090:4; Tó-22 7259-7260:14, 7265:59, 7267-7272:7, 7259-7261:6, 7268:8, 7291?:28, 7272-7274:2, 7300:11, 7304-7309:1, 7311-7318:19, 7325:3; Tó-23 7093-7094:13, 7099:44, 7101-7104:198, 7109-7111:4, 7120-7121:60, 7126-7130:119, 7131-7132:31， 7133-7144:4， 7145-7148:4， 7149-7150:5， 7151-7160:20, 7166-7168:4; Tó-26 7376-7379:1, 7393, 7394:12, 7397, 7398:10; Tó-27 7457-7460:6; Tó-28 6416:8; Tó-29 7790:20, 7794:100, 7799:35, 7800:83, 7805-7809:88, 7810-7816:5, 7825:10, 7880-7882:5, 7898:5; Tó-30 7643:86, 7644-7645:38, 7650-7654:25, 7660-7662:5, 7663, 7666:10, 7683, 7686:8, 7689-7691:6, 77118-7716:14; Tó-31 6801:5, 6831:1, 6873:1; Tó-33 8126:4, 8114:6, 8083:6, 8068:2, 8059:35, 8054:25, 8050:10, 8041:8, 8042:15.

Fragilaria lata (Cleve-Euler) Renberg - Tó-17 7592, 7593, 7594:5; Tó-20 6631:11; Tó-21 7070, 7073:5; Tó-23 7126-7130:1,7131-7132:21,7169-7177:10; Tó-27 7479:8; Tó-29 7963-7968:20.

Fragilaria leptostauron (Ehr.) Hust. - Tó-5 6782:1; Tó-11 5559:63; Tó-17 7562, 7563:10, 7592, 7593, 7594:2; Tó-21 7043-7045:2, 7048-7054:13, 7055-7056:10, 7058-7060:2, 7061-7063:4, 7064-7066:2; Tó-22 7267-7272:2, 7276-7277:10; Tó-23 7099:2, 7133-7144:2, 7169-7177:4, 7197-7207:5; Tó-29 7800:4, 7805-7809:4; Tó-30 7644-7645:4, 7650-7654:3, 7655-7659:12, 7660-7662:5, 7669-7671:9, 77118-7716:2; Tó-31 6782:1; Tó-33 8042:1.

Fragilaria leptostauron (Ehr.) Hust. var. martyi (Héribaud) Lange-Bert. - Tó-4 5533:15, 5530:14, 5529:22, 5528:10, 5527:27, 5526:17, 5525:5, 5524:10, 5523:29; Tó-5 6782:4, 6783:8, 6791:3, 6792:1, 6793:77, 6801:30, 6832:1, 6841:5, 6852:10, 6854:28, 6866:15, 6869:16, 6871:64, 6874:13; Tó-7 8386:18, 8387:4, 8402:28, 8403:21; Tó-8 8407:9, 8408:13, 8049:30; Tó-11 5559:2, 5555:2, 5553:14, 5552:28, 5551:75, 5550:65, 5549:73, 5548:40, 5547:9, 5546:23, 5545:49, 5544:39, 5543:96, 5542:102, 5541:77, 5540:130; Tó-17 7558-7560:26, 7561:10, 7562, 7563:43, 7570, 7571, 7574:6, 7581-7583:66, 7592, 7593, 7594:92, 7607-7612:68, 6713-7618:59, 7622-7624:162, 7625-7627:4; Tó-20 6618:8, 6619:16, 6623:24, 6628:14, 6629-6630:20, 6631:15, 6641:32, 6660, 6661:50, 6670:91, 6681:72, 6691:10, 6701:42, 6707:145, 6709:8, 6719:45; Tó-21 7043-7045:1, 7046-7047:25, 7048-7054:22, 7058-7060:54,7061-7063:106, 7064-7066:15, 7067-7069:85, 7070, 7073:108, 7075-7077:147, 7336! 7081-7082:168, 7083-7084:35, 7085-7087:128, 7088-7090:145; Tó-22 7259-7261:5, 7268:33, 7291?:9, 7272-7274:4, 7298:10, 7300:6, 7304-7309:4, 7311-7318:43, 7325:35; Tó-23 7109-7111:42, 7112-7119:30, 7145-7148:6, 7166-7168:5, 7169-7177:98, 7178-7184:59, 7185-7196:15, 7197-7207:138, 7208-7222:271; Tó-26 7365:25, 7366-7367:13, 7373:40, 7375:18, 7383, 7384:24, 7387-7392:60, 7393, 7394:80, 7395, 7396:27, 7397, 7398:20, 7399-7401:135; Tó-27 7457-7460:120， 7463-7466:45， 7467-7469:54， 7470-7472:33， 7473-7474:67, 7475-7476:50, 7477:5, 7478:12, 7479:63, 7481:55, 7482-7483:100, 7484:25, 7485-7486:50, 7487:35, 7488:34; Tó-28 6459:6, 6457:2, 6455:6, 6452:13, 6450:5, 6427:4, 6424:22, 6423:10, 6420:10, 6419:18, 6416:6; Tó-29 7794:5, 7825:10, 7860-7863:5, 7864-7866:5, 7869-7872:15, 7875:16, 7880-7882:91, 7893-7895:15, 7896-7897:25, 7898-7993:12, 7963-7968:200, 7969-7971:35; Tó-30 7643:6, 7644-7645:14， 7650-7654:1，7655-7659:5， 7663， 7666:3， 7669-7671:5, 7672-7678:25, 7680:12, 7683, 7686:16, 7689-7691:78, 7692-7701:32, 7702-7704:86, 7705-7707:52, 7708-7710:42, 77118-7716:53, 7717:38, 7498-7499:164, 7500-7503:236, 7504:14, 7925-7927:342; Tó-31 6782:4, 6783:8, 6791:3, 6792:1, 6793:77, 6801:30, 6832:1, 6841:5, 6852:10, 6854:28, 6866:15, 6869:16, 6871:64, 6874:13; Tó-33 7922:97, 7434:126, 7492:57, 8243:265, 8150:315, $8144: 73,8138: 80,8132: 143,8126: 116,8120: 15,8114: 107,8108: 40,8100: 20,8086: 4,8083: 2$, 8068:15, 8041:2, 8042:10.

Fragilaria parasitica (W. Sm.) Grun. - Tó-5 6801:1; Tó-31 6801:1.

Fragilaria pinnata Ehr. - Tó-5 6782:1, 6791:47, 6792:40, 6793:75, 6795:40, 6796:61, 6801:23, 6802:23, 6831:1, 6832:1, 6854:12, 6866:10, 6871:20, 6873:7, 6874:14; Tó-7 8386:44, 8387:66, 8402:82, 8388:2; Tó-8 8405:24, 8406:2, 8407:93, 8408:14, 8049:25; Tó-11 5559:7, 5546:2, 
5542:6; Tó-17 7561:3，7562，7563:33，7567-7568:1，7592，7593，7594:21，7607-7612:2， 6713-7618:3; Tó-20 6618:32, 6619:42, 6623:24, 6628:12, 6629-6630:2, 6631:13, 6660, 6661:17, 6681:21, 6691:10, 6701:15, 6707:3; Tó-21 7043-7045:87, 7048-7054:53, 7055-7056:123, 7058-7060:5, 7061-7063:27; Tó-22 7259-7260:2, 7276-7277:5, 7291?:44, 7272-7274:42, 7298:4, 7304-7309:21, 7311-7318:26, 7325:4; Tó-23 7093-7094:8, 7099:8, 7101-7104:95, 7109-7111:87, 7112-7119:24, 7120-7121:9, 7126-7130:44, 7131-7132:90, 7133-7144:90, 7145-7148:56, 7161-7165:20, 7166-7168:27, 7169-7177:118, 7178-7184:4, 7197-7207:5; Tó-26 7364:9, 7365:5, 7370, 7371:2, 7375:4, 7387-7392:62, 7397, 7398:10, 7399-7401:19; Tó-28 6455:15, 6450:5, 6427:30, 6424:4, 6423:21, 6416:8; Tó-29 7817-7819:55, 7963-7968:5; Tó-30 7643:102, 7644-7645:6, 7650-7654:3, 7655-7659:8, 7660-7662:10, 7663, 7666:5, 7672-7678:2, 7680:5, 7683, 7686:7, 7500-7503:2; Tó-31 6782:1, 6791:47, 6792:40, 6793:75, 6795:40, 6796:61, 6801:23, 6802:23, 6831:1, 6832:1, 6854:12, 6866:10, 6871:20, 6873:7, 6874:14; Tó-33 8068:10, 8059:10, 8054:4, 8041:5, 8042:94.

Fragilaria pinnata Ehr. var. lancettula (Schumann) Hust. - Tó-23 7131-7132:9, 7145-7148:10; Tó-30 7680:5.

Fragilaria pulchella Lange-Bert. - Tó-22 7298:2.

Fragilaria robusta (Fusey) Manguin - Tó-11 5542:3; Tó-23 7126-7130:3, 7145-7148:4; Tó-29 7817-7819:5

Fragilaria subsalina (Grun.) Lange-Bert. - Tó-30 7644-7645:1.

Fragilaria ulna (Nitzsch) Lange-Bert. - Tó-4 5530:3, 5529:4, 5528:10, 5524:7; Tó-5 6783:2, 6796:5, 6801:5, 6802:1, 6831:9, 6832:31, 6841:2, 6852:2, 6854:5, 6866:14, 6867:8, 6873:3, 6874:2; Tó-7 8387:5, 8402:28, 8403:33, 8400:28; Tó-8 8404:7, 8406:5, 8408:26; Tó-11 5559:2, 5556:1, 5555:7, 5552:3, 5550:8, 5548:6, 5546:5, 5545:7, 5544:6, 5543:19, 5542:36, 5541:50, 5540:20; Tó-17 7563:2, 7558-7560:10, 7581-7583:20, 7592, 7593, 7594:55, 7595, 7596, 7597, 7599, 7600:38, 7607-7612:30, 6713-7618:2, 7622-7624:7; Tó-20 6618:4, 6628:1, 6629-6630:3, 6631:6, 6633:6, 6660, 6661:21, 6670:4, 6681:37, 6691:2, 6701:15, 6707:30, 6709:13; Tó-21 7043-7045:30, 7048-7054:24, 7055-7056:1, 7061-7063:19, 7064-7066:15, 7067-7069:4, 7070, 7073:45, 7075-7077:25, 7336! 7081-7082:16, 7083-7084:17, 7085-7087:6, 7088-7090:10; Tó-22 7259-7260:1, 7265:1, 7267-7272:1, 7259-7261:4, 7291?:4, 7272-7274:22, 7298:5, 7300:3, 7301-7303:4, 7304-7309:1, 7311-7318:7, 7325:13; Tó-23 7093-7094:2, 7099:7, 7101-7104:8, 7109-7111:13, 7112-7119:1, $7120-7121: 5, \quad 7126-7130: 10, \quad 7133-7144: 3,7145-7148: 7, \quad 7149-7150: 13, \quad 7151-7160: 15$, 7166-7168:7, 7169-7177:5, 7178-7184:9, 7185-7196:48, 7197-7207:27, 7208-7222:72; Tó-26 7365:4, 7380-7382:20, 7387-7392:1, 7395, 7396:17, 7397, 7398:7, 7399-7401:22; Tó-27 7457-7460:2, 7470-7472:2, 7475-7476:3, 7478:2, 7479:2, 7482-7483:7, 7484:14, 7485-7486:5, 7487:4; Tó-28 6465:1, 6452:1, 6423:3, 6419:4; Tó-29 7805-7809:4, 78, 547, 855:5, 7869-7872:10, 7875:5, 7880-7882:5, 7884-7892:4, 7896-7897:5, 7898-7993:5, 7904-7906:5, 7963-7968:5, 7969-7971:20; Tó-30 7644-7645:85, 7646-7649:40, 7650-7654:72, 7655-7659:6, 7660-7662:2, 7663, 7666:5, 7669-7671:3, 7672-7678:2, 7683, 7686:2, 7689-7691:16, 7692-7701:2, 7702-7704:6, 7708-7710:14, 77118-7716:9, 7717:14, 7498-7499:22, 7500-7503:63, 7504:6, 7925-7927:10; Tó-31 6783:2, 6796:5, 6801:5, 6802:1, 6831:9, 6832:31, 6841:2, 6852:2, 6854:5, 6866:14, 6867:8, 6873:3, 6874:2; Tó-33 7922:7, 7434:19, 7492:10, 8243:38, 8150:20, 8144:122, 8138:17, 8132:25, 8126:16, 8120:15, 8114:31, 8108:15, 8100:30, 8090:7, 8086:10, 8084:16, 8083:30, 8054:2, 8050:19.

Fragilaria ulna (Nitzsch) Lange-Bert. var. angustissima Sippen - Tó-11 5556:2.

Fragilaria ulna (Nitzsch) Lange-Bert. var. acus (Kütz.) Lange-Bert. - Tó-7 8400:4; Tó-23 7093-7094:2, 7099:4, 7149-7150:10; Tó-30 7692-7701:1, 7702-7704:2.

Fragilaria ulna (Nitzsch) Lange-Bert. var. danica Sippen - Tó-11 5553:10; Tó-20 6629-6630:1; Tó-21 7043-7045:2.

Fragilaria virescens Ralfs - Tó-7 8388:7; Tó-17 7562, 7563:16, 7564:10, 7592, 7593, 7594:15; Tó-21 7048-7054:20, 7058-7060:20; Tó-22 7259-7261:13, 7268:1; Tó-23 7093-7094:2, 
7099:8, 7101-7104:73, 7109-7111:106, 7126-7130:20, 7151-7160:20; Tó-26 7393, 7394:5, 7395, 7396:4, 7397, 7398:2; Tó-27 7485-7486:4, 7487:10, 7488:4; Tó-30 7655-7659:181, 7663, 7666:1, 7692-7701:1, 77118-7716:1, 7717:4, 7500-7503:6; Tó-33 8041:1, 8042:3.

Fragilaria virescens Ralfs var. balatonis Pant. - Tó-30 7643:1.

Fragilaria virescens Ralfs var. elliptica Hust. - Tó-30 7644-7645:1.

Fragilaria zelleri Hérib. - Tó-30 7644-7645:1.

Gomphonema acuminatum Ehr. - Tó-4 5524:5; Tó-5 6841:1; Tó-17 7563:4, 7564:4, 7558-7560:2, 7581-7583:6, 7595, 7596, 7597, 7599, 7600:9, 7607-7612:4; Tó-20 6623:2, 6633:2, 6634:2, 6701:2; Tó-21 7046-7047:10, 7048-7054:5, 7070, 7073:5; Tó-23 7151-7160:3, 7166-7168:5, 7185-7196:4, 7208-7222:4; Tó-27 7475-7476:4，7487:4; Tó-30 7650-7654:2, 7689-7691:2, 7705-7707:4; Tó-31 6841:1; Tó-33 8083:2.

Gomphonema affine Kütz. - Tó-26 7397, 7398:3; Tó-30 7663, 7666:5.

Gomphonema angustatum (Kütz.) Rabh. - Tó-8 8406:4, 8407:6; Tó-21 7043-7045:15; Tó-22 7259-7261:4; Tó-23 7145-7148:15, 7178-7184:3; Tó-29 7794:10, 7800:5, 7805-7809:5, 7825:10; Tó-30 7689-7691:5; Tó-33 8150:5, 8138:2, 8126:4, 8114:4, 8050:5.

Gomphonema angustum Agardh - Tó-4 5523:2; Tó-5 6871:1; Tó-7 8388:2; Tó-11 5559:6, 5552:2, 5550:4, 5544:2, 5543:3, 5541:8; Tó-17 7561:2, 7562, 7563:6, 7607-7612:8; Tó-20 6628:3, 6631:4, 6633:5, 6641:4, 6660, 6661:2, 6681:2; Tó-21 7046-7047:15, 7048-7054:11; Tó-22 7291?:3, 7272-7274:3, 7300:1, 7301-7303:2, 7325:2; Tó-23 7099:2, 7101-7104:9, 7131-7132:8, 7145-7148:2, 7161-7165:8, 7166-7168:8, 7169-7177:8, 7178-7184:3, 7185-7196:22, 7197-7207:16, 7208-7222:8; Tó-26 7366-7367:3, 7397, 7398:2, 7399-7401:3; Tó-27 7484:2; Tó-29 7817-7819:5, 7869-7872:5, 7904-7906:3; Tó-30 7643:2, 7644-7645:1, 7646-7649:1, 7663, 7666:6, 7672-7678:9, 7689-7691:2, 7500-7503:1; Tó-31 6871:1; Tó-33 7434:2, 8144:4, 8114:2, 8100:12, 8084:5, 8059:2, 8054:21, 8050:8.

Gomphonema augur Ehr. - Tó-23 7208-7222:10; Tó-30 7500-7503:2.

Gomphonema clavatum Ehr. - Tó-4 5525:5; Tó-11 5559:1, 5548:2; Tó-17 7603-7606:3, 6713-7618:2; Tó-21 7043-7045:3, 7046-7047:5, 7055-7056:2; Tó-23 7099:4; Tó-29 7790:5; Tó-30 7717:2.

Gomphonema clevei Fricke - Tó-20 6619:2, 6628:4, 6631:2.

Gomphonema gracile Ehr. - Tó-11 5555:2; Tó-20 6631:1; Tó-22 7325:2; Tó-23 7166-7168:5;

Tó-29 7869-7872:5; Tó-30 7644-7645:2; Tó-33 8050:5.

Gomphonema lanceolatum Ehr. - Tó-17 7551:2.

Gomphonema minutum Agardh - Tó-20 6681:2.

Gomphonema olivaceum (Hornemann) Bréb. - Tó-23 7208-7222:5; Tó-27 7478:4.

Gomphonema olivaceum (Hornemann) Bréb. var. calcareum (Cl.) Cl. - Tó-30 7717:2.

Gomphonema parvulum Kütz. - Tó-8 8405:2; Tó-21 7048-7054:10; Tó-23 7166-7168:5; Tó-33 8054:5

Gomphonema truncatum Ehr. - Tó-5 6802:2; Tó-20 6628:5, 6707:2; Tó-21 7043-7045:8, 7055-7056:4, 7058-7060:5, 7067-7069:4, 7083-7084:4; Tó-23 7120-7121:4, 7126-7130:9, 7131-7132:3, 7145-7148:12, 7149-7150:2, 7151-7160:2, 7161-7165:2, 7166-7168:4, 7197-7207:4; Tó-29 78, 547, 855:5, 7963-7968:5; Tó-30 7644-7645:11, 7702-7704:2; Tó-31 6802:2; Tó-33 7922:4, 8150:20, 8126:4.

Gomphonema ventricosum Greg. - Tó-17 7558-7560:10.

Gyrosigma acuminatum (Kütz.) Rabh. - Tó-8 8407:4, 8408:2; Tó-11 5556:2, 5553:2, 5552:20, 5548:2, 5546:4, 5544:10, 5543:4; Tó-20 6641:2; Tó-22 7259-7260:5, 7272-7274:3; Tó-26 7365:4; Tó-27 7463-7466:15, 7467-7469:5, 7481:4, 7485-7486:4; Tó-29 7898-7993:17; Tó-30 7689-7691:4, 77118-7716:2; Tó-33 8086:5. 
Gyrosigma attenuatum (Kütz.) Rabh. - Tó-4 5527:10, 5526:10, 5525:20, 5524:2; Tó-5 6793:4, 6795:1, 6796:1, 6801:1, 6802:1; Tó-7 8402:3, 8403:4; Tó-8 8404:2, 8405:5, 8049:9; Tó-11 5559:4, 5552:2, 5551:2, 5549:2, 5548:1, 5547:4, 5546:2, 5543:2, 5541:11, 5540:23; Tó-17 7592, 7593, 7594:2, 7595, 7596, 7597, 7599, 7600:13; Tó-20 6631:1, 6660, 6661:5, 6681:6, 6691:1, 6707:5; Tó-21 7043-7045:10, 7046-7047:5, 7048-7054:24, 7061-7063:5, 7067-7069:3, 7075-7077:10, 7336! 7081-7082:5, 7088-7090:2; Tó-22 7291?:6, 7311-7318:2; Tó-23 7099:14, 7101-7104:15, 7120-7121:2, 7126-7130:28, 7131-7132:5, 7133-7144:4, 7145-7148:4, 7149-7150:22, 7151-7160:20, 7166-7168:51, 7185-7196:4, 7197-7207:15, 7208-7222:24; Tó-26 7380-7382:20, 7383, 7384:2, 7393, 7394:4, 7397, 7398:3, 7399-7401:9; Tó-27 7467-7469:15, 7470-7472:4, 7475-7476:3, 7488:8; Tó-28 6457:3, 6455:2, 6454:1, 6424:2, 6423:4, 6419:2; Tó-29 7810-7816:5, 7875:5, 7893-7895:15, 7896-7897:5, 7904-7906:3, 7963-7968:4; Tó-30 7643:2, 7644-7645:1, 7646-7649:10, 7702-7704:1, 77118-7716:1, 7717:2; Tó-31 6793:4, 6795:1, 6796:1，6801:1，6802:1; Tó-33 7922:15, 7434:5, 7492:3, 8144:12, 8120:16, 8090:4.

Gyrosigma kützingii (Grun.) Cl. - Tó-5 6791:4, 6792:1, 6793:5; Tó-7 8388:1; Tó-8 8404:2; Tó-11 5547:5，5546:12， 5545:6; Tó-22 7304-7309:2; Tó-23 7109-7111:8， 7112-7119:2， 7131-7132:8, 7133-7144:1, 7149-7150:1, 7161-7165:3, 7166-7168:12, 7169-7177:18, 7185-7196:15; Tó-26 7365:5; Tó-27 7470-7472:2, 7473-7474:4, 7477:5, 7478:8, 7479:2, 7488:2; Tó-29 7817-7819:5; Tó-31 6791:4, 6792:1, 6793:5.

Gyrosigma peisonis (Grun.) Hust. - Tó-5 6802:4; Tó-31 6802:4.

Gyrosigma spencerii (W. Sm.) Cl. - Tó-30 7702-7704:2.

Hantzschia amphioxys (Ehr.) Grun. - Tó-5 6832:2; Tó-8 8049:1; Tó-11 5553:4, 5550:2; Tó-17 7563:4, 7558-7560:6, 7562, 7563:2; Tó-21 7070, 7073:5, 7336! 7081-7082:5; Tó-22 7268:5; Tó-23 7151-7160:1; Tó-30 7683, 7686:2; Tó-31 6832:2; Tó-33 8084:2, 8083:3.

Hantzschia amphioxys (Ehr.) Grun. var. constricta Pant. - Tó-21 7336! 7081-7082:5.

Hantzschia amphioxys (Ehr.) Grun. var. maior Grun. - Tó-17 7567:3.

Hantzschia elongata (Hantzsch.) Grun. - Tó-11 5548:2; Tó-28 6423:1.

Hantzschia virgata (Roper) Grun. - Tó-17 7622-7624:1; Tó-30 7650-7654:2.

Hantzschia virgata (Roper) Grun. var. capitella Hust. - Tó-21 7064-7066:1.

Mastogloia balatonis Pant. - Tó-20 6633:2.

Mastogloia braunii Grun. - Tó-5 6801:1; Tó-31 6801:1.

Mastogloia elliptica Ag. - Tó-4 5527:4, 5524:2, 5523:8; Tó-7 8402:3, 8403:8, 8400:2; Tó-8 8407:7, 8049:2; Tó-11 5556:9, 5553:2, 5551:4, 5548:1, 5546:6, 5544:2; Tó-17 7592, 7593, 7594:5, 7603-7606:10; Tó-20 6641:4, 6707:2; Tó-21 7085-7087:5; Tó-22 7259-7260:2, 7265:7, 7259-7261:4, 7268:1, 7291?:2, 7298:1, 7300:10, 7301-7303:4, 7304-7309:2, 7311-7318:12, 7325:4; Tó-23 7101-7104:5, 7166-7168:11, 7185-7196:12, 7197-7207:5, 7208-7222:2; Tó-26 7364:4, 7370, 7371:13, 7373:17, 7383, 7384:10; Tó-27 7470-7472:2, 7475-7476:2, 7478:4; Tó-29 7790:5, 7794:20, 7800:10, 7805-7809:10, 7880-7882:5; Tó-30 7655-7659:1, 7663, 7666:4, 7680:4, 7683, 7686:2, 7689-7691:12, 7692-7701:8, 7705-7707:2, 7498-7499:5; Tó-33 7922:4, 8243:10, 8144:9, 8138:15.

Mastogloia elliptica Ag. var. dansei (Thw.) Grun. - Tó-4 5530:4, 5525:5; Tó-11 5547:6, 5542:3; Tó-20 6631:3, 6691:1; Tó-21 7088-7090:3; Tó-23 7197-7207:6, 7208-7222:5; Tó-26 7383, 7384:4, 7399-7401:2; Tó-27 7475-7476:7; Tó-28 6420:2; Tó-29 7790:5, 7800:15, 7805-7809:15; Tó-30 7643:4; Tó-33 8114:6, 8059:2, 8054:12, 8042:3.

Mastogloia elliptica Ag. var. amphicephala Grun. - Tó-30 7672-7678:5. 6802:1.

Mastogloia grewillei W. Sm. - Tó-5 6801:1, 6802:1; Tó-30 7705-7707:1; Tó-31 6801:1,

Mastogloia smithii Thw. - Tó-4 5526:10; Tó-5 6792:1; Tó-11 5551:5, 5540:5; Tó-20 6641:6; Tó-21 7061-7063:5, 7336! 7081-7082:5; Tó-22 7259-7260:1; Tó-26 7364:3, 7365:7, 7370, 7371:5, 
7380-7382:5, 7387-7392:6; Tó-27 7457-7460:21, 7470-7472:8; Tó-29 7869-7872:5, 7896-7897:5, 7898-7993:2; Tó-30 7644-7645:5, 77118-7716:3, 7498-7499:2; Tó-31 6792:1; Tó-33 8150:5, 8138:10, 8126:8, 8054:18.

Mastogloia smithii Thw. var. lacustris Grun. - Tó-7 8400:4; Tó-11 5552:2, 5551:10, 5545:4, 5544:7; Tó-17 7625-7627:1; Tó-26 7370, 7371:5; Tó-27 7457-7460:4, 7463-7466:8, 7475-7476:1; Tó-29 7790:20, 7800:50, 7805-7809:50; Tó-30 7689-7691:1; Tó-33 8100:3, 8090:4, 8059:55, 8054:42, 8042:2

Melosira ambigua (Grun.) O. Müll. - Tó-5 6802:1, 6841:17, 6852:3, 6866:2; Tó-7 8388:10, 8389:19; Tó-8 8404:89, 8405:4; Tó-17 6713-7618:2, 7622-7624:5, 7625-7627:8; Tó-20 6618:104, 6623:16, 6628:3, 6691:5, 6701:4; Tó-21 7043-7045:10, 7048-7054:20, 7058-7060:15, 7088-7090:24; Tó-22 7259-7260:12, 7265:22, 7267-7272:10, 7325:2; Tó-23 7093-7094:20, 7099:4, 7101-7104:18, 7126-7130:7, 7131-7132:29, 7161-7165:62, 7166-7168:117, 7185-7196:5; Tó-29 7817-7819:155, 7825:50; Tó-30 7663, 7666:37, 7692-7701:8; Tó-31 6802:1, 6841:17, 6852:3, 6866:2.

Melosira lineata (Dillwyn) Agardh - Tó-20 6629-6630:1, 6681:1; Tó-23 7208-7222:11. Melosira subarctica O. Müll. - Tó-20 6631:2.

Melosira varians Ag. - Tó-8 8049:2; Tó-20 6623:16, 6628:5, 6631:3, 6633:8; Tó-23 7151-7160:2; Tó-30 77118-7716:2.

Meridion circulare (Greville) Ag. - Tó-5 6801:1; Tó-20 6628:1, 6631:1; Tó-30 7689-7691:1; Tó-31 6801:1.

Navicula amphibola Cl. - Tó-17 7563:4, 7564:4, 6713-7618:1; Tó-21 7055-7056:5; Tó-23 7101-7104:1; Tó-27 7473-7474:4; Tó-30 7644-7645:1.

Navicula bacillum Ehr. - Tó-4 5530:4, 5528:20; Tó-20 6681:1; Tó-21 7043-7045:4, 7061-7063:2; Tó-22 7298:3; Tó-23 7099:2, 7101-7104:1, 7131-7132:3, 7133-7144:4, 7145-7148:1, 7149-7150:3, 7161-7165:1, 7166-7168:2, 7178-7184:3, 7185-7196:6; Tó-26 7365:5, 7375:19; Tó-27 7488:2; Tó-29 7810-7816:5; Tó-30 7663, 7666:4, 7669-7671:2, 7680:2, 7692-7701:1; Tó-33 8059:8, 8054:7.

Navicula binodis Ehr. - Tó-4 5527:6, 5525:10, 5523:5; Tó-7 8402:12; Tó-23 7131-7132:4, 7145-7148:2, 7149-7150:17, 7161-7165:2, 7169-7177:4; Tó-27 7473-7474:19, 7475-7476:2, 7477:20, 7478:24, 7481:4; Tó-29 78, 677, 868:15, 7898-7993:5; Tó-30 7680:4, 7683, 7686:2, 77118-7716:8

Navicula bulnheimii Grun. - Tó-29 7800:103, 7805-7809:103.

Navicula capitata Ehr. var. hungarica (Grun.) Ross - Tó-4 5528:15, 5527:8, 5526:50; Tó-5 6802:1; Tó-7 8387:4, 8402:2, 8388:2, 8389:4; Tó-8 8404:7, 8406:2, 8408:2; Tó-11 5559:2, 5556:4, 5547:4; Tó-21 7048-7054:45; Tó-23 7120-7121:20, 7126-7130:8, 7131-7132:6, 7149-7150:3, 7166-7168:6, 7169-7177:6, 7185-7196:5, 7197-7207:5; Tó-26 7387-7392:5, 7395, 7396:2; Tó-27 7475-7476:3, 7478:4, 7481:9, 7487:4; Tó-29 7869-7872:5; Tó-30 7644-7645:20, 7669-7671:2, 7680:4, 7689-7691:4; Tó-31 6802:1; Tó-33 7922:5, 7492:9.

Navicula capitatoradiata Germain - Tó-21 7043-7045:5.

Navicula cari Ehr. - Tó-4 5525:10; Tó-5 6801:1; Tó-7 8389:4; Tó-11 5550:14, 5545:2; Tó-17 6713-7618:5; Tó-20 6709:5; Tó-21 7043-7045:5; Tó-22 7259-7261:2, 7291?:4; Tó-23 7133-7144:4; Tó-29 7800:5, 7805-7809:5, 7864-7866:20, 7896-7897:51, 7898-7993:5; Tó-30 7644-7645:3, 7680:8; Tó-33 8059:2.

Navicula cf. spicula (Hickie) Cleve - Tó-7 8387:1.

Navicula cincta (Ehr.) Ralfs - Tó-4 5524:7; Tó-17 7562, 7563:2, 7592, 7593, 7594:3; Tó-21 7043-7045:2, 7061-7063:2; Tó-22 7291?:2; Tó-29 7864-7866:5; Tó-30 7643:4, 7644-7645:1, 7650-7654:5, 7660-7662:1, 7680:19, 7683, 7686:12.

Navicula costulata Grun. - Tó-21 7043-7045:15, 7048-7054:15, 7055-7056:52; Tó-22 7304-7309:4, 7311-7318:4; Tó-23 7109-7111:2, 7161-7165:3, 7166-7168:4; Tó-26 7380-7382:2; 
Tó-27 7467-7469:17, 7473-7474:16, 7475-7476:9; Tó-29 7896-7897:18; Tó-30 7680:12, 7689-7691:2, 7702-7704:2, 77118-7716:2.

Navicula costulata Grun. var. hungarica Pant. - Tó-30 7683, 7686:1.

Navicula cryptocephala Kütz. - Tó-4 5527:4; Tó-8 8406:6; Tó-17 7564:4; Tó-20 6709:2; Tó-21 7048-7054:13; Tó-23 7112-7119:4, 7166-7168:2; Tó-26 7366-7367:5; Tó-27 7473-7474:4, 7475-7476:2; Tó-29 7800:5, 7805-7809:5, 7864-7866:20.

Navicula cuspidata Kütz. - Tó-4 5529:4, 5528:15, 5524:2; Tó-5 6795:1, 6796:2; Tó-7 8388:2, 8389:2; Tó-11 5555:2; Tó-17 7622-7624:1; Tó-20 6628:1, 6631:2, 6660, 6661:2; Tó-22 7268:1; Tó-23 7166-7168:8; Tó-27 7463-7466:28, 7473-7474:4; Tó-29 7794:10, 7869-7872:15; Tó-30 7683, 7686:2; Tó-31 6795:1, 6796:2; Tó-33 7434:10, 8144:5.

Navicula digitoradiata (Gregory) Ralfs - Tó-21 7048-7054:5; Tó-23 7120-7121:3.

Navicula diluviana Krasske - Tó-20 6628:2.

Navicula elginensis (Gregory) Ralfs - Tó-4 5528:5; Tó-7 8403:2, 8389:8; Tó-8 8404:7, 8405:2, 8407:12, 8408:3; Tó-11 5559:6; Tó-17 7562, 7563:8, 7625-7627:3; Tó-21 7043-7045:2, 7048-7054:15, 7055-7056:10, 7075-7077:10; Tó-23 7099:5, 7112-7119:3, 7131-7132:2, 7145-7148:3, 7151-7160:14, 7166-7168:3; Tó-26 7393, 7394:3, 7397, 7398:4; Tó-27 7478:4; Tó-30 7643:2, 7689-7691:2; Tó-33 7434:15, 8068:4, 8054:2.

Navicula elginensis (Gregory) Ralfs var. cuneata (M. Moller ex Foged) Lange-Bert. Tó-5 6802:1; Tó-31 6802:1.

Navicula exigua (Greg.) Grun. - Tó-17 7622-7624:2; Tó-23 7166-7168:2; Tó-33 8120:2.

Navicula gastrum (Ehr.) Kütz. - Tó-8 8049:2; Tó-17 7562, 7563:3, 7589, 7590, 7591:1, 7592, 7593, 7594:6, 6713-7618:18, 7622-7624:2; Tó-21 7043-7045:1, 7085-7087:5, 7088-7090:4; Tó-22 7325:1; Tó-23 7151-7160:3, 7166-7168:5, 7185-7196:5; Tó-26 7365:4; Tó-29 7963-7968:5; Tó-33 8150:5, 8138:5.

Navicula gottlandica Grun. - Tó-7 8400:53; Tó-8 8049:6; Tó-21 7048-7054:5; Tó-23 7099:2, 7145-7148:9, 7169-7177:6; Tó-29 7860-7863:7; Tó-30 7663, 7666:2; Tó-33 8090:13, 8086:40, 8083:5.

Navicula hasta Pant. - Tó-4 5527:3; Tó-8 8407:6; Tó-33 7434:5.

Navicula humerosa Bréb. - Tó-17 7622-7624:2.

Navicula hungarica Grun. var. capitata (Ehr.) Cl. - Tó-23 7151-7160:3, 7166-7168:5.

Navicula hustedtii Krasske - Tó-30 7646-7649:1.

Navicula jaernefeltii Hust. - Tó-20 6719:1.

Navicula kotschyi Grun. - Tó-20 6628:2, 6631:16, 6633:12.

Navicula lacustris Greg. - Tó-4 5530:4; Tó-8 8407:2, 8408:2; Tó-11 5559:2; Tó-23 7101-7104:1, 7197-7207:7; Tó-26 7373:5, 7375:38, 7385, 7386:10; Tó-27 7463-7466:16, 7487:12; Tó-29 7963-7968:5; Tó-30 7663, 7666:6, 7680:4.

Navicula laevissima Kütz. - Tó-23 7166-7168:7; Tó-30 7644-7645:4, 7646-7649:1; Tó-33 8243:5, 8132:8, 8126:4.

Navicula lanceolata (Ag.) Ehr. - Tó-4 5529:13; Tó-7 8389:3; Tó-8 8407:4, 8408:9; Tó-11 5559:8; Tó-20 6629-6630:1; Tó-23 7109-7111:47, 7112-7119:3, 7133-7144:5, 7169-7177:32; Tó-26 7380-7382:4, 7383, 7384:5; Tó-29 7800:8, 7805-7809:8; Tó-30 7646-7649:2, 7663, 7666:4; Tó-33 8054:3.

Navicula laterostrata Hust. - Tó-22 7291?:6; Tó-29 7800:6, 7805-7809:6.

Navicula leptostigma Hust. - Tó-21 7088-7090:10.

Navicula lóczyi Pant. - Tó-26 7364:2, 7365:11, 7366-7367:30.

Navicula menisculus Schum. - Tó-4 5530:2, 5529:9, 5524:5; Tó-7 8387:3, 8388:4, 8403:2; Tó-8 8404:2, 8405:5; Tó-11 5556:4，5547:2， 5544:2; Tó-23 7126-7130:2, 7145-7148:4, 
7166-7168:4, 7197-7207:10; Tó-26 7383, 7384:5, 7397, 7398:2; Tó-30 7644-7645:3, 7683, 7686:1; Tó-33 7434:6, 8068:2.

Navicula minima Grun. - Tó-20 6628:6, 6629-6630:1, 6631:3, 6633:7, 6670:1, 6701:4.

Navicula mutica Kütz. - Tó-5 6854:1; Tó-17 7607-7612:2, 6713-7618:5; Tó-30 7644-7645:3, 7655-7659:2; Tó-31 6854:1.

Navicula oblonga Kütz. - Tó-4 5531:4, 5530:30, 5529:44, 5528:25, 5526:15, 5524:12, 5523:2; Tó-5 6801:5, 6832:1, 6841:1, 6866:2, 6867:2, 6871:3; Tó-7 8402:3, 8403:3, 8400:105; Tó-8 8404:4, 8406:17, 8407:2, 8408:2, 8049:2; Tó-11 5555:7, 5553:21, 5542:14, 5541:18; Tó-17 7581-7583:4, 7603-7606:7, 7607-7612:6, 7622-7624:4; Tó-20 6628:3, 6629-6630:2, 6633:1, 6641:8, 6660, 6661:2, 6681:2, 6691:5; Tó-21 7043-7045:5, 7046-7047:18, 7048-7054:3, 7058-7060:3, 7061-7063:3, 7067-7069:5, 7075-7077:10, 7336! 7081-7082:5, 7085-7087:7; Tó-22 7259-7260:10, 7265:1, 7259-7261:2, 7268:2, 7291?:8, 7272-7274:2, 7298:6, 7300:1, 7301-7303:19, 7304-7309:1, 7325:2; Tó-23 7099:4, 7101-7104:3, 7120-7121:2, 7126-7130:8, 7131-7132:8, 7145-7148:2, 7149-7150:5, 7151-7160:16, 7166-7168:5, 7169-7177:14, 7178-7184:44, 7185-7196:7, 7197-7207:30, 7208-7222:5; Tó-26 7364:54, 7366-7367:15, 7370, 7371:10, 7373:62, 7375:18, 7397, 7398:4，7399-7401:4; Tó-27 7457-7460:2, 7463-7466:3, 7467-7469:20, 7470-7472:5, 7475-7476:26, 7479:9, 7484:4, 7485-7486:7, 7487:4; Tó-28 6455:9, 6452:1, 6423:3, 6420:10; Tó-29 7790:10, 7800:5, 7805-7809:30, 78, 547, 855:10, 7864-7866:6, 78, 677, 868:25, 7884-7892:5; Tó-30 7644-7645:4, 7646-7649:30, 7650-7654:20, 7663, 7666:7, 7672-7678:4, 7683, 7686:3, 7689-7691:4, 7705-7707:3, 7708-7710:12, 7498-7499:2, 7500-7503:3, 7504:5; Tó-31 6801:5, 6832:1, 6841:1, 6866:2, 6867:2, 6871:3; Tó-33 8144:4, 8126:4, 8108:2, 8100:6, 8090:3, 8083:3, 8059:24, 8054:50.

Navicula ordinaria Hust. - Tó-23 7161-7165:2.

Navicula peregrina (Ehr.) Kütz. - Tó-17 7622-7624:1; Tó-33 7922:5.

Navicula placentula (Ehr.) Grun. - Tó-4 5526:1, 5525:7; Tó-5 6795:1, 6801:1; Tó-11 5555:1, 5552:7, 5550:4, 5548:10, 5546:2, 5543:5; Tó-17 7551:2, 7603-7606:5, 7622-7624:3; Tó-20 6631:2, 6681:1; Tó-21 7043-7045:3, 7048-7054:5; Tó-22 7304-7309:4; Tó-23 7112-7119:4, 7149-7150:1, 7151-7160:11, 7166-7168:14, 7197-7207:5; Tó-26 7399-7401:6; Tó-27 7475-7476:6, 7478:8, 7479:4, 7481:8; Tó-29 7898-7993:5; Tó-30 7643:4, 7644-7645:1, 7683, 7686:2, 7705-7707:4, 7708-7710:3; Tó-31 6795:1, 6801:1; Tó-33 8120:2, 8068:4.

Navicula placentula (Ehr.) Grun. f. latiuscula (Grun.) Meister - Tó-29 7963-7968:5.

Navicula placentula (Ehr.) Grun. f. rostrata Mayer - Tó-4 5527:8; Tó-7 8403:5; Tó-21 7048-7054:5, 7055-7056:3, 7058-7060:5, 7064-7066:5; Tó-23 7151-7160:3; Tó-26 7375:5, 7397, 7398:5; Tó-27 7481:8.

Navicula placentula (Ehr.) Grun. f. yenisseyensis (Grun.) Meist. - Tó-22 7268:1.

Navicula platystoma Ehr. - Tó-5 6801:1; Tó-11 5545:4; Tó-22 7325:1; Tó-30 7689-7691:2; Tó-31 6801:1.

Navicula plicata Donkin - Tó-22 7259-7261:2, 7301-7303:1.

Navicula protracta Grun. - Tó-4 5524:6; Tó-11 5555:4; Tó-23 7101-7104:2, 7166-7168:5; Tó-26 7365:1, 7375:10; Tó-27 7463-7466:4.

Navicula pseudotuscula Hust. - Tó-4 5530:3, 5529:12, 5528:30, 5527:4, 5524:11; Tó-7 8403:2; Tó-27 7487:2; Tó-33 7492:7.

Navicula pupula Kütz. - Tó-20 6619:2, 6628:2, 6633:2; Tó-23 7166-7168:2.

Navicula pygmaea Kütz. - Tó-11 5546:4.

Navicula radiosa Kütz. - Tó-4 5530:4, 5529:16, 5528:5, 5524:5; Tó-5 6802:1; Tó-7 8389:8, 8400:68; Tó-8 8404:2; Tó-11 5551:2, 5548:4, 5542:3; Tó-17 7562, 7563:2, 7592, 7593, 7594:3; Tó-20 6628:14, 6629-6630:1, 6631:3, 6633:2, 6634:3, 6641:2, 6681:1, 6691:1, 6719:1; Tó-21 7043-7045:9, 7046-7047:5, 7048-7054:15, 7058-7060:5, 7061-7063:2; Tó-22 7259-7261:2, 7325:1; Tó-23 7093-7094:4, 7101-7104:5, 7109-7111:24, 7112-7119:86, 7131-7132:3, 7133-7144:2, 
7145-7148:6, 7149-7150:18, 7151-7160:20, 7166-7168:15, 7169-7177:5, 7178-7184:14, 7197-7207:6, 7208-7222:7; Tó-26 7366-7367:5; Tó-27 7482-7483:3, 7484:2; Tó-28 6454:1, 6427:4; Tó-29 7794:20, 7800:40, 7805-7809:85, 7864-7866:5; Tó-30 7644-7645:11, 7646-7649:7, 7650-7654:5, 7660-7662:2, 7672-7678:2, 7680:2, 7689-7691:2, 7717:4; Tó-31 6802:1; Tó-33 8150:5, 8114:3, 8108:7, 8090:3, 8086:2, 8059:2, 8054:8.

Navicula reinhardtii Grun. - Tó-17 7607-7612:4; Tó-20 6670:1.

Navicula rhynchocephala Kütz. - Tó-4 5529:2; Tó-21 7048-7054:15; Tó-23 7161-7165:5, 7166-7168:2; Tó-27 7463-7466:6, 7481:2.

Navicula schoenfeldii Hust. - Tó-23 7131-7132:3; Tó-30 7644-7645:5, 7650-7654:5.

Navicula scutelloides W. Sm. - Tó-4 5527:11, 5526:29, 5525:15, 5524:31, 5523:27; Tó-5 6854:5, 6866:1, 6867:2, 6869:3, 6871:6, 6873:1, 6874:3; Tó-7 8403:4; Tó-8 8408:2; Tó-11 5550:4, 5545:6, 5544:12, 5542:9, 5540:15; Tó-17 7564:2, 7567-7568:2, 7570, 7571, 7574:8, 7581-7583:49, 7592, 7593, 7594:90, 7595, 7596, 7597, 7599, 7600:129, 7607-7612:73, 6713-7618:51, 7622-7624:90, 7625-7627:55; Tó-20 6628:1, 6629-6630:1, 6670:11, 6681:1，6701:5，6709:2, 6719:2; Tó-21 7061-7063:1，7064-7066:5，7067-7069:5, 7070, 7073:21，7075-7077:23， 7336! 7081-7082:20, 7083-7084:6, 7085-7087:36, 7088-7090:12; Tó-22 7325:11; Tó-23 7185-7196:7, 7197-7207:12, 7208-7222:50; Tó-26 7373:4, 7375:3, 7387-7392:2, 7393, 7394:12, 7395, 7396:6, 7397, 7398:2, 7399-7401:15; Tó-27 7467-7469:5, 7470-7472:4, 7473-7474:10, 7475-7476:10, 7478:4, 7479:4, 7481:6, 7482-7483:4, 7484:2, 7485-7486:2, 7487:10, 7488:5; Tó-28 6454:22, 6452:5, 6450:6, 6427:4, 6424:2; Tó-29 7896-7897:27, 7898:5, 7898-7993:20, 7904-7906:3, 7963-7968:20, 7969-7971:5; Tó-30 7650-7654:2, 7683, 7686:4, 7689-7691:4, 7692-7701:10, 7708-7710:4, 77118-7716:10, 7717:4, 7498-7499:15, 7500-7503:49; Tó-31 6854:5, 6866:1, 6867:2, 6869:3, 6871:6, 6873:1, 6874:3; Tó-33 7922:6, 7434:16, 7492:15, 8150:15, 8144:6, 8138:25, $8132: 8,8126: 12$.

Navicula scutum (Schum) Van Heurch - Tó-22 7304-7309:1.

Navicula siofokensis Pant. - Tó-22 7268:1; Tó-26 7375:2.

Navicula subhamulata Grun. - Tó-4 5525:5; Tó-8 8049:2; Tó-23 7166-7168:7; Tó-29 7898-7993:7.

Navicula subrotundata Hust. - Tó-20 6631:7.

Navicula tridentula Krasske - Tó-23 7151-7160:1.

Navicula tripunctata (O. F. Müller) Bory - Tó-11 5544:2; Tó-21 7061-7063:4; Tó-29 7800:5, 7805-7809:5; Tó-30 7689-7691:9.

Navicula tuscula (Ehr.) Grun. - Tó-5 6796:1, 6802:1; Tó-11 5553:2, 5552:4, 5551:4, 5549:4, 5540:5; Tó-17 7595, 7596, 7597, 7599, 7600:8, 7603-7606:13, 7607-7612:2, 7622-7624:4, 7625-7627:5; Tó-20 6629-6630:1, 6681:2, 6691:2; Tó-21 7043-7045:5, 7048-7054:2, 7061-7063:9, 7064-7066:5, 7075-7077:5; Tó-22 7265:3, 7267-7272:1, 7301-7303:2, 7311-7318:1, 7325:1; Tó-23 7101-7104:9, 7126-7130:11, 7185-7196:8, 7197-7207:8, 7208-7222:17; Tó-26 7365:20, 7366-7367:7, 7375:35, 7395, 7396:3, 7397, 7398:2, 7399-7401:2; Tó-27 7463-7466:12, 7481:2, 7487:5; Tó-28 6454:4, 6423:1; Tó-29 7790:5, 7817-7819:5; Tó-30 7644-7645:4, 7650-7654:4, 7660-7662:2, 7669-7671:2, 7672-7678:12, 7680:10, 7683, 7686:7, 7689-7691:4, 7702-7704:2, 7705-7707:2, 7717:3, 7500-7503:4; Tó-31 6796:1, 6802:1; Tó-33 8114:7, 8059:9, 8054:2.

Navicula tuscula (Ehr.) Grun. f. minor Hust. - Tó-11 5548:10, 5542:6; Tó-22 7291?:2, 7304-7309:2; Tó-23 7120-7121:13, 7131-7132:2; Tó-26 7370, 7371:2, 7383, 7384:5, 7397, 7398:4; Tó-27 7457-7460:3, 7478:3, 7484:2, 7487:2; Tó-29 7898-7993:1, 7963-7968:5; Tó-30 7683, 7686:2, 7689-7691:2, 7692-7701:11; Tó-33 8150:5.

Navicula tuscula (Ehr.) Grun. f. rostrata Hust. - Tó-26 7375:5.

Navicula veneta Kütz. - Tó-27 7485-7486:2.

Navicula viridula (Kütz.) Ehr. - Tó-23 7109-7111:1. 
Neidium affine (Ehr.) Pfitzer - Tó-17 7562, 7563:17; Tó-23 7208-7222:5; Tó-33 8108:2.

Neidium ampliatum (Ehr.) Krammer - Tó-21 7048-7054:5.

Neidium bisulcatum (Lagerst.) Cl. - Tó-17 6713-7618:4.

Neidium distincte-punctatum Hust. - Tó-8 8408:20; Tó-11 5552:5; Tó-23 7131-7132:3, 7133-7144:5, 7169-7177:5; Tó-26 7370, 7371:4,7387-7392:4; Tó-27 7478:4; Tó-29 7898-7993:5.

Neidium dubium (Ehr.) Cl. - Tó-5 6802:1; Tó-21 7061-7063:5; Tó-23 7145-7148:3, 7166-7168:9; Tó-26 7370, 7371:6, 7385, 7386:4; Tó-27 7473-7474:6, 7475-7476:5, 7478:9; Tó-30 7683, 7686:2, 7500-7503:2; Tó-31 6802:1.

Neidium iridis (Ehr.) Cl. - Tó-4 5530:15, 5529:17, 5528:10, 5527:9, 5525:10, 5524:11; Tó-5 6802:1; Tó-7 8387:3, 8400:15; Tó-8 8049:2; Tó-11 5556:2, 5553:26, 5550:2, 5546:2, 5542:5; Tó-17 7562, 7563:8; Tó-20 6631:2, 6633:3; Tó-21 7043-7045:3, 7048-7054:2, 7064-7066:5; Tó-22 7276-7277:1, 7291?:2; Tó-23 7093-7094:1, 7101-7104:1, 7131-7132:7, 7133-7144:4, 7151-7160:6, 7169-7177:2; Tó-26 7373:5, 7385, 7386:5; Tó-27 7463-7466:2, 7479:2, 7481:5; Tó-29 7860-7863:12, 7864-7866:5, 78, 677, 868:20, 7898-7993:7, 7963-7968:6; Tó-30 7644-7645:7, 7672-7678:2, 7689-7691:2, 77118-7716:2; Tó-31 6802:1; Tó-33 8100:2.

Neidium kozlowii Mereshkowsky - Tó-5 6793:6; Tó-11 5559:1, 5556:1, 5551:5, 5550:2, 5549:10, 5548:4; Tó-21 7048-7054:5; Tó-22 7276-7277:1; Tó-23 7112-7119:2, 7208-7222:10; Tó-27 7457-7460:12; Tó-29 7810-7816:6; Tó-31 6793:6; Tó-33 8068:5.

Neidium productum (W.Sm.) Cl. - Tó-23 7166-7168:2; Tó-30 7644-7645:5, 77118-7716:5.

Nitzschia acula Hantzsch - Tó-4 5527:2; Tó-7 8388:2, 8400:8; Tó-11 5559:2, 5556:2, 5547:2, 5546:4, 5542:5; Tó-17 7558-7560:42; Tó-20 6691:1; Tó-21 7048-7054:5, 7064-7066:10, 7067-7069:5; Tó-22 7291?:1, 7304-7309:4; Tó-23 7109-7111:29, 7112-7119:15, 7126-7130:8, 7133-7144:7, 7149-7150:3, 7208-7222:6; Tó-27 7473-7474:2, 7477:15, 7478:8, 7481:3, 7485-7486:2, 7488:2; Tó-29 7794:10, 7860-7863:35, 7864-7866:28, 7963-7968:10; Tó-30 7660-7662:3.

Nitzschia amphibia Grun. - Tó-5 6801:5, 6871:1; Tó-7 8402:6, 8403:2; Tó-8 8404:2; Tó-17 7564:6, 7561:2, 7562, 7563:4, 7592, 7593, 7594:2; Tó-20 6623:2, 6628:2, 6629-6630:2, 6634:2, 6701:2; Tó-21 7043-7045:2, 7048-7054:1; Tó-22 7259-7260:1; Tó-23 7101-7104:12, 7133-7144:6, 7161-7165:1; Tó-26 7373:5, 7385, 7386:5, 7393, 7394:2; Tó-28 6423:1; Tó-29 7790:20, 7800:22, 7805-7809:22, 7825:5, 7896-7897:5, 7963-7968:10; Tó-30 7689-7691:3, 7692-7701:5; Tó-31 6801:5, 6871:1; Tó-33 7492:5, 8090:2, 8086:2, 8059:14, 8054:17.

Nitzschia amphibioides Hust. - Tó-30 7663, 7666:5; Tó-33 8059:4.

Nitzschia angustata (W. Sm.) Grun. - Tó-4 5531:2, 5530:25, 5529:4, 5527:12, 5524:23, 5523:10; Tó-5 6841:1; Tó-7 8402:25, 8389:35, 8400:30; Tó-8 8408:4; Tó-11 5559:4, 5556:2, 5551:5, 5548:17, 5547:8, 5546:4, 5544:6, 5543:15, 5542:5; Tó-20 6628:8, 6631:4, 6633:9, 6641:2, 6670:2, 6681:6, 6691:6, 6701:2; Tó-21 7043-7045:5; Tó-22 7259-7261:14; Tó-23 7093-7094:9, 7099:1, 7101-7104:1, 7109-7111:15, 7112-7119:10, 7131-7132:3, 7149-7150:10, 7151-7160:11, 7166-7168:1; Tó-27 7463-7466:5, 7473-7474:5, 7475-7476:14, 7477:20, 7478:12, 7479:2, 7481:9, 7482-7483:2, 7485-7486:4; Tó-30 7663, 7666:1, 7672-7678:2; Tó-31 6841:1; Tó-33 7922:17, 8120:2, 8100:6, 8090:11, 8086:5.

Nitzschia commutata Grun. - Tó-5 6801:1; Tó-17 7562, 7563:2; Tó-22 7311-7318:1; Tó-31 6801:1; Tó-33 8084:2, 8083:13.

Nitzschia constricta (Kütz.) Ralfs - Tó-29 7864-7866:10.

Nitzschia debilis (Arnott) Grun. - Tó-22 7304-7309:4; Tó-27 7473-7474:2; Tó-30 7717:2.

Nitzschia delicatula Grun. - Tó-23 7099:4, 7161-7165:1.

Nitzschia directa Pant. - Tó-17 7592, 7593, 7594:4.

Nitzschia fasciculata Grun. - Tó-21 7336! 7081-7082:5; Tó-26 7380-7382:3.

Nitzschia filiformis (W. Sm.) van Heurck - Tó-7 8389:4; Tó-27 7481:5. 
Nitzschia frustulum (Kütz.) Grun. - Tó-5 6866:5; Tó-7 8388:8, 8403:6; Tó-8 8406:6; Tó-17 7607-7612:4, 6713-7618:1; Tó-20 6628:5, 6629-6630:1, 6631:3, 6707:3; Tó-21 7067-7069:2, 7088-7090:4; Tó-22 7267-7272:1; Tó-23 7101-7104:4, 7208-7222:2; Tó-26 7397, 7398:2, 7399-7401:2; Tó-28 6452:1; Tó-30 7660-7662:2, 7680:2, 7498-7499:2, 7500-7503:1; Tó-31 6866:5.

Nitzschia gracilis Hantzsch - Tó-23 7169-7177:2. 7384:2.

Nitzschia hungarica Grun. - Tó-20 6628:4; Tó-22 7259-7261:4, 7301-7303:1; Tó-26 7383,

Nitzschia hybrida Grun. - Tó-20 6670:2.

Nitzschia levidensis (W. Sm.) Grun. in van Heurck - Tó-4 5533:2; Tó-23 7133-7144:3.

Nitzschia linearis W. Sm. - Tó-7 8389:4; Tó-20 6628:1; Tó-21 7085-7087:3; Tó-27 7467-7469:2; Tó-29 7800:5, 7805-7809:5.

Nitzschia obtusa W. Sm. - Tó-22 7272-7274:3; Tó-23 7133-7144:5; Tó-30 7500-7503:1.

Nitzschia parvula W. Sm. - Tó-22 7272-7274:1; Tó-30 7925-7927:10.

Nitzschia recta Hantzsch - Tó-4 5524:5, 5523:7; Tó-7 8388:4, 8403:2; Tó-8 8408:4; Tó-11 5550:6, 5549:2, 5548:4, 5547:12; Tó-17 7558-7560:8, 7603-7606:2; Tó-23 7093-7094:17, 7101-7104:1, 7166-7168:7, 7169-7177:5; Tó-26 7399-7401:3; Tó-27 7463-7466:2, 7473-7474:6, 7475-7476:6; Tó-29 7810-7816:21, 7963-7968:10; Tó-30 7643:3, 7644-7645:9, 7669-7671:2, 7672-7678:3, 7702-7704:1, 77118-7716:10; Tó-33 8243:15, 8150:16.

Nitzschia sigma (Kütz.) W. Sm. - Tó-17 7563:3; Tó-21 7043-7045:2; Tó-23 7133-7144:5.

Nitzschia sigmoidea (Nitzsch) W. Sm. - Tó-4 5525:5; Tó-17 6713-7618:1; Tó-20 6628:1, 6633:2; Tó-23 7112-7119:2, 7126-7130:2, 7131-7132:2, 7151-7160:26, 7169-7177:10, 7185-7196:3; Tó-27 7481:7; Tó-29 7805-7809:10.

Nitzschia sinuata (Thwaites?) Grun. - Tó-23 7197-7207:3.

Nitzschia spectabilis (Ehr.) Hust. - Tó-11 5548:4; Tó-17 7562, 7563:17, 7592, 7593, 7594:2, 7607-7612:3, 6713-7618:2; Tó-21 7043-7045:13, 7048-7054:20, 7055-7056:23, 7061-7063:3, 7064-7066:12, 7067-7069:12, 7083-7084:9; Tó-22 7259-7260:3， 7259-7261:4， 7291?:1, 7304-7309:3, 7311-7318:2; Tó-23 7101-7104:4, 7126-7130:23, 7131-7132:5, 7133-7144:15, 7145-7148:8, 7149-7150:5, 7166-7168:10, 7169-7177:20, 7178-7184:3, 7185-7196:4, 7208-7222:15; Tó-26 7376-7379:7, 7383, 7384:2, 7385, 7386:10, 7393, 7394:4, 7395, 7396:5; Tó-28 6457:7, 6454:7, 6450:2, 6423:10, 6420:1, 6419:2; Tó-29 7805-7809:12; Tó-30 7644-7645:1, 7650-7654:5, 7655-7659:2, 7660-7662:3, 7663, 7666:1, 7672-7678:3, 7680:4, 7683, 7686:6, 7708-7710:3, 77118-7716:3, 7717:4, 7925-7927:11.

Nitzschia sublinearis Hust. - Tó-7 8389:8, 8400:18; Tó-8 8404:4; Tó-17 7558-7560:2; Tó-22 7311-7318:1; Tó-23 7169-7177:4; Tó-29 7898-7993:4; Tó-33 8086:2.

Nitzschia subtilis Grun. - Tó-8 8405:2.

Nitzschia tryblionella Hantzsch - Tó-7 8389:2; Tó-8 8406:4; Tó-21 7048-7054:4, 7058-7060:5; Tó-22 7291?:2, 7304-7309:10; Tó-23 7112-7119:16; Tó-27 7463-7466:1; Tó-30 7650-7654:4, 7663, 7666:2, 7925-7927:10.

Nitzschia tubicola Grun. - Tó-17 7592, 7593, 7594:5, 7595, 7596, 7597, 7599, 7600:5, 6713-7618:4.

Nitzschia umbonata (Ehr.) Lange-Bert. - Tó-23 7112-7119:2; Tó-29 7869-7872:10, 7875:5, 7880-7882:5, 7896-7897:5; Tó-33 8100:4.

Nitzschia vermicularis (Kütz.) Hantzsch - Tó-7 8400:3; Tó-23 7169-7177:4; Tó-27 7481:2.

Nitzschia vitrea Norman - Tó-4 5524:12; Tó-5 6793:7; Tó-7 8388:9; Tó-8 8049:2; Tó-11 5547:4, 5546:2, 5544:2, 5543:13, 5542:5; Tó-17 7592, 7593, 7594:10, 7607-7612:8, 6713-7618:2; Tó-20 6691:1; Tó-21 7043-7045:2, 7046-7047:10, 7061-7063:4, 7064-7066:11, 7070, 7073:5, 7075-7077:10, 7083-7084:2; Tó-23 7099:3, 7145-7148:4, 7197-7207:8, 7208-7222:25; Tó-26 
7365:12, 7387-7392:3, 7393, 7394:2, 7399-7401:2; Tó-27 7467-7469:5, 7475-7476:9, 7477:10, 7479:4，7484:2, 7485-7486:2, 7487:6; Tó-28 6455:1; Tó-30 7692-7701:2, 77118-7716:4, 7498-7499:1, 7500-7503:6; Tó-31 6793:7; Tó-33 8138:15, 8114:2.

Oestrupia zachariasii (Reich.) Hust. - Tó-4 5529:4, 5527:10; Tó-26 7364:5, 7365:40, 7383, 7384:4; Tó-27 7473-7474:6, 7475-7476:1; Tó-30 7689-7691:1; Tó-33 8120:9.

Pinnularia acrosphaerica Rabh. - Tó-17 7558-7560:14.

Pinnularia balatonis (Pant.) Mills - Tó-22 7272-7274:2.

Pinnularia braunii (Grun.) Cl. - Tó-7 8389:2; Tó-23 7131-7132:1.

Pinnularia brevicostata Cl. - Tó-22 7267-7272:1; Tó-17 7564:3; Tó-23 7109-7111:3.

Pinnularia gentilis (Donkin) Cl. - Tó-30 7683, 7686:1.

Pinnularia gibba E. - Tó-17 7558-7560:10; Tó-33 8138:15, 8126:4, 8108:10, 8100:14, 8086:10, 8041:1, 8042:4.

Pinnularia interrupta W. Sm. - Tó-21 7043-7045:2.

Pinnularia lata (Bréb.) W. Sm. - Tó-22 7304-7309:2.

Pinnularia maior (Kütz.) Rbh. - Tó-4 5524:5; Tó-17 7592, 7593, 7594:2, 7603-7606:5; Tó-20 6628:1; Tó-21 7058-7060:5; Tó-22 7259-7260:5; Tó-23 7185-7196:2, 7197-7207:6; Tó-26 7365:3, 7370, 7371:3; Tó-29 7810-7816:5.

Pinnularia microstauron (Ehr.) Cl. - Tó-4 5529:16, 5528:15; Tó-11 5556:2, 5546:1; Tó-17 7558-7560:6; Tó-20 6631:12, 6633:2; Tó-22 7259-7261:29, 7268:2, 7301-7303:1; Tó-23 7109-7111:2, 7112-7119:13, 7169-7177:2, 7178-7184:4, 7169-7177:1; Tó-26 7364:94, 7366-7367:27; Tó-30 7683, 7686:2; Tó-33 8144:5.

Pinnularia microstauron (Ehr.) Cl. var. brebissonii (Kütz.) Mayer - Tó-4 5533:1, 5525:5, 5524:10, 5523:7; Tó-7 8386:2, 8402:11, 8403:2, 8389:2, 8400:8; Tó-8 8406:7, 8049:9; Tó-11 5559:1, 5553:2, 5552:4, 5549:2, 5544:1, 5543:8, 5542:15; Tó-17 7561:4, 7562, 7563:4, 7570, 7571, 7574:8; Tó-20 6631:5, 6633:1; Tó-22 7259-7261:29, 7272-7274:1; Tó-23 7101-7104:4, 7109-7111:28, 7112-7119:15, 7126-7130:2, 7133-7144:4, 7169-7177:22, 7178-7184:6; Tó-26 7364:28, 7366-7367:5, 7375:4; Tó-27 7457-7460:2, 7463-7466:3, 7467-7469:10, 7473-7474:14, 7475-7476:4, 7479:5, 7485-7486:6, 7487:6; Tó-28 6419:1; Tó-29 78, 547, 855:4, 7860-7863:10, 7880-7882:5, 7904-7906:5; Tó-30 7663, 7666:2, 7669-7671:1, 7672-7678:2, 7500-7503:2; Tó-33 7434:5, 8150:5, 8090:5, 8086:6, 8084:6, 8083:2.

Pinnularia nobilis Ehr. - Tó-5 6792:1; Tó-31 6792:1.

Pinnularia nodosa Ehr. - Tó-11 5556:2.

Pinnularia pulchra Oestrup - Tó-20 6633:1; Tó-30 7683, 7686:2.

Pinnularia viridis (Nitzsch.) Ehr. - Tó-4 5524:5; Tó-5 6793:5, 6802:1, 6841:3; Tó-7 8386:2; Tó-11 5555:4, 5552:2, 5545:2, 5544:2; Tó-17 7551:2, 7563:2, 7558-7560:6, 7561:4, 7562, 7563:6, 6713-7618:3; Tó-20 6628:1，6633:1; Tó-21 7061-7063:4，7064-7066:10, 7336! 7081-7082:5; Tó-22 7291?:2, 7272-7274:5; Tó-23 7093-7094:2, 7109-7111:3, 7120-7121:1, 7131-7132:2, 7149-7150:4, 7161-7165:2, 7166-7168:9, 7169-7177:2, 7185-7196:3, 7208-7222:1; Tó-26 7373:8, 7383, 7384:2, 7397, 7398:4, 7399-7401:2; Tó-27 7473-7474:2; Tó-29 7805-7809:15; Tó-30 7650-7654:4, 7669-7671:3, 7683, 7686:1, 7689-7691:2, 7500-7503:4; Tó-31 6793:5, 6802:1, 6841:3; Tó-33 8132:4, 8126:5, 8084:2, 8083:2.

Rhoicosphaenia abbreviata (Agardh) Lange-Bert. - Tó-4 5524:6; Tó-11 5559:2, 5556:4; Tó-20 6629-6630:6; Tó-23 7151-7160:4.

Rhopalodia acuminata Krammer var. protracta (Grun.) Krammer - Tó-30 7650-7654:2.

Rhopalodia gibba (Ehr.) O. Müll. - Tó-4 5529:16, 5528:5, 5527:10, 5526:1, 5525:1; Tó-5 6792:1, 6793:6, 6795:1, 6796:5, 6801:1, 6802:3, 6832:15, 6841:5, 6854:1, 6867:1, 6873:2; Tó-7 8386:2, 8388:2, 8403:2, 8400:2; Tó-8 8404:6, 8406:12, 8407:10, 8049:3; Tó-11 5559:4, 5556:2, 5555:2, 5553:7, 5552:3, 5550:8, 5549:6, 5548:6, 5545:1, 5543:4; Tó-17 7563:12, 7564:12, 7566:5, 
7558-7560:31, 7561:6, 7562, 7563:10, 7592, 7593, 7594:9, 7595, 7596, 7597, 7599, 7600:4 7625-7627:3; Tó-20 6618:4, 6629-6630:1, 6631:10, 6633:3, 6634:20, 6641:2, 6660, 6661:1, 6681:3 Tó-21 7043-7045:20, 7048-7054:9, 7067-7069:2, 7075-7077:5, 7336! 7081-7082:5, 7088-7090:13; Tó-22 7259-7260:7, 7276-7277:5, 7259-7261:2, 7268:1, 7272-7274:1, 7304-7309:1, 7311-7318:5 7325:5; Tó-23 7093-7094:6, 7101-7104:1, 7109-7111:13, 7112-7119:3, 7126-7130:4, 7145-7148:5, 7149-7150:5， 7151-7160:17， 7166-7168:42， 7169-7177:5， 7178-7184:23， 7185-7196:25, 7208-7222:48; Tó-26 7364:11, 7385, 7386:10, 7397, 7398:2; Tó-27 7484:2; Tó-28 6455:3; Tó-29 7805-7809:5, 78, 547, 855:15, 7880-7882:10; Tó-30 7643:8, 7644-7645:8, 7672-7678:2, 7683, 7686:10, 7689-7691:2, 7692-7701:14, 7708-7710:2, 77118-7716:4; Tó-31 6792:1, 6793:6, 6795:1, 6796:5, 6801:1, 6802:3, 6832:15, 6841:5, 6854:1, 6867:1, 6873:2.

Rhopalodia gibba (Ehr.) O. Müll. var. paralella (Grun.) H. et M. Peragallo - Tó-4 5529:8, 5527:2, 5523:5; Tó-5 6801:3; Tó-11 5546:6; Tó-17 7563:3; Tó-20 6629-6630:1; Tó-21 7043-7045:3, 7046-7047:6, 7048-7054:3, 7055-7056:1, 7061-7063:3; Tó-22 7265:8, 7291?:4, 7304-7309:2; Tó-23 7093-7094:2, 7112-7119:3, 7126-7130:2, 7133-7144:4, 7149-7150:10, 7151-7160:9, 7178-7184:2, 7185-7196:3, 7197-7207:28; Tó-26 7376-7379:10, 7380-7382:5, 7399-7401:9; Tó-27 7475-7476:7, 7482-7483:8; Tó-28 6454:3; Tó-29 7790:5, 7800:10, 7805-7809:65, 7810-7816:20, 7898:5, 7904-7906:5; Tó-30 7643:5, 7680:2, 7705-7707:2, 7708-7710:4, 77118-7716:8; Tó-31 6801:3.

Scoliopleura peisonis Grun. - Tó-4 5530:39, 5529:17, 5528:40, 5526:8; Tó-7 8400:51; Tó-8 8406:10, 8407:8; Tó-11 5555:10, 5553:23, 5552:4, 5549:5, 5548:2, 5542:3; Tó-22 7259-7260:1, 7268:1, 7272-7274:21; Tó-23 7109-7111:4, 7169-7177:29, 7178-7184:5, 7185-7196:5, 7197-7207:10; Tó-26 7364:4, 7365:15, 7366-7367:12, 7373:23, 7383, 7384:1, 7399-7401:2; Tó-27 7463-7466:114, 7467-7469:30, 7473-7474:8, 7478:7, 7479:59, 7485-7486:13, 7487:20, 7488:2; Tó-28 6457:1, 6455:4, 6454:5, 6423:3, 6420:1; Tó-29 7860-7863:77, 7864-7866:35, 78, 677, 868:80, 7869-7872:10, 7893-7895:45, 7898-7993:10, 7904-7906:3; Tó-30 7643:3,77118-7716:2; Tó-33 8086:10, 8084:6. Stauroneis acuta W. Sm. - Tó-5 6801:6; Tó-21 7064-7066:6; Tó-23 7112-7119:3, 7126-7130:10; Tó-31 6801:6.

Stauroneis anceps Ehr. - Tó-7 8389:2; Tó-11 5555:4; Tó-17 7564:4; Tó-21 7061-7063:5; Tó-23 7131-7132:1, 7133-7144:2, 7151-7160:4; Tó-30 7669-7671:2; Tó-33 8059:2, 8054:6.

Stauroneis bacillum (Grun.) Cl. - Tó-29 7790:8, 7810-7816:7.

Stauroneis obtusa Lagerst. - Tó-21 7043-7045:2; Tó-23 7197-7207:7; Tó-28 6423:1, 6419:4.

Stauroneis phoenicenteron Ehr. - Tó-17 7562, 7563:4; Tó-21 7043-7045:2, 7048-7054:10; Tó-22 7259-7260:1, 7265:1; Tó-23 7126-7130:4; Tó-26 7387-7392:5; Tó-29 7904-7906:5; Tó-30 7650-7654:2, 7672-7678:3; Tó-33 8100:4.

Stauroneis producta Grun. - Tó-8 8407:14; Tó-11 5559:4; Tó-20 6681:2, 6691:5; Tó-21 7048-7054:23, 7055-7056:1, 7083-7084:2; Tó-22 7267-7272:2; Tó-23 7166-7168:2, 7197-7207:5; Tó-26 7373:3; Tó-27 7475-7476:2, 7481:2; Tó-28 6423:5; Tó-33 8114:17, 8042:6.

Stauroneis salina W. Sm. - Tó-17 7562, 7563:2, 7603-7606:5, 7607-7612:5; Tó-20 6629-6630:1, 6631:1.

Stauroneis smithii Grun. - Tó-4 5526:1, 5525:5; Tó-5 6795:1; Tó-8 8405:2, 8049:5; Tó-11 5548:5; Tó-20 6618:4, 6623:2, 6629-6630:2, 6641:4, 6681:2; Tó-21 7043-7045:3, 7055-7056:5, 7336! 7081-7082:14, 7085-7087:1; Tó-22 7265:5, 7268:1, 7291?:1; Tó-23 7099:1, 7133-7144:5, 7151-7160:2, 7166-7168:2, 7185-7196:14, 7197-7207:7; Tó-26 7370, 7371:20, 7380-7382:19; Tó-27 7470-7472:9, 7473-7474:6, 7478:2, 7479:5, 7481:15; Tó-29 7898-7993:10; Tó-30 7680:11, 7683, 7686:9, 7689-7691:5, 77118-7716:4, 7498-7499:2, 7500-7503:3; Tó-31 6795:1; Tó-33 8114:3. 
Stauroneis smithii Grun. var. incisa Pant. - Tó-27 7473-7474:4, 7475-7476:12, 7478:4, 7479:8, 7481:7, 7487:2; Tó-28 6423:4.

Stauroneis smithii Grun. var. sagitta (Cl.) Hust. - Tó-4 5524:5; Tó-5 6866:1; Tó-7 8386:2, 8387:6, 8388:1, 8403:2, 8389:4; Tó-8 8404:2, 8408:2; Tó-11 5552:2, 5546:2, 5545:5; Tó-17 7562, 7563:4, 7595, 7596, 7597, 7599, 7600:8, 7625-7627:3; Tó-20 6628:11, 6631:20, 6691:2; Tó-21 7043-7045:5, 7055-7056:6, 7061-7063:2, 7085-7087:1; Tó-22 7265:6, 7291?:4, 7304-7309:5, 7311-7318:12; Tó-23 7109-7111:19, 7112-7119:26, 7161-7165:4, 7185-7196:5, 7208-7222:22; Tó-26 7370, 7371:10, 7380-7382:5, 7383, 7384:15, 7387-7392:3, 7399-7401:2; Tó-27 7457-7460:4, 7463-7466:5, 7473-7474:2, 7475-7476:2, 7481:4; Tó-28 6454:5; Tó-29 7896-7897:10, 7898-7993:3, 7963-7968:5; Tó-30 7650-7654:1, 7655-7659:1, 7663, 7666:2, 7669-7671:4, 7672-7678:4, 7680:38, 7683, 7686:37, 7689-7691:7, 7702-7704:5, 77118-7716:3; Tó-31 6866:1; Tó-33 7922:4, 7434:5, 7492:10, 8132:19, 8120:15, 8059:2.

Stephanodiscus astraea (Ehr.) Grun. - Tó-23 7109-7111:12, 7112-7119:11, 7166-7168:7; Tó-29 7904-7906:2.

Stephanodiscus minutulus (Kütz.) Cleve et Moeller - Tó-23 7109-7111:8, 7112-7119:48, 7151-7160:1; Tó-29 7963-7968:5; Tó-33 7434:3.

Surirella balatonis Pant. - Tó-27 7473-7474:3.

Surirella bifrons Ehr. - Tó-4 5525:5, 5523:17; Tó-5 6841:3; Tó-11 5559:4, 5552:2, 5547:4; Tó-17 7592, 7593, 7594:2; Tó-20 6628:1, 6629-6630:3, 6631:1, 6634:8, 6701:2; Tó-21 7043-7045:3, 7046-7047:12, 7055-7056:5, 7061-7063:7; Tó-22 7267-7272:1, 7259-7261:4, 7268:2, 7272-7274:12, 7301-7303:1; Tó-23 7099:1, 7109-7111:5, 7112-7119:5, 7126-7130:5, 7197-7207:5; Tó-26 7375:4; Tó-27 7467-7469:4, 7470-7472:2, 7481:2, 7487:1; Tó-28 6465:2, 6459:5, 6454:1, 6419:2; Tó-30 7643:6, 7655-7659:3, 7708-7710:5; Tó-31 6841:3.

Surirella bifrons Ehr. var. margaritifera Pant. - Tó-11 5546:4, 5545:1, 5544:2.

Surirella birostrata Hust. - Tó-20 6641:2; Tó-30 7680:6, 7692-7701:3; Tó-33 8068:4.

Surirella biseriata Bréb. - Tó-4 5531:2, 5529:8, 5528:3, 5527:2, 5525:10; Tó-8 8408:8, 8049:4; Tó-11 5556:5, 5549:2, 5548:4, 5547:6, 5546:4, 5544:2; Tó-17 7595, 7596, 7597, 7599, 7600:4; Tó-20 6628:16, 6660, 6661:2, 6670:1, 6691:1, 6707:2, 6709:2; Tó-21 7043-7045:6, 7046-7047:12, 7055-7056:2, 7058-7060:5, 7061-7063:4; Tó-22 7259-7260:2, 7272-7274:8, 7304-7309:4, 7325:1; Tó-23 7109-7111:8, 7133-7144:2, 7149-7150:4, 7151-7160:4, 7161-7165:1, 7166-7168:4, 7169-7177:4, 7178-7184:12, 7197-7207:15, 7208-7222:10; Tó-26 7365:5, 7375:20, 7376-7379:27, 7380-7382:3, 7385, 7386:20; Tó-27 7457-7460:2, 7463-7466:15, 7467-7469:5, 7470-7472:10, 7475-7476:9, 7479:4, 7481:2, 7487:2; Tó-28 6457:1, 6450:6, 6423:1; Tó-29 7790:15, 7810-7816:7, 7864-7866:15, 78, 677, 868:5; Tó-30 7650-7654:5, 7705-7707:4, 7708-7710:6; Tó-33 8083:10.

Surirella brebissonii Krammer et Lange-Bert. - Tó-17 7607-7612:8; Tó-20 6641:4; Tó-21 7046-7047:10, 7048-7054:6; Tó-23 7112-7119:2, 7133-7144:3, 7149-7150:3, 7169-7177:2; Tó-33 8090:2, 8086:3.

Surirella capronii Bréb. - Tó-27 7478:2.

Surirella cf. striatula Turpin - Tó-11 5543:3.

Surirella crumena Bréb. - Tó-20 6629-6630:1, 6634:2; Tó-23 7169-7177:5, 7178-7184:3; Tó-26 7380-7382:2; Tó-28 6420:1.

Surirella gracilis Grun. - Tó-11 5559:9, 5556:4, 5547:2; Tó-21 7067-7069:3.

Surirella linearis W. Sm. - Tó-4 5533:3, 5527:4, 5526:5, 5525:10, 5523:13; Tó-5 6832:3; Tó-7 8388:4, 8389:4; Tó-8 8406:6; Tó-11 5542:15; Tó-20 6633:20; Tó-22 7291?:2, 7272-7274:5; Tó-23 7112-7119:4, 7149-7150:4, 7178-7184:15; Tó-26 7399-7401:2; Tó-31 6832:3.

Surirella linearis W. Sm. var. helvetica (Brun) Meister - Tó-11 5543:10; Tó-20 6631:1, 6641:8; Tó-23 7169-7177:5; Tó-27 7481:2; Tó-30 77118-7716:7. 
Surirella ovalis Bréb. - Tó-4 5526:5; Tó-11 5555:2, 5552:2; Tó-22 7259-7261:15; Tó-26 7364:4; Tó-30 7705-7707:2, 77118-7716:3.

Surirella ovata Kütz. var. brevicostata Pant. - Tó-4 5533:2; Tó-8 8408:8; Tó-21 7055-7056:2; Tó-22 7268:1, 7272-7274:4; Tó-23 7145-7148:2; Tó-30 7705-7707:1.

Surirella peisonis Pant. - Tó-4 5533:17; Tó-7 8400:8; Tó-11 5553:2; Tó-20 6633:12, 6634:4; Tó-22 7259-7261:12, 7268:1, 7272-7274:4, 7301-7303:1, 7304-7309:1; Tó-23 7169-7177:10, 7178-7184:14; Tó-26 7364:27, 7365:5, 7366-7367:20; Tó-27 7457-7460:2, 7473-7474:2; Tó-29 78, 677, 868:2; Tó-30 7669-7671:3.

Surirella robusta Ehr. - Tó-4 5529:4, 5528:3, 5527:10; Tó-23 7166-7168:5, 7197-7207:10, 7208-7222:5; Tó-26 7399-7401:2; Tó-27 7475-7476:4; Tó-30 7643:1.

Surirella splendida (Ehr.) Kütz. - Tó-11 5548:2; Tó-23 7197-7207:5.

Surirella tenera Greg. - Tó-4 5529:2, 5527:4; Tó-23 7109-7111:1, 7151-7160:6, 7166-7168:2, 7169-7177:4; Tó-26 7365:2; Tó-28 6423:1.

Surirella turgida W. Sm. - Tó-4 5530:14, 5528:5; Tó-11 5551:4; Tó-22 7304-7309:1; Tó-23 7169-7177:3; Tó-26 7385, 7386:13; Tó-27 7463-7466:4, 7475-7476:5.

Surirella turgida W. Sm. var. marginata Pant. - Tó-4 5529:9, 5524:5, 5523:5; Tó-11 5548:10; Tó-21 7061-7063:3; Tó-22 7259-7261:1; Tó-23 7112-7119:5, 7166-7168:4, 7185-7196:5, 7197-7207:15, 7208-7222:5; Tó-28 6455:2, 6424:4, 6423:7; Tó-30 7672-7678:1, 77118-7716:3.

Synedra rostrata Pant. - Tó-21 7083-7084:3.

Tabellaria fenestrata (Lyngb.) Kütz. - Tó-8 8404:8; Tó-17 7558-7560:4; Tó-20 6619:2, 6631:5; Tó-21 7043-7045:15, 7046-7047:11, 7055-7056:16; Tó-23 7099:4, 7101-7104:35, 7126-7130:4, 7131-7132:8, 7133-7144:4, 7145-7148:25, 7149-7150:23, 7151-7160:19, 7161-7165:15; Tó-30 7644-7645:11, 7646-7649:15, 7655-7659:1.

Tabellaria flocculosa (Roth.) Kütz. - Tó-7 8387:2; Tó-23 7093-7094:2, 7099:7, 7101-7104:7, 7131-7132:10, 7133-7144:10; Tó-30 7644-7645:3.

Tetracyclus lacustrus Ralfs - Tó-20 6628:5, 6629-6630:12.

\section{CONCLUSIONS}

This enumeration confirms the well-known fact that Lake Balaton has a rich, diversified algal-diatom flora not only in present time, but even going back to 13,000-15,000 years. The presence of Eunotia and Pinnularia taxa confirm the one-time peat occurrence at the lower layers.

The high portion of the broken and damaged forms indicates that the accumulation process in the Lake Balaton is wind disturbed, as shown by the upper few (2-3) cm of the lake sediment.

The neotypification or synonimication of taxa described by J. Pantocsek would be a much needed and urgent task for the Hungarian algology, as Szemes emphasized it more than a half century ago (Szemes 1957). This big task has not been implemented until now.

Acknowledgments - We would like to express our thanks to the Geological Institute of Hungary for providing financial support for the work as well as to the Hungarian Scientific 
Research Fund (OTKA Project 550, T 022371 and T 43078) for funding some of the analyses and the final interpretation of the results.

\section{REFERENCES}

Brenner, M., Whitmore, T. J., Lasi, M. A. and Cable, P. H. (1999): A multi-proxy trophic state reconstruction for shallow Orange Lake, Florida, USA: possible influence of macrophytes on limnetic nutrient concentrations. - J. Paleolimn. 321(2): 215-233.

Cserny, T. (2002): A balatoni negyedidőszaki üledékek kutatási eredményei. - Földt. Közlöny (különszám) 132: 193-213. [in Hungarian]

Cserny, T. and Nagy-Bodor, E. (2000): Limnogeological investigations on Lake Balaton. - In: Gierlowski-Kordesch, E. and Kelts, K. (eds): Lake basins through space and time. AAPG Studies in Geology 46: 605-618.

Cserny, T., Nagy-Bodor, E. and Hajós, M. (1991b): Contributions to the sedimentology and evolution history of Lake Balaton. - In: Pécsi, M. and Schweitzer, F. (eds): Quaternary environment in Hungary, Studies in Geography in Hungary, 26. Akadémiai Kiadó, Budapest, pp. 75-84.

Cserny, T., Földvári, M., Ikrényi, K., Nagy-Bodor, E., Hajós, M., Szurominé Korecz, A. and Wojnárovits, L.-né (1991a): A Balaton aljzatába mélyített Tó 24. sz. fúrás földtani vizsgálatának eredményei. - Magy. Áll. Földtani Intézet évi jelentése az 1989. évről, pp. 177-238. [in Hungarian]

Krammer, K. and Lange-Bertalot, H. (1986): Bacillariophyceae 1. Teil: Naviculaceae. - In: Ettl, H., Gerloff, J., Heynig, H. and Mollenhauer, D. (eds): Süsswasserflora von Mitteleuropa, vol. 2/1. G. Fischer, Stuttgart and New York, 876 pp.

Krammer, K. and Lange-Bertalot, H. (1988): Bacillariophyceae 2. Teil: Bacillariaceae, Epithemiaceae, Surirellaceae. - In: Ettl, H., Gerloff, J., Heynig, H. and Mollenhauer, D. (eds): Süsswasserflora von Mitteleuropa, vol. 2/2. G. Fischer, Stuttgart and New York, 596 pp.

Krammer, K. and Lange-Bertalot, H. (1991a): Bacillariophyceae 3. Teil: Centrales, Fragilariaceae, Eunotiaceae. - In: Ettl, H., Gerloff, J., Heynig, H. and Mollenhauer, D. (eds): Süsswasserflora von Mitteleuropa, vol. 2/3. G. Fischer, Stuttgart and New York, 576 pp.

Krammer, K. and Lange-Bertalot, H. (1991b): Bacillariophyceae 4. Teil: Achnanthaceae. - In: Ettl, H., Gärtner, G., Gerloff, J., Heynig, H. and Mollenhauer, D. (eds): Süsswasserflora von Mitteleuropa, vol. 2/4. G. Fischer, Stuttgart and New York, 437 pp.

Lotter, A. F., Pienitz, R. and Schmidt, R. (1999): Diatoms as indicators of environmental change near arctic and alpine treeline. - In: Stoermer, E. F. and Smol, J. P. (eds): Diatoms: applications no the environmental and Earth sciences. Cambridge University Press, Cambridge, pp. 205-226.

Padisák, J. (1997): Botanikai kutatások a Balatonon. - In: Salánki, J. and Nemcsók, J. (eds): A Balaton kutatás eredményei: 1981-1996. MTA VEAB, Miniszterelnöki Hivatal Balatoni Titkársága, Veszprém, pp. 97-135. [in Hungarian]

Pantocsek, J. (1901): Die Kieselalgen oder Bacillarien des Balaton. - In: Resultate der wissenschaftlichen Erforschung des Balatonsees. II. Band. Budapest Druck der K. und K. Hofbuchdruckerei des Victor Hornyánszky. 
Ponader, K., Pienitz, R., Vincent, W. and Gajewski, K. (2002): Limnological conditions in a subarctic lake (northern Quebec, Canada) during the late-Holocene: Analyses based on fossil diatoms. - J. Paleolimn. 27: 353-366.

Stoermer, E. F. and Smol, J. P. (eds) (1999): Diatoms: applications to the environmental and Earth sciences. - Cambridge University Press, Cambridge.

Szemes, G. (1957): Die Diatomeen des Balatonsees. (A Balaton kovamoszatai.) - Annal. biol. Tihany 24: 193-270.

Tamás, G. (1963): Kieselalgen des Balaton-Sees 1956-1961. - Annal. biol. Tihany 30: 167-218.

Tamás, G. (1964): Die Algenflora des Balaton-Sees. (Zusammengestellt nach Angaben aus den Jahren 1959-1963.) - Annal. biol. Tihany 31: 245-253.

Tamás, G. (1966): Tájékozódó jellegú algológiai vizsgálatok a Balaton fenékiszapján az 1965. évi gyújtések alapján. - Annal. biol. Tihany 33: 193-210. [in Hungarian]

Tamás, G. (1967): Quantitative algologische Untersuchungen im Bodenschlamm des Balaton auf Grund der Sammlungen des Jahres 1966. - Annal. biol. Tihany 34: 233-254.

Tamás, G. (1968): Quantitative Untersuchungen des Mikrophytobentos aus dem Eprofundal des Balaton-Sees auf Grund der Sammlungen des Jahres 1967. - Annal. biol. Tihany 35: 227-246.

Tamás, G. (1971): Quantitative investigations on microphytobenthos in 25 transversal sections of Lake Balaton. - Annal. biol. Tihany 38: 269-283.

Tamás, G. (1974): The biomass changes of microphytobenthos in Lake Balaton during the 1960s. - Annal. biol. Tihany 41: 343-356.

Tamás, G. and Gellért, J. (1958): Parti kövek bevonatának kovamoszatai és csillósai a Tihanyi-félsziget keleti részén. (Über Diatomeen und Ciliaten aus dem Aufwuchs der Ufersteine am Ostufer der Halbinsel Tihany.) - Annal. biol. Tihany 25: 241-250.

Uherkovich, G. (1988): Weitere Beiträge zur Kenntnis der Algenvegetation auf der Sedimentoberfläche im Balaton (Plattensee, Ungarn). - Limnologica (Berlin) 19(2): 35-59.

Uherkovich, G. (1992): Beiträge zur Kenntnis der Algenvegetation auf der Sedimentoberfläche im Schilfgürtel des Plattensees (Balaton, Ungarn). - Limnologica (Berlin) 22(2): 165-187.

Uherkovich, G. (1996): Adatok a Balaton nyugati medencéje üledékfelszíni algavegetációja ismeretéhez. (Data to the knowledge for the algal vegetation of the sediment surface in Lake Balaton, Hungary.) - Somogyi múzeumok közleményei, Kaposvár 12: 223-255. [in Hungarian]

Uherkovich, G. and Lantos, T. (1987): Angaben zur Kenntnis der Algenvegetation auf der Sedimentoberfläche im Balaton (Plattensee), Ungarn. - Limnologica (Berlin) 18(1): $29-67$. 